\title{
Review and Assessment of En-Route Transit Information Systems
}

of Transportation

Federal Transit

Administration

July 1995

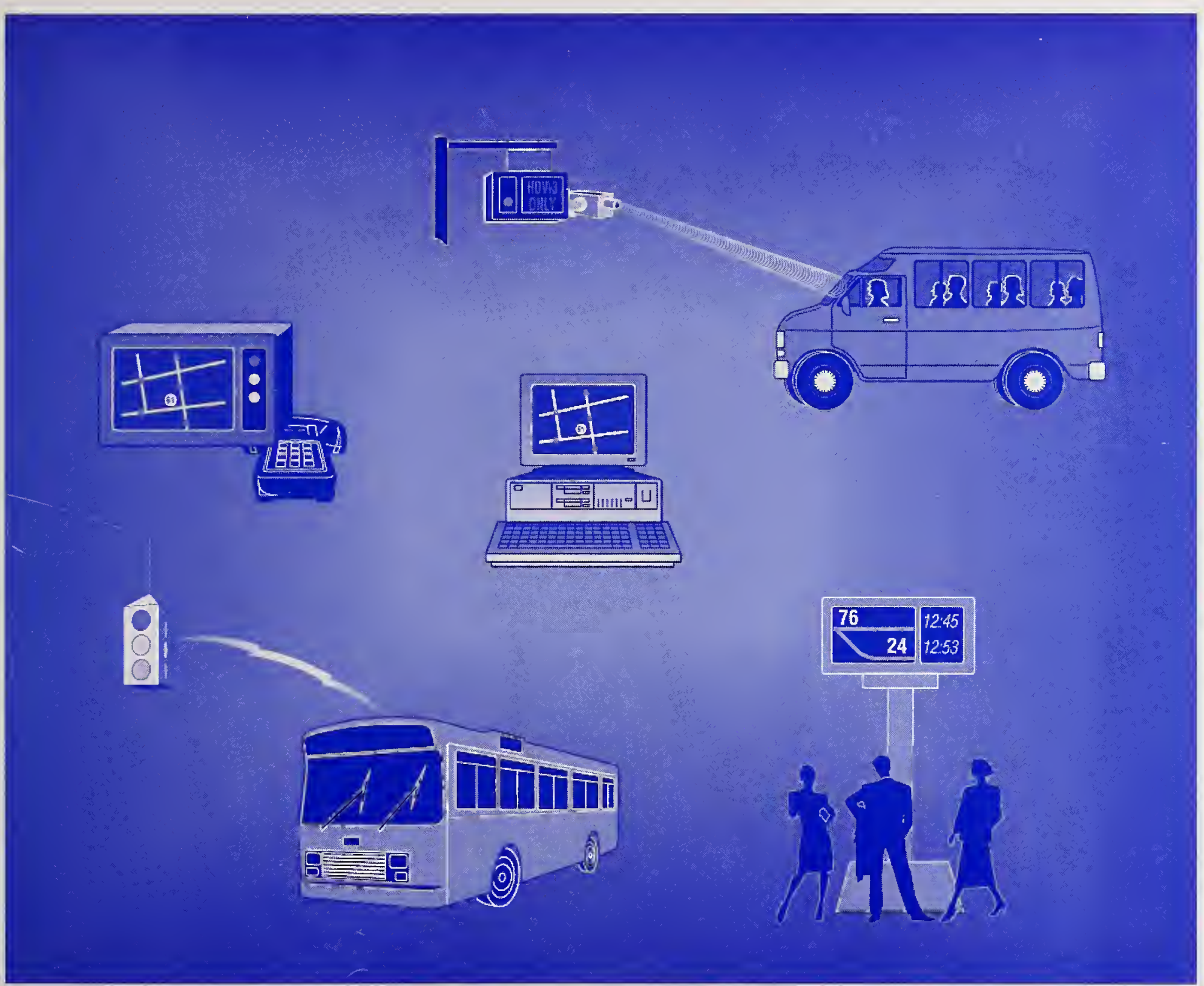

ADVANCED PUBLIC TRANSPORTATION SYSTEMS PROGRAM A Component of the Department ITS Initiative

Office of Mobility Innovation 



\section{Review and Assessment of En-Route Transit Information Systems}

Final Report July 1995

Prepared by

EG\&G Dynatrend Inc.

24 New England Executive Park

Burlington MA 01803-5203

Prepared for

US Department of Transportation

Volpe National Transportation Systems Center Kendall Square

Cambridge MA 02142

Sponsored by

Office of Mobility Innovation

Federal Transit Administration

400 Seventh Street SW

Washington DC 20590

Distributed in Cooperation with

Technology Sharing Program

Research and Special Programs Administration U.S. Department of Transportation

Washington DC 20590

DOT-T-96-03 



\section{PREFACE}

Traditionally, en-route transit information has been disseminated manually in the form of paper schedules, or by telephone through transit agency customer information services. Further, realtime information, such as actual bus arrival or departure time, has not been available to give the customer real-time schedule information. With the advent of advanced public transportation systems (APTS), such as automatic vehicle location (AVL), real-time en-route transit information can be made available to the customer in a variety of forms.

However, en-route transit information systems (ERTISs) are in their infancy in North America, primarily because APTS technologies that must be used to support ERTISs are just beginning to be fully implemented. The implementation of these APTS technologies must be stable before ERTISs can be successfully demonstrated in North America. This is evidenced by the fact that only one ERTIS is currently in operation as part of an Intelligent Transportation System (ITS) Operational Test in North America.

Thus, there are two key issues that are addressed by the study described in this report: a review of the current efforts to design, develop and implement en-route transit information systems, and a discussion of the state-of-the-art in ERTISs with respect to the User Service Development Plan (USDP) identified in the National Program for ITS: Volume 2.

This report is organized as follows. Section 1 provides an introduction. Section 2 defines the term "en-route transit information systems," and identifies the ERTISs that are included as part of this study. Section 3 describes the state-of-the-art in ERTISs by identifying each ERTIS and its current stage of development. Section 4 identifies the technologies that are/will be employed in each ERTIS for collecting and disseminating transit information. Section 5 describes the natural integration of ERTISs with advanced traveler information systems (ATIS), and preliminary results from existing ERTISs. Section 6 presents the results and conclusions of the study, and Section 7 presents recommendations for future activities related to ERTISs with respect to the User Service Development Plan.

This study was conducted by Carol L. Schweiger of EG\&G Dynatrend for the Research and Special Programs Administration/Volpe National Transportation Systems Center (VNTSC) of the United States Department of Transportation (DOT), under the sponsorship of the APTS Program, Federal Transit Administration (FTA) and the guidance of Mr. Ronald J. Fisher, P.E., former director of the Office of Training, Research, and Rural Transportation, FTA. Guidance was also provided by Robert S. Ow, VNTSC. 


\section{METRIC/ENGLISH CONVERSION FACTORS}

ENGLISH TO METRIC

\section{LENGTH (APPROXIMATE)}

1 inch $($ in) $=2.5$ centimeters $(\mathrm{cm})$

1 foot $(\mathrm{ft})=30$ centimeters $(\mathrm{cm})$

1 yard $(y d)=0.9$ meter $(\mathrm{m})$

1 mile $(\mathrm{mi})=1.6$ kilometers $(\mathrm{km})$
METRIC TO ENGLISH

\section{LENGTH (APPROXIMATE)}

1 millimeter $(\mathrm{mm})=0.04$ inch (in)

1 centimeter $(\mathrm{cm})=0.4$ inch (in)

1 meter $(\mathrm{m})=3.3$ feet $(\mathrm{ft})$

1 meter $(\mathrm{m})=1.1$ yards $(\mathrm{yd})$

1 kilometer $(\mathrm{km})=0.6 \mathrm{mile}(\mathrm{mi})$

\begin{tabular}{|c|c|}
\hline AREA (APPROXIMATE) & AREA (APPROXIMATE) \\
\hline 1 square inch $\left(\mathrm{sq}\right.$ in, $\left.\mathrm{in}^{2}\right)=\underset{\left(\mathrm{cm}^{2}\right)}{6.5 \text { square centimeters }}$ & 1 square centimeter $\left(\mathrm{cm}^{2}\right)=0.16$ square inch (sq in, in $\left.{ }^{2}\right)$ \\
\hline 1 square foot $\left(\mathrm{sq} \mathrm{ft}, \mathrm{ft}^{2}\right)=0.09$ square meter $\left(\mathrm{m}^{2}\right)$ & 1 square meter $\left(m^{2}\right)=\frac{1.2 \text { square yards }(s q y d \text {, }}{\left.y d^{2}\right)}$ \\
\hline $\begin{aligned} 1 \mathrm{square} \text { yard }\left(\mathrm{sq} \mathrm{yd}, \mathrm{yd}^{2}\right)= & 0.8 \text { square meter }\left(\mathrm{m}^{2}\right) \\
1 \text { square mile }\left(\mathrm{sq} \mathrm{mi}, \mathrm{mi}^{2}\right)= & 2.6 \text { square kilometers } \\
& \left(\mathrm{km}^{2}\right) \\
1 \text { acre }=0.4 \text { hectare }(\text { he })= & 4.000 \text { square meters }\left(\mathrm{m}^{2}\right)\end{aligned}$ & $\begin{aligned} 1 \text { square kilometer }\left(\mathrm{km}^{2}\right) & =0.4 \text { square mile }\left(\mathrm{sq} \mathrm{mi}, \mathrm{mi}^{2}\right) \\
10,000 \text { square meters }\left(\mathrm{m}^{2}\right) & =1 \text { hectare }(\mathrm{ha})=2.5 \text { acres }\end{aligned}$ \\
\hline
\end{tabular}

\begin{tabular}{|c|c|}
\hline $\begin{aligned} \text { MASS - WEIGHT } & \text { (APPROXIMATE) } \\
1 \text { ounce }(\mathrm{oz}) & =28 \text { grams }(\mathrm{gm}) \\
1 \text { pound }(\mathrm{lb}) & =0.45 \mathrm{kilogram}(\mathrm{kg}) \\
1 \text { short ton }=2,000 \text { pounds }(\mathrm{lb}) & =0.9 \text { tonne }(\mathrm{t})\end{aligned}$ & $\begin{array}{c}\text { MASS - WEIGHT (APPROXIMATE) } \\
1 \text { gram }(\mathrm{gm})=0.036 \text { ounce }(\mathrm{oz}) \\
1 \text { kilogram }(\mathrm{kg})=2.2 \text { pounds }(\mathrm{lb}) \\
1 \text { tonne }(\mathrm{t})= \\
1,000 \text { kilograms }(\mathrm{kg})=1.1 \text { short tons }\end{array}$ \\
\hline
\end{tabular}

\begin{tabular}{|c|c|}
\hline 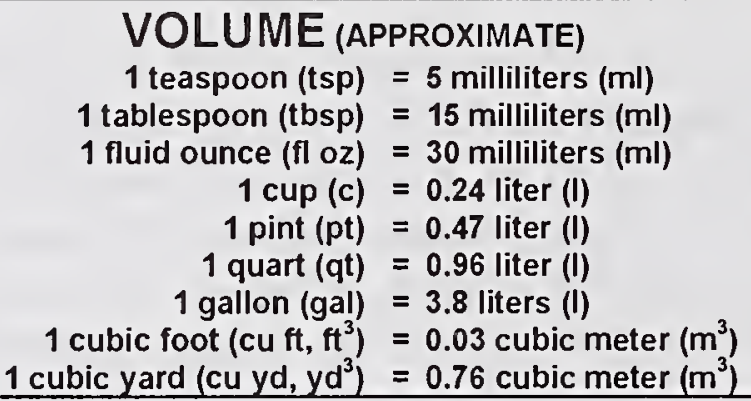 & 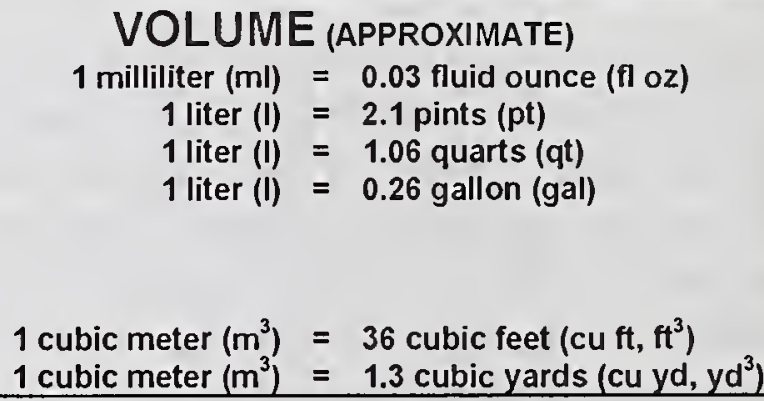 \\
\hline $\begin{array}{l}\text { TEMPERATURE (EXACT) } \\
{[(x-32)(5 / 9)]^{\circ} \mathrm{F}=y^{\circ} \mathrm{C}}\end{array}$ & $\begin{array}{l}\text { TEMPERATURE (EXACT) } \\
{[(9 / 5) y+32]^{\circ} \mathrm{C}=x^{\circ} \mathrm{F}}\end{array}$ \\
\hline
\end{tabular}

\section{QUICK INCH - CENTIMETER LENGTH CONVERSION}

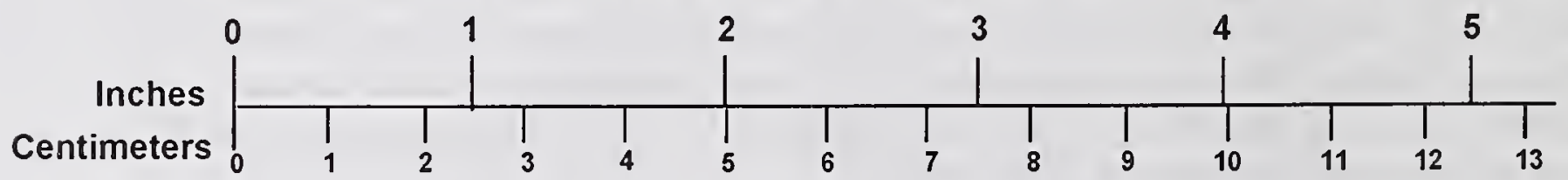

\section{QUICK FAHRENHEIT - CELSIUS TEMPERATURE CONVERSION}

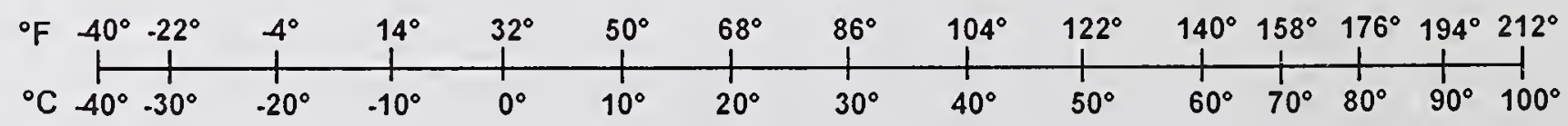

For more exact and or other conversion factors, see NIST Miscellaneous Publication 286, Units of Weights and Measures. Price \$2.50 SD Catalog No. C13 10286 


\section{TABLE OF CONTENTS}

Section

Page

1. INTRODUCTION $\ldots \ldots \ldots \ldots \ldots \ldots \ldots \ldots \ldots \ldots \ldots$

1.1 Study Objectives $\ldots \ldots \ldots \ldots \ldots \ldots \ldots \ldots \ldots \ldots \ldots \ldots$

1.2 Technical Approach to Study $\ldots \ldots \ldots \ldots \ldots \ldots \ldots \ldots \ldots$

1.3 Report Organization . . . . . . . . . . . . . . . . 3

2. EN-ROUTE TRANSIT INFORMATION SYSTEMS $\ldots \ldots \ldots \ldots \ldots \ldots$

2.1 Definition of En-Route Transit Information Systems $\ldots \ldots \ldots \ldots$

2.2 Transit Agencies Contacted $\ldots \ldots \ldots \ldots \ldots \ldots \ldots$

3. STATE OF THE ART IN ERTIS $\ldots \ldots \ldots \ldots \ldots \ldots \ldots \ldots$

3.1 Systems in Planning/Definition and Development . . . . . . . . . . 9

3.1.1 Ann Arbor Transportation Authority (AATA) . . . . . . . . . 9

3.1.2 Vancouver, British Columbia (BC Transit) . . . . . . . . . 14

3.1.3 CALTRANS/Los Angeles County Metropolitan Transportation Authority (LACMTA) . . . . . . . . . . . . . . . . 14

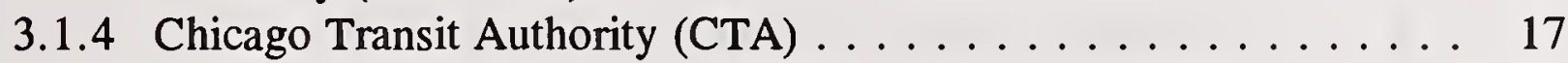

3.1.5 Dallas Area Rapid Transit (DART) . . . . . . . . . . . . . . . 17

3.1.6 Metropolitan Transit Authority of Harris County (Houston Metro) . . . . . . . . . . . . . . . . . . . . . 17

3.1.7 Mass Transit Administration of Maryland (MTA) . . . . . . . . . 19

3.1.8 Metropolitan Transportation Authority (MTA) - New York City

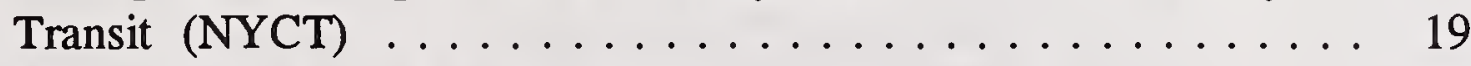

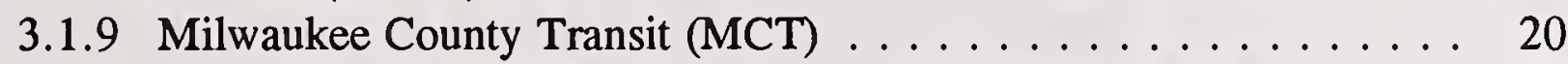

3.1.10 Montreal Urban Community Transit Corporation (MUCTC) . . . . 20

3.1.11 New Jersey Transit (NJT) . . . . . . . . . . . . . . 21

3.1.12 Orange County Transportation Authority (OCTA) . . . . . . . 25

3.1.13 Ottawa-Carleton Regional Transit Commission (OC Transpo) . . . . 25

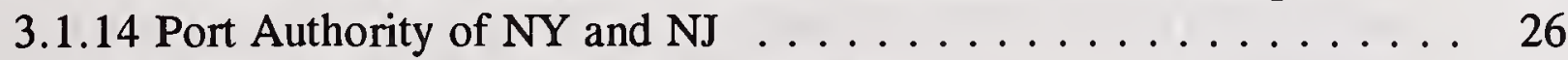

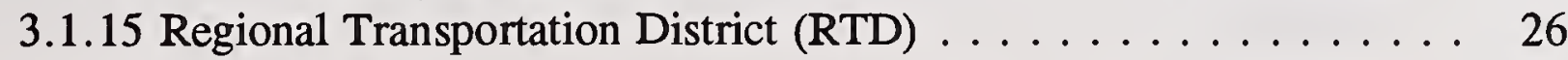

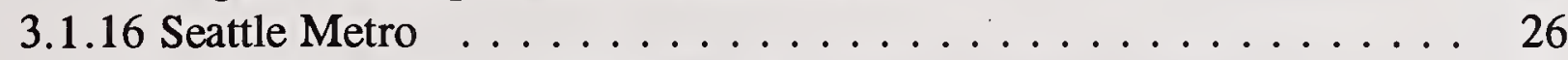

3.1.17 Toronto Transit Commission (TTC) . . . . . . . . . . . . 27

3.1.18 Tri-County Metropolitan Transportation District of Oregon

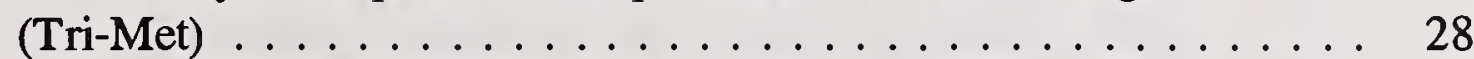

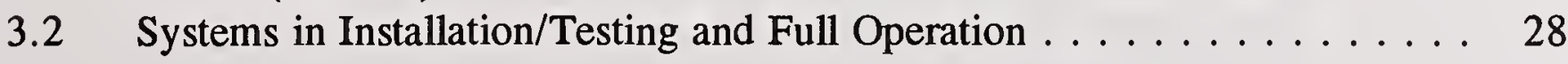

3.2.1 Bay Area Rapid Transit (BART) $\ldots \ldots \ldots \ldots \ldots \ldots \ldots . \ldots . \ldots . \ldots$

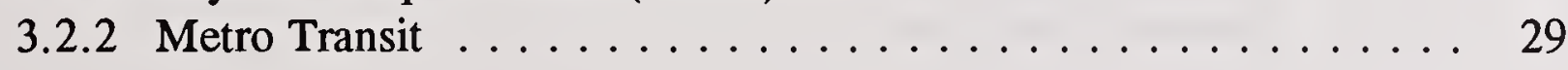




\section{TABLE OF CONTENTS (continued)}

Section

Page

3.2.3 Travlink Project/Metropolitan Council Transit Operations (MCTO) 29

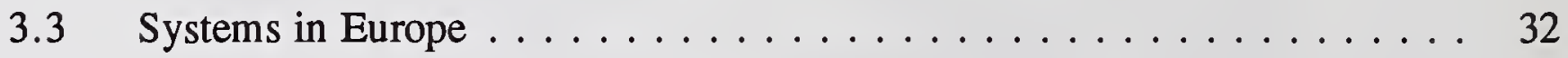

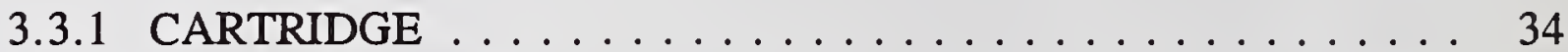

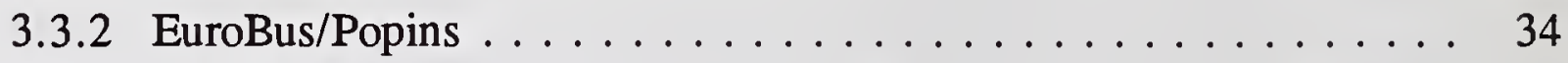

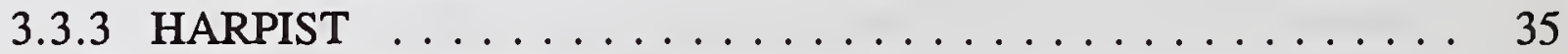

3.3.4 Information in Public Transport (INPUT) $\ldots \ldots \ldots \ldots \ldots . \ldots 36$

3.3.5 London, Lyon, Amsterdam, Munich and Dublin (LLAMD) . . . . 36

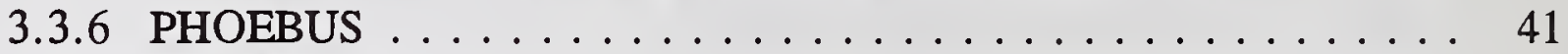

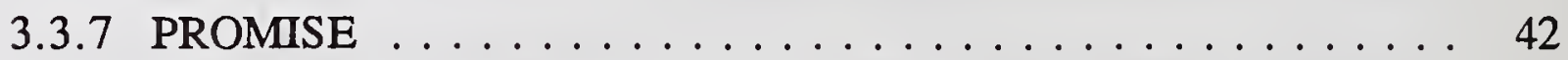

3.3.8 Priority and Informatics in Public Transport (PROMPT)/STOPWATCH . . . . . . . . . . . . 43

3.3.9 Quadrilateral Advanced Research on Telematics for Environment

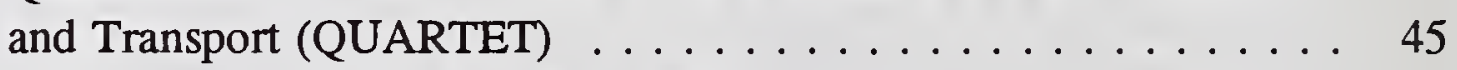

3.3.10 Southampton-Cologne-Piraeus (SCOPE) $\ldots \ldots \ldots \ldots \ldots \ldots$

4. INFORMATION AND TECHNOLOGIES EMPLOYED IN ERTIS $\ldots \ldots \ldots \ldots$

4.1 Transit Information Distributed by ERTISs $\ldots \ldots \ldots \ldots \ldots \ldots$

4.1.1 Ann Arbor Transportation Authority (AATA) . . . . . . . . . 51

4.1.2 Dallas Area Rapid Transit (DART) . . . . . . . . . . . . . 51

4.1.3 Metropolitan Transportation Authority (MTA) - New York City Transit $(\mathrm{NYCT}) \ldots \ldots \ldots \ldots \ldots \ldots \ldots \ldots$

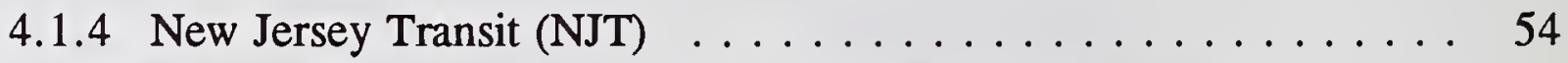

4.1.5 Travlink Project/Metropolitan Council Transit Operations

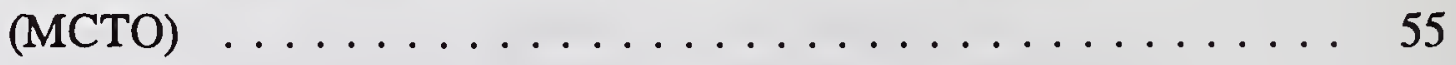

4.2 Transit Information Dissemination $\ldots \ldots \ldots \ldots \ldots \ldots \ldots$

5. INTEGRATION OF ERTIS AND ADVANCED TRAVELER INFORMATION

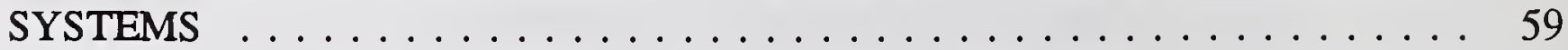

5.1 Chicago Transit Authority (CTA) . . . . . . . . . . . . . 59

5.2 Dallas Area Rapid Transit (DART) . . . . . . . . . . . . . . 59

5.3 Mass Transit Administration of Maryland (MTA) . . . . . . . . . . 59

5.4 New Jersey Transit (NJT) . . . . . . . . . . . . . . . . . . . 59

5.5 Travlink Project/Metropolitan Council Transit Operations (MCTO) . . . . 62

5.6 COUNTDOWN ........................ 63

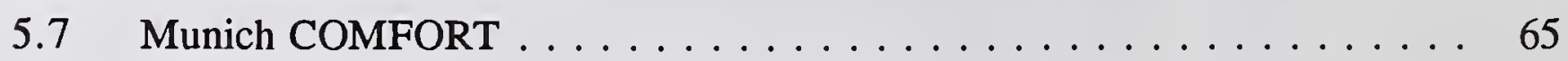


TABLE OF CONTENTS (continued)

Section

Page

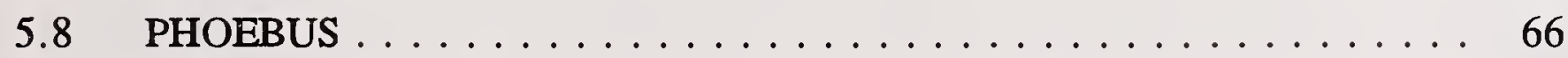

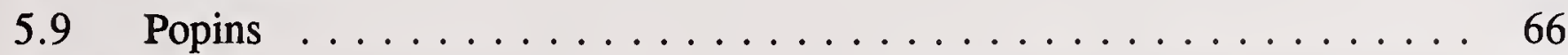

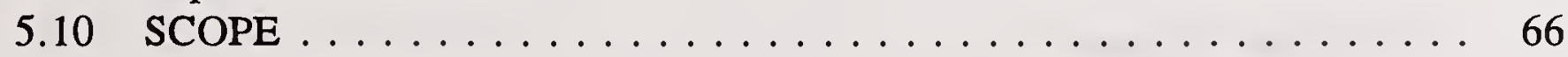

6. RESULTS AND CONCLUSIONS . . . . . . . . . . . . . . . . . 69

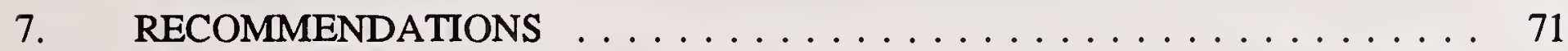

APPENDIX A. LIST OF INTERVIEW QUESTIONS $\ldots \ldots \ldots \ldots \ldots \ldots$ A-1

APPENDIX B. LIST OF CONTACTS $\ldots \ldots \ldots \ldots \ldots \ldots \ldots \ldots$ B-1

APPENDIX C. USER SERVICE DEVELOPMENT PLAN FOR EN-ROUTE

TRANSIT INFORMATION $\ldots \ldots \ldots \ldots \ldots \ldots \ldots \ldots$ C-1

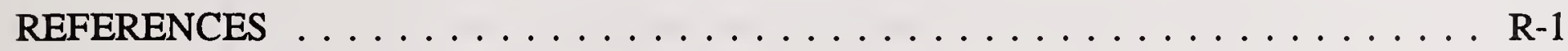




\section{LIST OF FIGURES}

Figure

Page

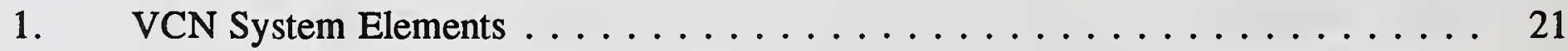

2. NJT En-Route Information Services $\ldots \ldots \ldots \ldots \ldots \ldots \ldots$

3. Sample Travlink Monitor/Electronic Sign Display . . . . . . . . . . . 31

4. Popins Media $\ldots \ldots \ldots \ldots \ldots \ldots \ldots \ldots \ldots \ldots \ldots \ldots \ldots \ldots \ldots \ldots \ldots$

5. AlterEgo Screen Example ........................ 37

6. Southampton System Architecture ... . . . . . . . . . . . . . . 44

7. CENTRO Public Transport Passenger Information System . . . . . . . . . . . 49 


\section{LIST OF TABLES}

Table Page

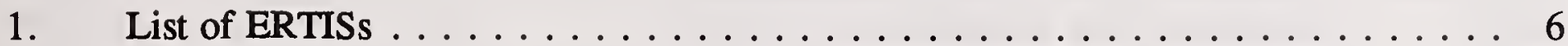

2. European Projects Reviewed $\ldots \ldots \ldots \ldots \ldots \ldots$

3. ERTIS Stage of Development $\ldots \ldots \ldots \ldots \ldots \ldots$

4. Passenger Information Problems and Information Systems Needed _ . . . . . . 46

5. Functional Specification of PIS $\ldots \ldots \ldots \ldots$

6. Transit Information Currently Distributed by the ERTIS . . . . . . . . . . . . 52

7. Sources of Transit Information Currently Distributed by the ERTIS _... . . 53

8. Travlink Transit Data Collection Specifications $\ldots \ldots \ldots \ldots \ldots \ldots$

9. Travlink Traffic Data Collection Specifications _... . . . . . . . . . 54

10. Transit Distribution Technologies . . . . . . . . . . . . . . . . 56

11. Travlink Traveler Information Distribution . . . . . . . . . . . . . 57

12. Preliminary Travlink Project Cost . . . . . . . . . . . . . . . . . . 64

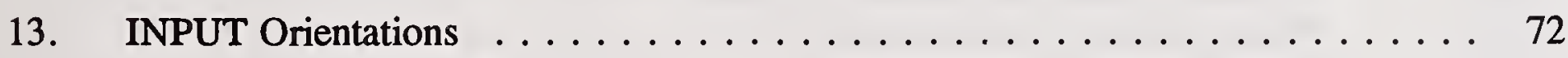




\section{LIST OF ACRONYMS AND ABBREVIATIONS}

$\begin{array}{ll}\text { AATA } & \text { Ann Arbor Transportation Authority } \\ \text { AC Transit } & \text { Alameda-Contra Costa Transit District } \\ \text { ADA } & \text { Americans with Disabilities Act of 1990 } \\ \text { AIS } & \text { Advanced Information Services } \\ \text { APC } & \text { Automatic Passenger Counter } \\ \text { APTS } & \text { Advanced Public Transportation Systems } \\ \text { ATIS } & \text { Advanced Traveler Information Systems } \\ \text { AVI } & \text { Automatic Vehicle Identification } \\ \text { AVL } & \text { Automatic Vehicle Location } \\ \text { AVLC } & \text { Automatic Vehicle Location and Control } \\ \text { AVM } & \text { Automatic Vehicle Monitoring } \\ \text { BART } & \text { Bay Area Rapid Transit } \\ \text { CAD } & \text { Computer-Aided Dispatch } \\ \text { CALTRANS } & \text { California Department of Transportation } \\ \text { CCCTA } & \text { Central Contra Costa Transit Authority } \\ \text { CCTV } & \text { Closed-Circuit Television } \\ \text { COMFORT } & \text { Cooperative Management for Urban and Regional Transport } \\ \text { CTA } & \text { Chicago Transit Authority } \\ \text { CTS } & \text { Commuter Transportation Services } \\ \text { DART } & \text { Dallas Area Rapid Transit } \\ \text { DEFA } & \text { Dynamic EFA } \\ \text { DOT } & \text { Department of Transportation } \\ \text { DRIVE } & \text { Dedicated Road Infrastructure for Vehicle Safety in Europe } \\ \text { DRS } & \text { Demand Responsive System } \\ \text { EFA } & \text { Elektronische Fahrplan Auskunft } \\ \text { ERTIS } & \text { En-Route Transit Information System } \\ \text { FHWA } & \text { Federal Highway Administration } \\ \text { FTA } & \text { Federal Transit Administration } \\ \text { GIS } & \text { Geographic Information System } \\ \text { GOTIC } & \text { Gothenburg Traffic Information Center } \\ \text { GPS } & \text { Global Positioning System } \\ \text { HAR } & \text { Highway Advisory Radio } \\ \text { HAT } & \text { Highway Advisory Telephone } \\ \text { HOV } & \text { High Occupancy Vehicle } \\ \text { INPUT } & \text { Information in Public Transport } \\ \text { ITS } & \text { Intelligent Transportation Systems } \\ \text { ITTS } & \text { Integrated Traffic and Transit System } \\ \text { LACMTA } & \text { Los Angeles County Metropolitan Transportation Authority } \\ \text { LCD } & \text { Liquid Crystal Display } \\ \text { LED } & \text { Light-Emitting Diode } \\ \text { LLAMD } & \text { London, Lyon, Amsterdam, Munich and Dublin } \\ \text { MARTA } & \text { Metropolitan Atlanta Rapid Transit Authority } \\ & \end{array}$




\section{LIST OF ACRONYMS AND ABBREVIATIONS (continued)}

MCT Milwaukee County Transit

MCTO Metropolitan Council Transit Operations

Mn/DOT Minnesota DOT

MTA Mass Transit Administration of Maryland

MTA-NYCT Metropolitan Transportation Authority-New York City Transit

MTC Metropolitan Transportation Commission

MUCTC Montreal Urban Community Transit Corporation

NJT New Jersey Transit

OCTA Orange County Transportation Authority

OC Transpo Ottawa-Carleton Regional Transit Commission

ORS

Optimum Route Software

P\&R

Park-and-Ride

PA

Public Address

PATH

Port Authority Trans-Hudson

PCD

Personal Communications Device

PIS

Passenger Information System

PROMPT

PTDB

Priority and Informatics in Public Transport

PTDC

Public Transport Data Base

PTPIS

Public Transport Data Center

QUARTET

RDS

Public Transport PIS

Radio Data System

ROMANSE Road Management System for Europe

RTD

Regional Transportation District

SCOPE Southampton-Cologne-Piraeus

SONET

TIDS

Synchronous Optical Network

TMC

Train Information Display System

Traffic Management Center

TRANSCOM Transportation Operations Coordinating Committee

Tri-Met

Tri-County Metropolitan Transportation District of Oregon

TRUST

TTC

UIP

Tracking Using Satellite Tracking

USDP

Toronto Transit Commission

VCN

User Information Post

VMS

User Service Development Plan

Variable Message Signs

VNTSC Volpe National Transportation Systems Center

VSCS

WWW

Vehicle Scheduling and Control System

Worldwide Web 



\section{INTRODUCTION}

The national intelligent transportation systems (ITS) program has identified 29 "user services" which represent tools and technologies used by travelers and transportation agencies to facilitate travel on any mode. ${ }^{1}$ These 29 user services have been organized into seven categories or "bundles," as follows:

- Travel and Transportation Management;

- Travel Demand Management;

- Public Transportation Operations;

- Electronic Payment;

- Commercial Vehicle Operations;

- Emergency Management; and

- Advanced Vehicle Control and Safety Systems.

The Public Transportation Operations bundle contains the following user services:

- Public Transportation Management;

- En-Route Transit Information;

- Personalized Public Transit; and

- Public Travel Security.

Generally, the "En-Route Transit Information" user service is defined as follows: "This service provides information to assist the traveler once public transportation travel begins. Real-time, accurate transit service information on board the vehicle helps travelers make effective transfer decisions and itinerary modifications as needed while a trip is underway. "2 The scope of the study described in this report is somewhat broader than this definition, since en-route transit information can be provided not only on-board the transit vehicle, but at transit stops, in transit/transfer centers, and at other transit-served locations.

Traditionally, en-route transit information has been disseminated manually in the form of paper schedules, or by telephone through transit agency customer information services. Further, real-time information, such as actual bus arrival or departure time, has not been traditionally available to give the customer real-time schedule information. With the advent of advanced public transportation systems (APTS), such as automatic vehicle location (AVL), real-time en-route transit information can be made available to the customer in a variety of forms.

Reference 45.

2

Reference 45, p. 14. 
However, en-route transit information systems (ERTISs) are in their infancy in North America, primarily because APTS technologies that must be used to support ERTISs are just beginning to be fully implemented. The implementation of these APTS technologies must be stable before ERTISs can be successfully demonstrated in North America. This is evidenced by the fact that only one ERTIS is in operation currently as part of an ITS Operational Test ${ }^{3}$ in North America.

Thus, there are two key issues that are addressed by the study described in this report: a review of the current efforts to design, develop and implement en-route transit information systems, and a discussion of the state-of-the-art in ERTISs with respect to the User Service Development Plan (USDP) identified in the National Program Plan for ITS: Volume 2.

This study was conducted by the Research and Special Programs Administration/John A. Volpe National Transportation Systems Center (VNTSC) of the United States Department of Transportation (DOT), under the sponsorship of the APTS Program, Federal Transit Administration (FTA) and the guidance of Mr. Ronald J. Fisher, P.E., former director of the Office of Training, Research, and Rural Transportation, FTA.

\subsection{STUDY OBJECTIVES}

This study was prompted by an interest on the part of FTA about the state-of-the-art in ERTISs in North America. A need was identified for a document whose objective is to review the current state-of-the-art and to assess the progress that is being made on the USDP for EnRoute Transit Information. This effort involved conducting a review of on-going efforts to implement en-route transit information services, assessing their status, assessing the extent to which travelers utilize en-route travel information services, and identifying major issues associated with their implementation. This effort will review the work identified in the EnRoute Transit Information User Service Development Plan, and will identify areas in which further work needs to be done in order to meet the Plan's objectives and schedule.

The objectives of this study were to:

- Conduct a review of existing ERTISs in North America and those under development;

- Assess their status in terms of design, development or implementation;

- Assess the extent to which travelers utilize ERTISs;

- Identify major issues associated with ERTIS implementation;

- Review the User Service Development Plan for En-Route Transit Information and identify the progress that has been made toward that Plan, and identify areas in which further work needs to be done in order to meet the Plan's objectives and schedule; and

3

Operational tests focus on the integration of systems and services, which takes place between initial project definition and full deployment. The U.S. Department of Transportation established an open solicitation process to provide opportunities to participate in the Operational Test program through partnerships between the pubic and private sectors. 
- Prepare a document that describes the state-of-the-art in ERTISs, discusses the progress being made against the Plan, and recommends areas which need further work.

\subsection{TECHNICAL APPROACH TO STUDY}

The study began by identifying existing ERTISs or those under development. Next, key ERTISs to be addressed in the study were selected based on their current status and progress, and the amount of information available on the ERTIS (see Section 2.2).

Once the final list of ERTISs was selected, a set of structured questions was developed to facilitate information gathering. A draft set of questions was applied to four agencies in order to "test" the questions and to solicit comments about the questions. Once the final set of questions was developed, the ERTISs were contacted either by site visits and/or telephone interviews to collect the data and any other information pertinent to the study. In most cases, the agency being contacted followed up the interview by filling out the list of interview questions.

After the data was collected, it was assimilated and analyzed in order to determine what stage of development each ERTIS was in, and to identify the progress of ERTIS activities in North America. In addition, examples of European ERTISs were included in the analysis in order to fully understand the potential for ERTIS development and implementation. This analysis was used to develop this report, which is organized as described in Section 1.3.

\subsection{REPORT ORGANIZATION}

This report is organized as follows. Section 2 defines the term "en-route transit information systems," and identifies the ERTISs that are included as part of this study. Section 3 describes the state-of-the-art in ERTISs by identifying each ERTIS and its current stage of development. Section 4 identifies the technologies that are/will be employed in each ERTIS for collecting and disseminating transit information. Section 5 describes the natural integration of ERTISs with advanced traveler information systems (ATIS), and preliminary results from existing ERTISs. Section 6 presents the results and conclusions of the study, and Section 7 presents recommendations for future activities related to ERTISs with respect to the User Service Development Plan. 



\section{EN-ROUTE TRANSIT INFORMATION SYSTEMS}

\subsection{DEFINITION OF EN-ROUTE TRANSIT INFORMATION SYSTEMS}

The term "en-route transit information" has been used to describe real-time information available to transit customers as they are making their trip. This information can include information on transit vehicle arrivals and departures, information on transfers and information on other transportation services. This en-route transit information could be provided on-board a transit vehicle, at a transit stop or transit center, and/or at an intermediate location, such as a shopping or business complex. However, the term en-route transit information is not widely used in the transit industry, and currently, the availability of real-time information is very limited. Further, a related term, advanced traveler information systems (ATIS), encompasses en-route transit information.

Thus, for this study, a definition of ERTIS was developed to define the scope of organizations that would be contacted to collect data. The definition is as follows:

An en-route transit information system provides information to transit riders after their trips have started. This information includes arrival and departure times, information on transfers and connections, information on other regional transportation services, and information on related services, such as park-and-ride lot availability. This information can be provided onboard a transit vehicle, at a transit stop or transit center, and at other locations, such as park-and-ride lots, through various media.

This definition broadens the term used in the National Program Plan by incorporating nonreal time information (such as printed schedules) and providing the information at a variety of locations through a variety of media. However, the User Service Development Plan for EnRoute Transit Information provides appropriate descriptions of the service provided, operational concepts and technologies, as shown in Appendix C.

\subsection{TRANSIT AGENCIES CONTACTED}

A list of ERTISs to contact was developed from the available literature (see References) and from contacts at the FTA. This list is shown in Table 1. 
TABLE 1. LIST OF ERTISs

\begin{tabular}{|c|c|}
\hline LOCATION & CONTACT AGENCY \\
\hline Ann Arbor, MI & $\begin{array}{l}\text { Ann Arbor Transportation Authority } \\
\text { (AATA) }\end{array}$ \\
\hline Atlanta, GA & $\begin{array}{l}\text { Metropolitan Atlanta Rapid Transit } \\
\text { Authority (MARTA) }\end{array}$ \\
\hline Baltimore, MD & $\begin{array}{l}\text { Mass Transit Administration of Maryland } \\
\text { (MTA) }\end{array}$ \\
\hline Chicago, IL & Chicago Transit Authority (CTA) \\
\hline Dallas, TX & Dallas Area Rapid Transit (DART) \\
\hline Denver, CO & Regional Transportation District (RTD) \\
\hline Halifax, Nova Scotia & Metro Transit \\
\hline Houston, TX & $\begin{array}{l}\text { Metropolitan Transit Authority of Harris } \\
\text { County (Houston Metro) }\end{array}$ \\
\hline Los Angeles, CA & $\begin{array}{l}\text { California Department of Transportation } \\
\text { (CALTRANS) [Smart Traveler Program] } \\
\text { and Los Angeles County Metropolitan } \\
\text { Transportation Authority (LACMTA) }\end{array}$ \\
\hline Milwaukee, WI & Milwaukee County Transit (MCT) \\
\hline Minneapolis/St. Paul, MN & $\begin{array}{l}\text { Travlink Project/Metropolitan Council } \\
\text { Transit Operations (MCTO) }\end{array}$ \\
\hline Montreal, Quebec & $\begin{array}{l}\text { Montreal Urban Community Transit } \\
\text { Corporation (MUCTC) }\end{array}$ \\
\hline New York, NY & $\begin{array}{l}\text { Port Authority of New York and New } \\
\text { Jersey }\end{array}$ \\
\hline New York, NY & $\begin{array}{l}\text { Metropolitan Transportation Authority } \\
\text { (MTA) - New York City Transit (NYCT) }\end{array}$ \\
\hline Newark, NJ & New Jersey Transit (NJT) \\
\hline
\end{tabular}

MARTA was contacted as part of this study, but they were in the very early definition stage, so no material was available to include in this report. They are developing a system, including an ERTIS, for the 1996 Summer Olympics. 
TABLE 1. LIST OF ERTISs (continued)

\begin{tabular}{||l|l|}
\hline \multicolumn{1}{|c|}{ LOCATION } & \multicolumn{1}{|c|}{ CONTACT AGENCY } \\
\hline Oakland/San Francisco, CA & $\begin{array}{l}\text { Bay Area Rapid Transit (BART) and } \\
\text { Metropolitan Transportation Commission } \\
\text { (MTC) }\end{array}$ \\
\hline Orange, CA & $\begin{array}{l}\text { Orange County Transportation Authority } \\
\text { (OCTA) }\end{array}$ \\
\hline Ottawa, Ontario & $\begin{array}{l}\text { Ottawa-Carleton Regional Transit } \\
\text { Commission (OC Transpo) }\end{array}$ \\
\hline Portland, OR & $\begin{array}{l}\text { Tri-County Metropolitan Transportation } \\
\text { District of Oregon (Tri-Met) }\end{array}$ \\
\hline Seattle, WA & $\begin{array}{l}\text { Municipality of Metropolitan Seattle } \\
\text { (Seattle Metro) }\end{array}$ \\
\hline Toronto, Ontario & Toronto Transit Commission (TTC) \\
\hline Vancouver, British Columbia & BC Transit \\
\hline
\end{tabular}

As described in Section 1.2, a detailed list of questions was developed and comments were solicited from: Travlink, MTC, NJT and CALTRANS. These ERTISs were chosen for the following reasons:

- Travlink, an ITS Operational Test, has the only operating ERTIS using real-time AVL data;

- MTC is actively involved in Travinfo, which is an ITS Operational Test that will implement a comprehensive, regionwide traveler information system, capable of supplying a broad array of devices and users with transportation information both before and during trips; and

- NJT has a comprehensive five-year ITS/APTS strategy, which includes ERTIS; and

- CALTRANS has implemented Smart Traveler Information Kiosks in Los Angeles as part of an ITS Operational Test.

Suggestions were made by each of these organizations to modify the draft list of interview questions. Most comments were incorporated into the final list of questions, however, those comments that were submitted late were not incorporated into the final list of questions but used in the telephone interviews. The final list of interview questions is shown in Appendix A. 
In addition to the direct contacts made in North America, information on ERTISs in Europe was collected from a variety of sources, including exhibits at and Proceedings from the First World Congress on Applications of Transport Telematics and Intelligent Vehicle-Highway Systems, held November 30 - December 3, 1994 in Paris, France. Selected European projects that were reviewed as part of this study are shown in Table 2.

TABLE 2. EUROPEAN PROJECTS REVIEWED

\begin{tabular}{||l|l||}
\hline \multicolumn{1}{|c|}{ PROJECT NAME } & \multicolumn{1}{c|}{ PROJECT CITIES } \\
\hline \hline CARTRIDGE & $\begin{array}{l}\text { Task Force to implement public transport trip planning } \\
\text { functions within driver guidance systems }\end{array}$ \\
\hline EUROBUS/POPINS & Marseilles, Madrid, Thessaloniki, Birmingham \\
\hline HARPIST & $\begin{array}{l}\text { Task Force to establish common functional } \\
\text { specifications for datamodels and terminology in } \\
\text { passenger information systems }\end{array}$ \\
\hline $\begin{array}{l}\text { Information in Public Transport } \\
\text { (INPUT) }\end{array}$ & $\begin{array}{l}\text { Task Force to establish guidelines and } \\
\text { recommendations for public transport passenger } \\
\text { information systems }\end{array}$ \\
\hline $\begin{array}{l}\text { London, Lyon, Amsterdam, } \\
\text { Munich and Dublin (LLAMD) }\end{array}$ & London, Lyon, Amsterdam, Munich and Dublin \\
\hline PHOEBUS & Brussels, North Belgium, Netherlands, Madrid \\
\hline PROMISE & Gothenburg, Birmingham \\
\hline $\begin{array}{l}\text { Priority and Informatics in Public } \\
\text { Transport } \\
\text { (PROMPT)/STOPWATCH }\end{array}$ & London, Southampton, Turin, Gothenburg \\
\hline $\begin{array}{l}\text { Quadrilateral Advanced Research } \\
\text { on Telematics for Environment } \\
\text { and Transport (QUARTET) }\end{array}$ & Athens, Birmingham, Stuttgart, Torino \\
\hline $\begin{array}{l}\text { Southampton-Cologne-Piraeus } \\
\text { (SCOPE) }\end{array}$ & Cologne, Piraeus, Southampton \\
\hline
\end{tabular}

Information from these European activities are presented in Section 3.3. 


\section{STATE OF THE ART IN ERTIS}

ERTISs have three key components: the information supplied to the customer, the technologies that support the information supplied to the customer, and the media through which the information is provided. The first question asked of each ERTIS addressed the stage of development that each component of the ERTIS was in at the time of the interview: planning/definition, development, installation, testing, full operation/implementation, and expansion. Most transit agencies interviewed are in the process of designing a system, or have a manual ERTIS in place, as shown in Table 3. The ERTISs that are currently using real-time data in North America are BART, Metro Transit and Travlink. These systems are described in Section 3.2 .

\subsection{SYSTEMS IN PLANNING/DEFINITION AND DEVELOPMENT}

Most of the North American ERTISs are in the planning or development stages. Agencies that were interviewed indicated that systems that were in planning or under development were anywhere from six months to beyond two years from implementation. Since many of the transit agencies developing these systems are in the process of installing AVL systems, realtime information to determine real-time arrival and departure information is not yet available. The following subsections describe each of these systems, and provide the status and expectations of each system.

\subsubsection{Ann Arbor Transportation Authority (AATA)}

AATA began development and implementation of their Intelligent Transportation System, which included a traveler information component. However, in late 1994, the contract with the vendor was terminated. Currently, the project is on hold.

AATA has a manual ERTIS, in the form of a publication titled The Ride Guide, "which lists all routes and schedules in the AATA service area. Information on bus transfers required to travel between various locations is generally available upon request from individual motor coach operators, as well as from information specialists at the various centers or by telephone." 


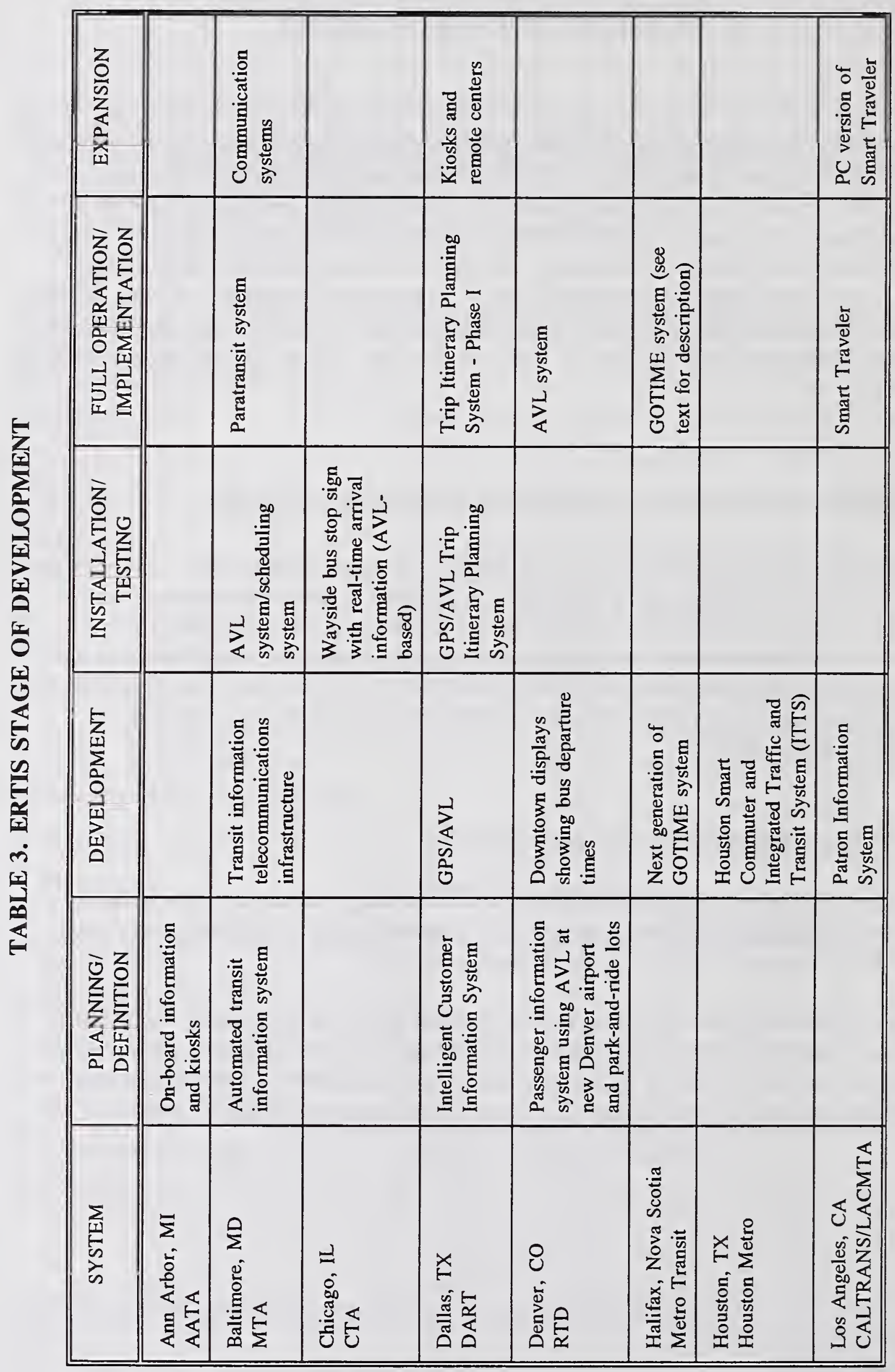




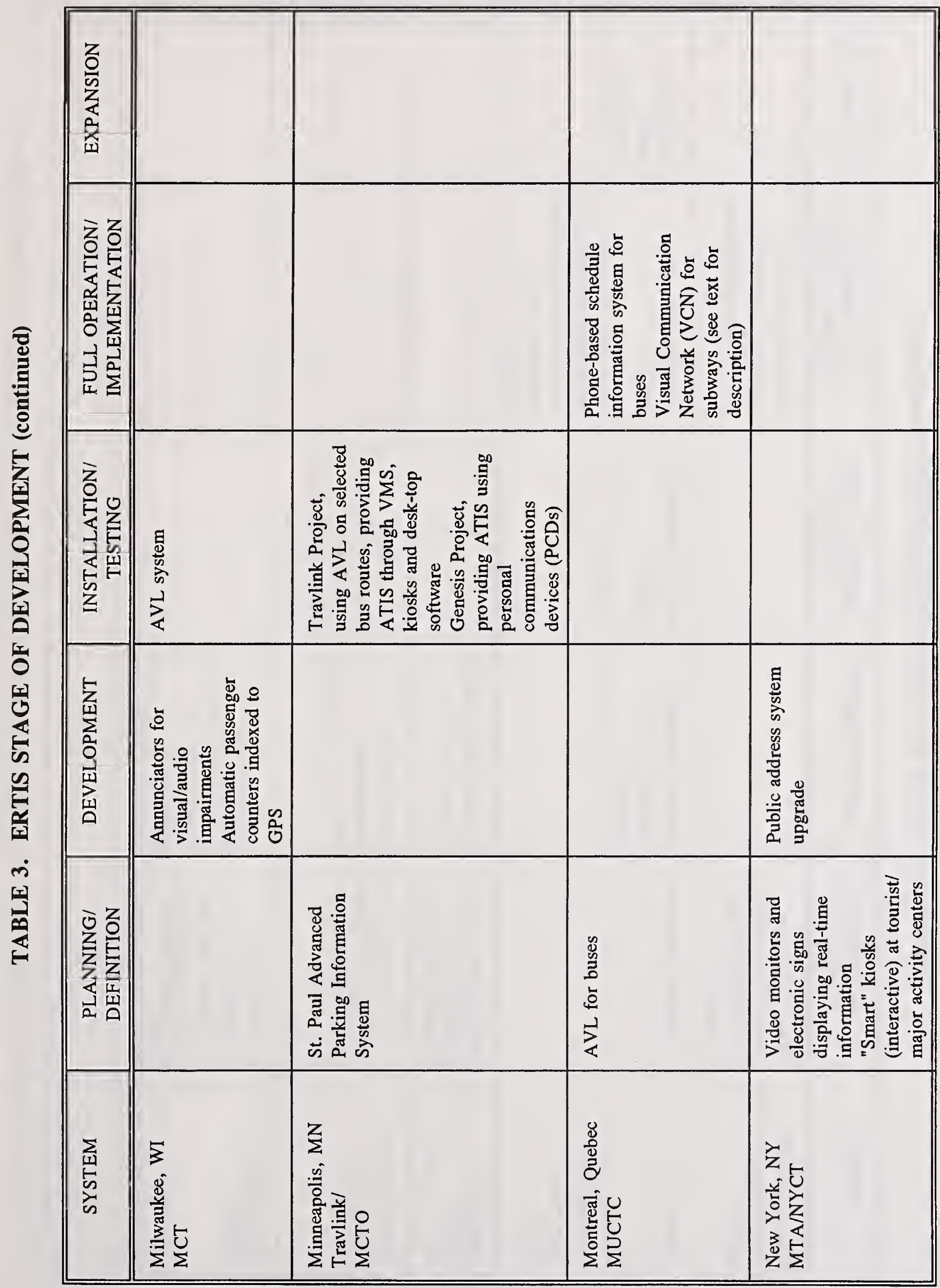




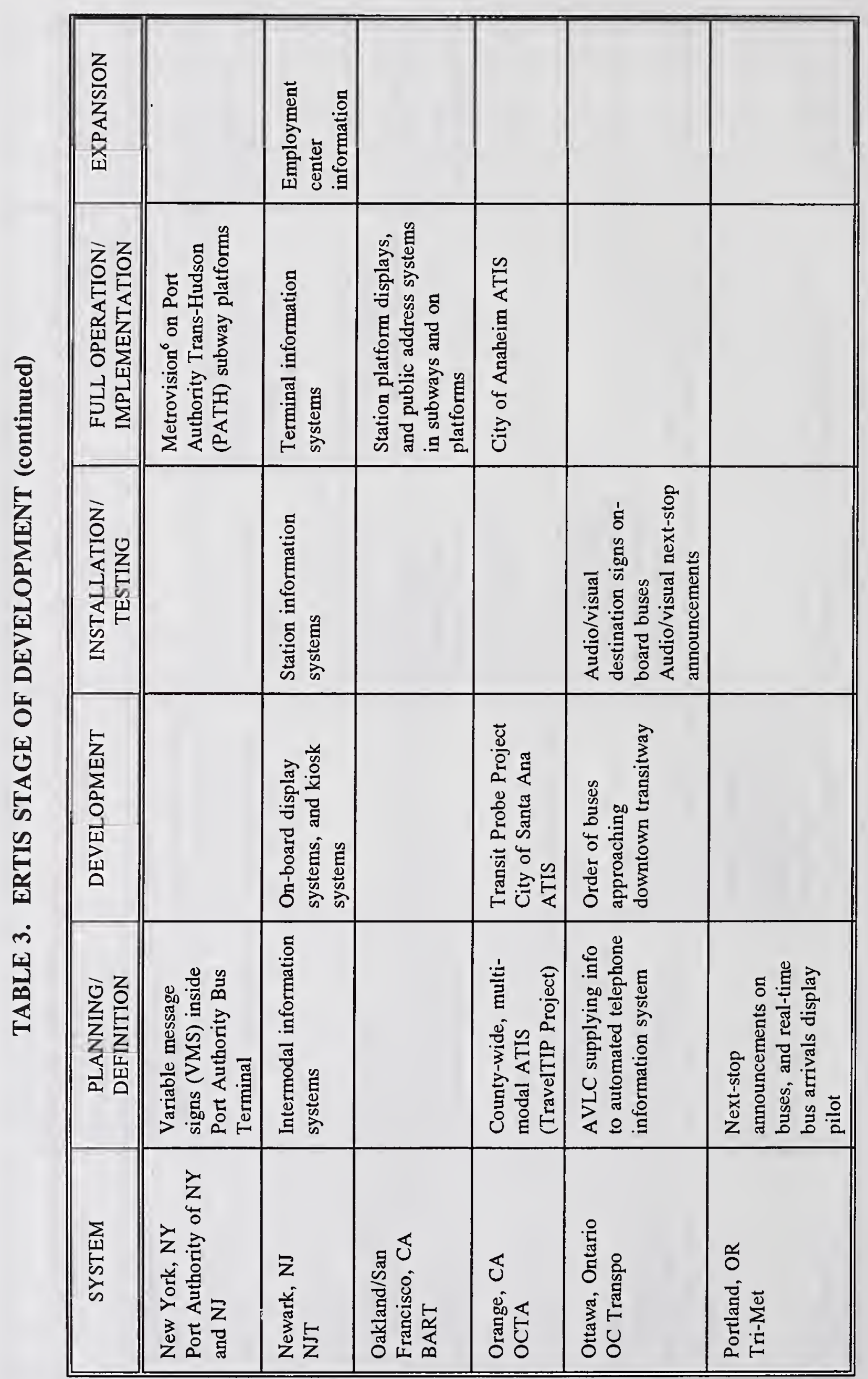

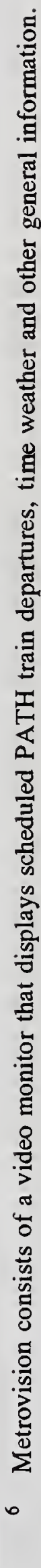




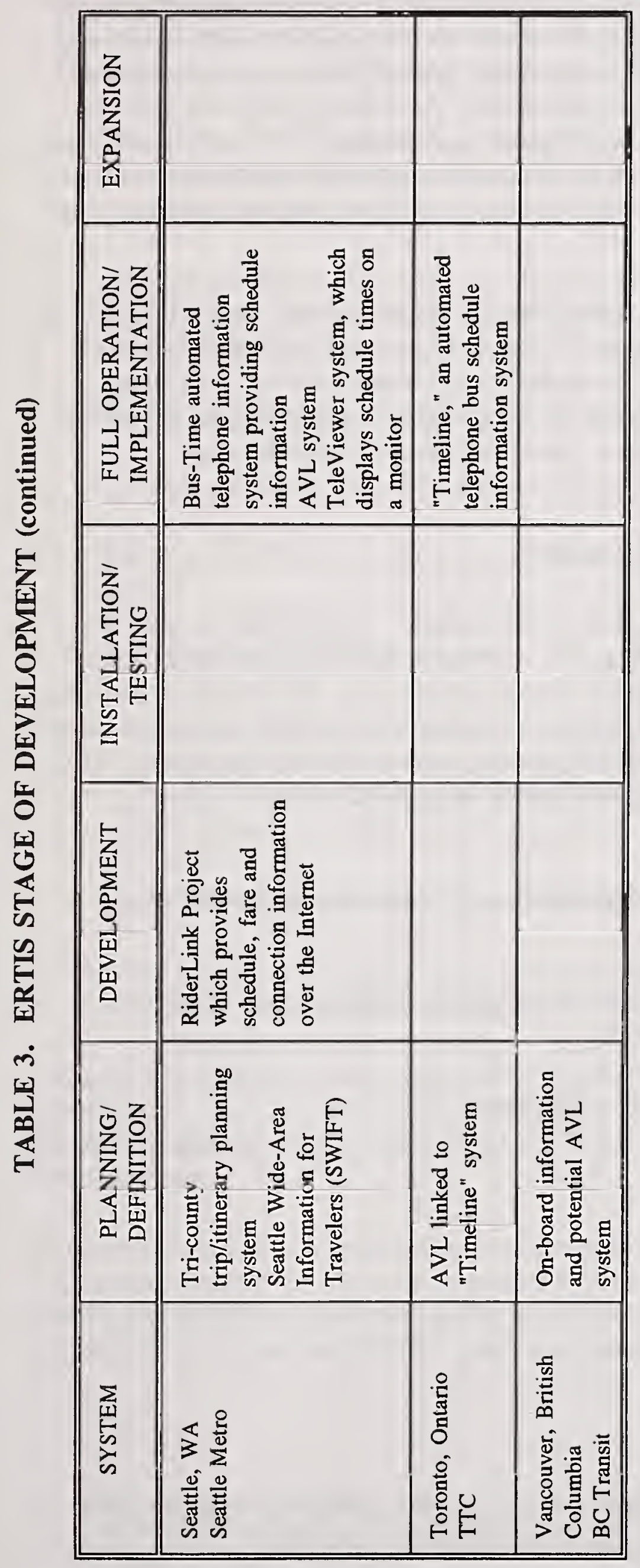


Originally, the traveler information component of the system was to include both interactive and non-interactive components. Interactive services were to include information kiosks and in-vehicle displays, and non-interactive services would include cable television broadcast and wayside information. Kiosks, placed at key locations throughout the service area, were to "display trip schedules, route maps, system and departure information. Travelers [would] use touch-screen displays and receive graphic display of possible routes and transfers necessary to travel between two locations. The kiosk [would] be capable of displaying and printing a copy of instructions for effecting such a trip. ${ }^{7}$

A communications link with the local cable television provider has already been established in advance of having real-time vehicle location and schedule information available. Originally, AATA planned on displaying schedule and route adherence information on a community access channel. Also, AATA specified a "countdown" system that would display the amount of time remaining before the arrival of the next transit vehicle at each transit stop.

\subsubsection{Vancouver, British Columbia (BC Transit)}

BC Transit has a manual ERTIS, which is called "INFOTUBE." INFOTUBE consists of plastic-mounted transit schedules on bus stop poles. Currently, INFOTUBE is being used at 50 out of the 6,000 bus stops throughout the BC Transit service area. BC Transit is assessing a system that would provide information on delays, re-routing, and incidents on-board transit vehicles (possibly on a light-emitting diode (LED) display mounted behind the driver). Also, they are currently assessing the potential implementation of an AVL system.

\subsubsection{CALTRANS/Los Angeles County Metropolitan Transportation Authority (LACMTA)}

CALTRANS is directing the SMART TRAVELER program ${ }^{8}$, which is a free automated information service to provide commuters with:

- Up-to-the-minute freeway conditions and traffic speeds;

- Customized transit route planning; and

- Real-time carpool matching.

7 Reference 47, pp. 78-79.

8 SMART TRAVELER is a public/private partnership directed by Caltrans in conjunction with the LACMTA, Commuter Transportation Services, Inc., Federal Highway Administration, FTA, Health and Welfare Data Center, IBM, North Communications, Pacific Bell and Pacific Bell Information Services. 
SMART TRAVELER provides the following media:

- Interactive (touch-screen) kiosks, which allow the traveler to:

- View up-to-the-minute freeway conditions throughout the Los Angeles area (data used to develop the conditions comes from roadway sensors which measure exact speed at various locations throughout the Los Angeles roadway system);

- Access LACMTA bus, train and shuttle schedules, routes and fares (information used for this activity comes directly from LACMTA's mainframe computer, which contains complete information on over 1,000 bus and train routes);

- Build transit itineraries, which can be printed at the kiosk; and

- Access the current list of carpoolers registered in the area;

- 1-800-COMMUTE telephone information service (operating 24 hours per day), which provides:

- List of kiosk locations;

- Automated Telephone Rideshare Matching system (called Ridestar from Commuter Transportation Services, Inc.), through which registered carpoolers can obtain a list of interested carpoolers, query the system based on specific needs on a specific day, and instantly send a personal voice message;

- LACMTA information; and

- Personal computer (PC) software, which will eventually allow participating employers and individuals to perform all the functions of a SMART TRAVELER kiosk.

Currently, 78 kiosks are fully installed and operational, and the PC software is not fully implemented yet. Also, the freeway conditions map that is displayed from kiosks is available through the Internet. In the future, SMART TRAVELER services may be available through cable television.

Separately, LACMTA is undertaking the development and implementation of a "Patron Information System" for all modes operated by LACMTA (rail and bus). This system will provide electronic informational signage in all passenger facilities and vehicles. The information to be provided by this system is separated into three categories': 
- Basic System Information Communications:

- Patron Schedule/Emergency Information, in audible and visual form, including:

-- Time of day

-- Track destination

-- Track location

-- Arrival and departure times (pre-planned or real/projected)

-- Special announcements (delays, emergency warning, linking to Emergency Broadcast System, etc.)

-- Disabled passenger access information

- General Transportation Information:

- Connection options

- Ticket information

- Travel time

- Traffic conditions

- Rideshare options

- Bikeway information

- Points of interest information and travel information

- Marketing, Commercial and Revenue Information Requirements and Capabilities:

- Service-oriented marketing promotions, such as construction progress updates, special ridership opportunities, etc.

- Information services (news, weather, sports, stock market, etc.)

- Community billboards (local and cultural events, job opportunities, etc.)

- Custom travel itineraries and maps

- Commercial advertising

A study performed by Diversified Technologies for LACMTA ${ }^{10}$ identified potential technologies for the Patron Information System, including closed-circuit television (CCTV) systems, interactive information kiosks, variable message signs (VMS), and fixed/static message signs. Each technology was evaluated on the basis of performance factors, specifically: quantity of information that can be communicated, quality and depth of the information that can be communicated, breadth of information that can be made available (i.e., information from adjoining and/or connecting transit systems), timeliness of information

Reference 23. 
being communicated, and number of patrons having ready access to or being served by the information. ${ }^{11}$ Further, each technology was evaluated qualitatively on the basis of:

- Human factors and Americans with Disabilities Act (ADA);

- Reliability;

- Safety;

- Security;

- Marketing;

- Disaster Survivability;

- Vandalism Resistance;

- Engineering/Technical;

- Operational and Maintenance; and

- Functionality.

Information and qualifications from potential vendors was due to LACMTA in early 1995.

\subsubsection{Chicago Transit Authority (CTA)}

CTA is in the process of procuring an AVL system that has wayside bus stop signs (audio and visual) that will display the arrival time (real-time) of the next three buses. Further, they will be installing experimental visual signs in some subway cars during early 1995. CTA currently provides en-route transit information on paper through printed schedules.

\subsubsection{Dallas Area Rapid Transit (DART)}

DART currently has a Customer Assistance Center, which provides a variety of information. Of the 2 million calls that the Center receives per year, $60-90$ percent of those calls are for schedule information. Customer information clerks have the Trip Itinerary Planning System (TIPS), which assists clerks in providing trip planning from origin to destination, with the least number of transfers. TIPS operates using a geographic information system (GIS) that contains a map database with all DART routes and stops, landmarks, and streets.

DART's AVL system is currently operational, but the route and schedule adherence capability is not operational yet.

\subsubsection{Metropolitan Transit Authority of Harris County (Houston Metro)}

Houston Metro is currently involved in two projects that relate to ERTIS: Houston Smart Commuter and Integrated Traffic and Transit System (ITTS). Houston Smart Commuter, an 
operational test sponsored by FTA, is assessing "the potential for encouraging greater utilization of high-occupancy commute modes (e.g., buses, carpools, and vanpools) by applying innovative approaches using advanced technologies to provide information. "12

One of the two components of the Houston Smart Commuter project is related to ERTIS: the bus component. "The bus component focuses on commuters living in the Kuykendahl [and Spring] park-and-ride lot market area[s] along I-45 North, and working in downtown Houston. The goal of this component is three-fold:

- Encourage a mode shift from single occupancy vehicles to buses,

- Change the times people choose to make their trips, and

- Shift travel routes.

"These changes in travel decisions will result from the provision of real-time information on traffic conditions, bus schedules, and directions on how to use the bus. The technologies to provide the real-time traffic and transit information [that are] under consideration include:

- Touch-tone and cellular telephones,

- Cable television,

- Videotex (both 'smart' and 'dumb' terminals), and

- Pocket systems. "13

"It is anticipated that the information delivery system will be capable of providing high quality graphical and text presentations, will be interactive, allowing users to query for additional information in response to specific traffic and transit needs, and will be user-friendly and capable of providing updated travel time and transit schedule information every three minutes. The real-time traffic and transit information utilized in the I-45 North component will be provided through the Traffic Management Center and METRO's Transit Information System." ${ }^{14}$

The ITTS consists of the following elements:

- Regional Computerized Traffic Signal System;

- Transit Operational Control and Management System; and

- Texas DOT Regional Freeway Management Center.

These elements will be integrated by a metropolitan area network using Synchronous Optical Network (SONET) technology.

\footnotetext{
12 Reference 35, p. 1

13 Reference 35, p. 2.

14 Reference 57, p. 7.
} 
An ATIS is a key component of the ITTS, and it will include en-route transit information. All 1,500 transit vehicles, transfer centers and 29 P\&R lots will be supported by the ITTS. "ATIS request and response are supported by the SONET network's interconnect with the public telephone network (including cellular), as well as direct field interconnects with kiosk terminals. "15 On-board traveler information will be available in addition to information displayed on VMS at P\&R lots, transfer centers and along the roadways, and on kiosks at P\&Rs and transfer centers.

\subsubsection{Mass Transit Administration of Maryland (MTA)}

MTA has tested one kiosk with a touch-screen, which contains static data from published timetables. The kiosk was not waterproof, so there was a problem with its operation when it rained. They are in the process of upgrading the kiosk hardware and software, and will be back in operation in early 1995 . Once their global positioning system (GPS) AVL system is installed on their buses, they are planning to use it to provide real-time information on schedules and actual vehicle location. It is expected that in three to four years, more kiosks will be deployed around the city of Baltimore.

\subsubsection{Metropolitan Transportation Authority (MTA) - New York City Transit (NYCT)}

MTA-NYCT is currently working on two major ERTIS projects. One project involves installing electronic message signs in subway stations, which will take place over the next six years. Phase 1 of this project consists of installing these signs in 54 stations that will initially display only incidents/exceptions. In five years, when the new central operations control center is fully implemented, these signs will display real-time arrivals and departures. Eventually, signs will be installed in all 469 subway stations.

The other project is an operational test, funded by FTA, that has two parts. Part A will install either variable message signs (VMS) or video monitors that contain real-time travel information (from a new AVL system) at 40 selected bus stops (20 VMS and 20 video monitors) on the M15 and M27/50 routes. These routes run both north/south and east/west directions, and serve crosstown and downtown trips. The VMS and monitors may display information including route number, expected arrival times, delay information, transfer points, and marketing information. Further, audio announcements may be made for the visuallyimpaired.

Part B will install "smart" interactive kiosks at major transit stops/tourist sites with interactive screens for traveler information. Kiosk locations may include South Ferry, South Street Seaport, Times Square (along Broadway), and Rockefeller Center. Information provided via the kiosks may include primary routes to particular locations, selected origins and destinations, alternate routes, updated schedules (based on AVL), fare information, tourist information, and other trip planning information. 


\subsubsection{Milwaukee County Transit (MCT)}

MCT is in the process of implementing an AVL system with route and schedule adherence capability. By May 1995, all buses and supervisory and support vehicles will have AVL installed. In 1995, 10\% of the bus fleet will have automatic passenger counters (APCs) installed. The APCs will be indexed to location determined by GPS. In 1996, annunciators for visual and audio impairments will be implemented. There are links being developed in the AVL system to provide real-time passenger information eventually.

\subsubsection{Montreal Urban Community Transit Corporation (MUCTC)}

Currently, a passenger information system for the bus system is a phone-based system, which provides published schedule data. An AVL system is being planned for the bus system. A project under development is to install VMS that will tell each bus driver where to park the bus in the garage at the end of the day, based on its schedule for the next day.

The Montreal subway system currently has the Visual Communications Network (VCN), developed by Telecite, installed in each subway car. This automated system "display[s] and orally communicate[s] instructions in case of emergency; information concerning schedules or system delays; the name of the next station on line; campaigns to promote use of the transit system; and security messages. The VCN can also provide non-essential visual information [such as]: news, weather, sports, local events, and advertising. ${ }^{16}$

"The VCN technology uses state-of-the-art flat matrix multi-colored, light-emitting diode (LED) displays in combination with proprietary user-friendly graphic workstation to produce highly readable and visually pleasing messages. The messages are transmitted via a data radio network from one (or more) control centers to receiver-equipped displays inside [subway] cars in a matter of seconds. A radio frequency tag identification system, located along the travel path, is used to automatically trigger the stop announcement system and to allow targeting of messages to specific geographical sectors in the city. "17 See Figure 1 for a diagram that depicts how the VCN operates.

Information on subway location and real-time status is available through the subway's control center, which has a total of eight computers (one for each line). This system is not used for customer information, but is an in-house system for management of the train services. Since subways run two-to-three minute headways during the peak hours and six-to-ten minute headways off-peak, MUCTC does not feel that there is a need for a passenger information system that displays real-time arrivals and departures. There are, however, some bus routes that have 30-minute headways, so that is where the information is most needed and not available yet.

Reference 60, p. 3016.

Reference 60, p. 3018. 


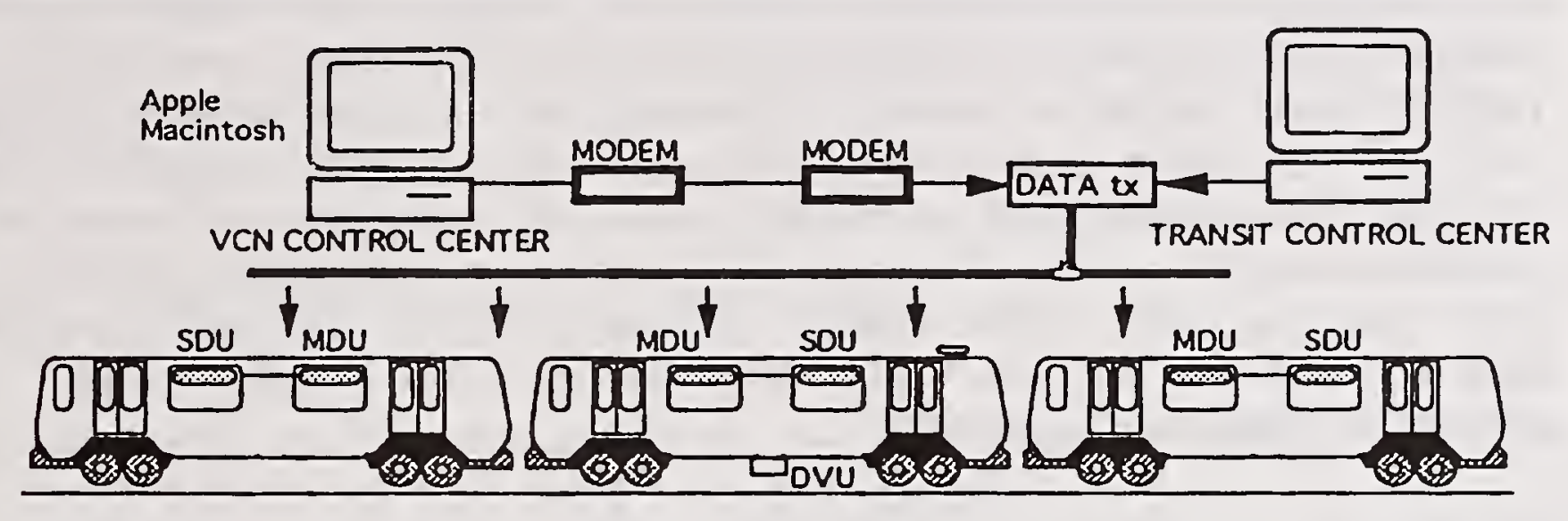

Figure 1. VCN System Elements A (Reference 59, p. 3019)

\subsubsection{New Jersey Transit (NJT)}

NJT has an extensive five-year plan to implement many APTS technologies, including en-route transit information..$^{18}$ Generally, their plan can be divided into three areas: Smart Bus Services, Smart Rail Services and Operations Support Services, which cover communications, information processing, administration, maintenance, and any other function that supports the integration of bus and rail services.

Currently, NJT has five projects related to en-route transit information:

- Train Information Display System (TIDS) Project. This project is a passenger information system for NJT Commuter Rail. "When fully implemented, it will provide passengers on the platforms and in waiting rooms with real-time information about commuter rail status and approaching commuter rail trains via visual displays, using liquid crystal display technology and television monitors; and via audio means, using digitized voice technology and public address announcements. If this TIDS test project is successful, it is expected that these passenger information measures will be incorporated system-wide. 
- "Multimedia kiosks. NJT is currently evaluating the capabilities of 'smart' kiosks commercially available from several vendors. Prototype testing of these interactive passenger information devices is scheduled to begin in 1995, with no date set for systemwide deployment. As envisioned by NJT, these devices will provide passengers with historical schedule, route, and fare information as well as real-time information on transit service status, travel times, and recommended alternate routings in the event of delays. They will provide trip planning services for passengers and be able to respond to passenger inquiries. These kiosks will be equipped with graphic display and printer capabilities and will show locations of bus stops and transfer points as well as local points of interest and commercial services, such as restaurants and shopping centers. They will be located in public places (e.g., malls, office complexes) and transit terminals. Real-time information updates would be sent from one of the control centers, or from a centralized transit information center if one is established.

- "On-board information display systems (bus and rail). NJT is initiating a pilot project to evaluate on-board display systems with real-time update capabilities which they hope to implement by the end of 1996. The proposed information system would be part of a passenger information network controlled from a centralized information collection/distribution center. This center may be at one of the existing control centers or at a new stand-alone facility dedicated to processing and disseminating passenger information. The intent is for on-board display systems to provide information about NJT services, and schedule changes and delays as well as paid advertising. With its present design, this system will require minimal involvement from vehicle operators.

- "Terminal information displays. In addition to the TIDS project, NJT is installing a new ComNet train arrival/departure LED matrix display board at the Hoboken rail terminal and studying the potential for a bus terminal information display system. NJT expects to have a prototype interactive bus terminal display system operational within three to five years. Terminal information displays are designed to provide passengers at bus and rail terminals with information concerning departure times and locations, connecting services, schedules, imminent departing/approaching trains, and delay lengths and causes. Such displays may be visual or audio. Presently, information is collected and distributed per terminals, on a stand-alone basis, by personnel located at the major terminals who make public address announcements or control visual information display boards. ${ }^{19}$

NJT has identified "En-Route Information Services" as a function within the category of Advanced Information Services (AIS), which cover "elements of the ITS dedicated to 
providing travelers with transportation-related information. "20 Figure 2 depicts the functionality of En-Route Information Services in relation to other NJT functions.

Further, NJT has defined potential VMS at park-and-ride locations (bus and rail) and at junctions of major roadways to give travelers information on alternatives for their trip. ${ }^{21}$ In the following two examples of VMS, travel time given is the shortest possible, considering projected traffic congestion and time until next transit departure, assuming optimal routing from this location onward.

Example 1: VMS at I-80, Exit 34

\begin{tabular}{||l|l|l|l|l|l|}
\hline & VIA: & I-80 & DOVER P\&R & & \\
\hline TRAVEL TO: & NEWARK & $80 \mathrm{~min}$ & $65 \mathrm{~min}$ & & \\
\hline & NEW YORK & $90 \mathrm{~min}$ & $105 \mathrm{~min}$ & & \\
\hline
\end{tabular}

Example 2: VMS at I-80, Exit 53

\begin{tabular}{||l|l|l|l|l|l||}
\hline & VIA: & I-80 & WILLOWBRK P\&R & US-46/NJ-3 & $\begin{array}{l}\text { MTN VIEW } \\
\text { P\&R }\end{array}$ \\
\hline TRAVEL TO: & UPTOWN NYC & $30 \mathrm{~min}$ & $35 \mathrm{~min}$ & - & - \\
\hline & DOWNTOWN NYC & - & $45 \mathrm{~min}$ & $60 \mathrm{~min}$ & $50 \mathrm{~min}$ \\
\hline & NEWARK & - & - & $40 \mathrm{~min}$ & $35 \mathrm{~min}$ \\
\hline
\end{tabular}

\footnotetext{
20 Reference 22 , p. 3.

21 Jim Kemp, Senior Planner, APTS Technologies, NJT
} 


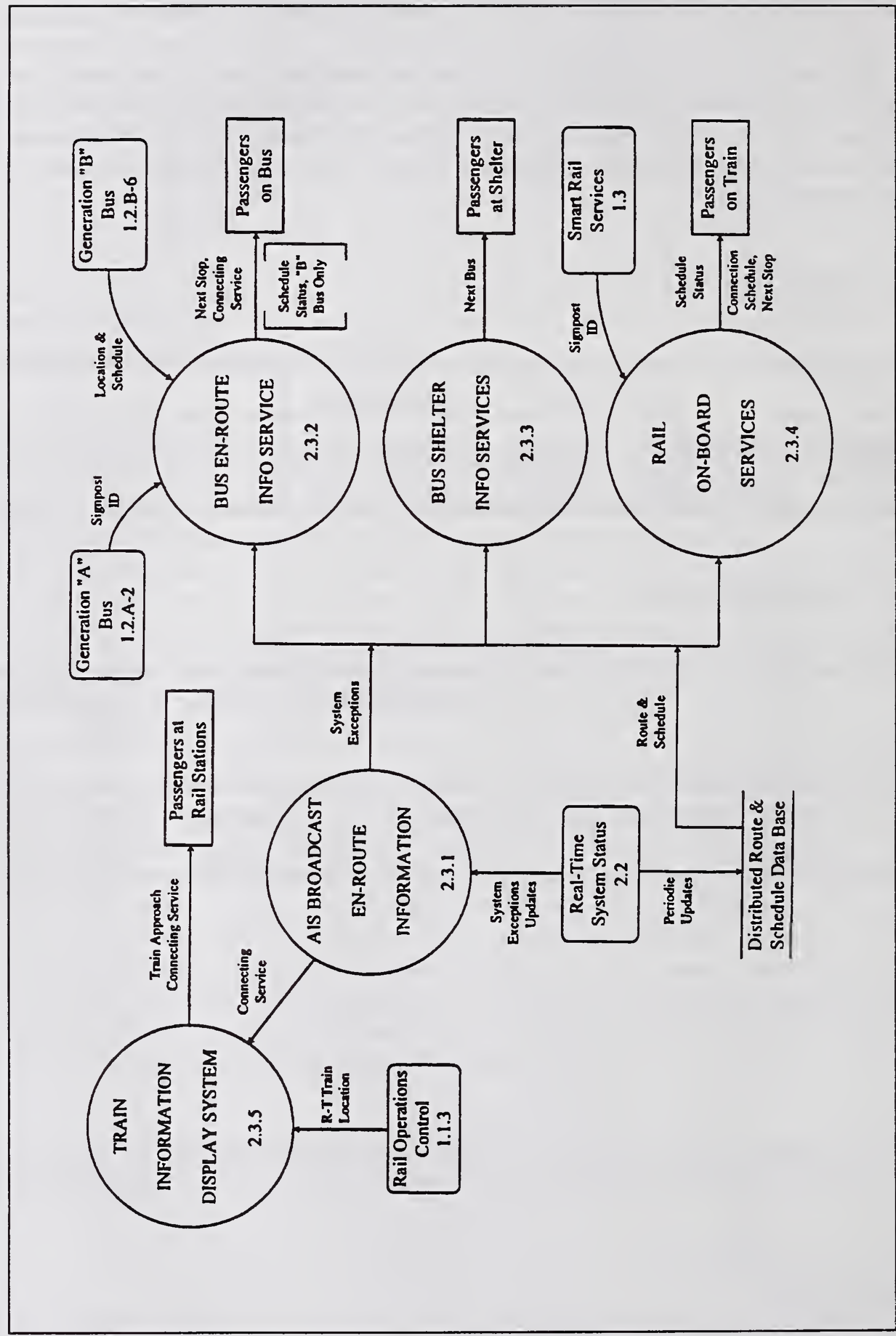

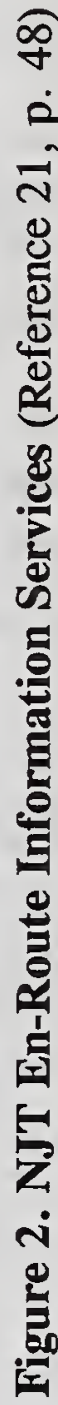




\subsubsection{Orange County Transportation Authority (OCTA)}

OCTA is part of a team that is beginning a project to integrate transit operations and traffic management. One of the goals of this project, called Transit Probe, is to "provide the public with both transit and traffic information with which to evaluate trip-making alternatives. Information will include transit schedule information (both real-time and fixed), availability of alternative routes, transit fares, and traffic congestion information to provide dual-mode information from which travelers can make mode and route choice decisions. Points of information dissemination will initially be targeted for transit/rail terminals/centers and through existing city systems. "22 This project, which is expected to start in late spring 1995, is being funded by the Federal Highway Administration (FHWA) and CALTRANS Division of New Technology and Research. Approximately 15 fixed-route vehicles will be equipped with GPS devices, and will be used as traffic probes. It is expected that these vehicles and an integrated system will be operational by the end of 1996 .

Currently, OCTA distributes transit information and receives traffic information manually. Other partners provide varying degrees of traveler information as follows:

- City of Anaheim provides real-time traffic information through cable television, highway advisory radio (HAR) and two kiosks;

- CALTRANS District 12 is in the process of upgrading to provide traffic information through VMS and HAR; and

- City of Santa Ana provides traffic information through VMS. Their ATIS is under development and is expected to be completed by mid 1996. This ATIS will provide realtime traffic information through cable television, HAR, highway advisory telephone (HAT) and one kiosk located at the Ronald Reagan Federal Courthouse.

Another OCTA project, TravelTIP, will provide multimodal traveler information for the entire county. TravelTIP is an ITS Early Deployment project, and will receive input directly from the Transit Probe project.

\subsubsection{Ottawa-Carleton Regional Transit Commission (OC Transpo)}

OC Transpo is currently involved with three projects that are related to ERTIS. The first project is the testing of Luminator's Mega Max destination signs on buses. This system also says the route number and destination as people are boarding and alighting. So far, it has been well-reviewed by the public. The second project is a system that announces the next stop on one bus (an articulated bus that operates on a transitway). It announces in both audio and visual means. Currently, this system is being tested. The third project, scheduled to be implemented by spring 1996 at bus stops, involves signage that will provide the order of buses 
approaching the downtown via the transitway. (Currently, there are 1,800 people per hour on 50 routes that converge in this downtown area.) This system will use AVL to detect the buses upstream before they arrive in the downtown area.

In the future, OC Transpo's Automatic Vehicle Location and Control (AVLC) system will eventually provide messages to their automated telephone information system, providing realtime schedule information.

\subsubsection{Port Authority of NY and NJ}

Currently, the Port Authority Trans-Hudson (PATH) subway system has Metrovision, which is a monitor-based system that displays scheduled subway departures, along with the time, weather and other related information.

The Port Authority Bus Terminal at 8th and 42nd Streets in New York City will eventually have VMS inside the terminal which will alert travelers to problems that are communicated from the Transportation Operations Coordinating Committee (TRANSCOM) and MTANYCT. Over 100 agencies participate in TRANSCOM. TRANSCOM exists through an interagency memorandum of understanding among its 15 members. TRANSCOM is administratively part of the Port Authority of New York and New Jersey. TRANSCOM "continuously monitors traffic conditions, construction schedules, road closings, accidents, weather-related incidents and any other event that might disrupt traffic on the estimated 6,000 miles of highway and 2,000 miles of track within the 500 square mile metropolitan area. ${ }^{23}$

\subsubsection{Regional Transportation District (RTD)}

RTD currently has an AVL system, which provides real-time information to dispatch. Two stations downtown will have displays that show real-time departures using the AVL system. Another RTD project, which will use AVL information interfaced with kiosk-type displays at the new Denver airport and at park-and-ride lots, is currently under development, pending full acceptance of the AVL system.

\subsubsection{Seattle Metro}

Seattle Metro is currently involved in three projects related to ERTIS. The first demonstration project is the TeleViewer at the Northgate Transit Center, which displays schedule times for routes on a large Sony monitor. It is based on the TeleRide-Sage product, called TeleRider, which is an automated telephone information system. It has been in operation for a year. 
The second project, which is being funded by FHWA and FTA, is called Riderlink.

Riderlink, which is currently in Phase 1 of development, provides the following information for the greater Seattle metropolitan area:

- Schedule information;

- Information on routes, buses and fares;

- Maps;

- Vanpool and ridematching information;

- Bicycle transportation information;

- Freeway congestion;

- Washington State's commute trip reduction law; and

- Other transportation information.

Riderlink is an on-line service that can be accessed via the Internet through the Worldwide Web (WWW). It can be used on a network or in a stand-alone mode. Seattle Metro is partnering with Overlake, a large employment center north of Seattle (consisting of companies such as Microsoft, Allied Signal, Nintendo, Eddie Bauer, Applied Microsystems, Safeco and others), on the Riderlink project. Even though Riderlink was intended primarily for employment centers and work sites, anyone with a personal computer that has WWW browsing capability can access Riderlink. "Later [in 1995], Riderlink will include information about Community Transit and Pierce Transit bus routes, ferry schedules, and construction updates [in addition to information about Seattle Metro]. Touchscreen kiosks will be installed at selected Overlake employment sites, and all Overlake employee transportation coordinators will have connections to Riderlink." ${ }^{24}$ The second phase of Riderlink development will investigate the feasibility of using real-time information to update schedules.

The third project related to ERTIS is a tri-county trip/itinerary planning system, which will provide information on trip details (e.g., routes, transfers, etc.). The maps are under development currently, and Seattle Metro plans to have a demonstration with one kiosk. The second phase of this project may include ferries.

\subsubsection{Toronto Transit Commission (TTC)}

Currently, TTC has a system called "Timeline," which is an automated system that provides a telephone number for every stop, so that a rider can call to find out when the next bus is scheduled to arrive. The plan is to link this system with their AVL system eventually to provide real-time information on next bus arrival. (They currently have AVL, but it is not linked to Timeline.) In addition, on the subway station platforms, TTC has something similar to Metrovision, which displays the time and other travel-related information. All other enroute transit information is provided manually through posted schedules. 


\subsubsection{Tri-County Metropolitan Transportation District of Oregon (Tri-Met)}

Tri-Met is in the process of installing a bus dispatch system that has a GPS AVL component. It is expected that this system will be fully installed by December 1995. The first garage should be operational on this system by mid-summer 1995 using real-time information. There are two projects related to this AVL system that will focus on passenger information. The first project involves the telephone operators who provide transit information. They will be receiving real-time information from the AVL system, including exception reports and text messages for re-routing. The re-routing information will come directly from the dispatchers. The second project involves the demonstration of ten monitors at "smart" bus stops that will display schedule countdown information, such as NEXT BUS IN "N" MINUTES. These monitors will be located in bus shelters and at transfer points, but not at time-transfer centers because usually the transfers are made immediately. Exception information will be received and displayed on the monitors as it will be received in dispatch. This pilot demonstration is being partially funded by FTA.

Eventually, Tri-Met is interested in displaying real-time arrivals/departures in the downtown transit mall. Currently, only schedules for the next buses on a particular line are displayed, not real-time information. Another possible project in the future is to install "smart" bus stop signs at stops along snow routes that are used in the winter to go around hills, rather than over them. Although this project has not been funded yet, Tri-Met expects that it will become important in the short-term.

\subsection{SYSTEMS IN INSTALLATION/TESTING AND FULL OPERATION}

\subsubsection{Bay Area Rapid Transit (BART)}

BART currently has station platform displays that display real-time arrival and departure information based upon real-time data collected through the fixed block data transmission system. This system tracks train consists using automatic identification readers, which are placed at trackside. These readers are hard-wired to station train control processors and the central computer. BART will be replacing/supplementing the existing system with a moving block system using radio transmitters/receivers placed along the wayside that poll the location of trains and determine the distance between trains. In addition, en-route transit information for BART is available through cable television and radio broadcast. Further, some BART stations have Metrovision. Information on other regional transportation services, travel directions, information on restaurants, museums and theaters, and weather is available manually from BART's customer service department.

Related to their existing ERTIS, BART is in the process of purchasing Transtar, which is a trip planning system from Commuter Transportation Services (CTS). Transtar is fully operational in Riverside and Long Beach. As part of this effort, MTC is developing a database for all 
transportation providers and carriers in the San Francisco/Oakland area. BART expects Transtar to be fully operational by April 1995. Eventually, Transtar will be located in the major BART transit center, and at various Central Contra Costa Transit Authority (CCCTA) County Connection and Alameda-Contra Costa Transit District (AC Transit) locations. Transtar does not currently handle real-time information, but data on detours or delays in the system can be manually input into Transtar and will be used as part of the data to create each trip plan.

\subsubsection{Metro Transit}

Metro Transit currently operates GOTIME, which "is a user information system that gives the real time at which the next two buses will reach a given stop. It is designed to transmit the information at home, over the telephone, in public places on a video screen and at the terminus over loudspeakers. A user who wants to obtain information over the telephone must call the number given at the bus stop of his[/her] choice. A voice synthesizer automatically gives the time of arrival of the next two buses at the stop corresponding to the telephone number called. The information is also available at various public places such as shopping centers and building lobbies. The information is displayed on a video screen, which allows the system to show a diagram of the routes and a description of the stops, along with the real time of arrival of the next buses at the stop where the screen is installed. Some particularly busy stops are equipped with loud speakers which, on request, will disseminate the same information for the stop that is given over the telephone. ${ }^{25}$

The next generation of GOTIME is in the process of being developed. The platform for the existing system is an HP1000, and the platform will be moved to UNIX with the next generation. The new GOTIME should be in place approximately March 1996.

\subsubsection{Travlink Project/Metropolitan Council Transit Operations (MCTO)}

Travlink, a Minnesota Guidestar ${ }^{26}$ operational test, represents the integration of a computeraided dispatch (CAD) and AVL system based on GPS, an ATIS and an automatic vehicle identification (AVI) system in the I-394 corridor in the Minneapolis/St. Paul metropolitan area. Travlink is using "a variety of devices and systems to distribute both real-time and static transit and traffic information to travelers. A primary objective is to determine the extent to which improved information can assist travelers with trip-making decisions and influence travel behavior. Travlink is designed to encourage commuters to consider alternatives to single-occupant travel, especially public transit. ${ }^{27}$

25

26

27

Reference 66, p. 47.

Minnesota Guidestar is Minnesota DOT's (Mn/DOT's) program for ITS, and is actively testing and deploying new technologies that improve the movement of people, goods and services.

Reference 84 , p. $1-1$. 
The Travlink project objectives can be summarized as follows:

- Identify changes in transit ridership due to improved customer information;

- Determine the performance of ITS technologies in a real-world environment;

- Determine customer acceptance of new technologies;

- Evaluate the impacts of transit service efficiency and quality; and

- Utilize public/private partnerships.

Metropolitan Council Transit Operations (MCTO) is the transit operator in the Minneapolis/St. Paul metropolitan area, and currently has a fleet of approximately 800 buses. They operate on 120 routes with over 1,000 branching combinations. The Travlink project selected 80 buses on nine routes to be equipped with GPS CAD/AVL. Real-time information from these buses is used together with traffic information collected from the Traffic Management Center ${ }^{28}$ (TMC) to provide Travlink users with real-time, route-specific information on the operating conditions of the highway and transit systems, and with other personal-use types of information.

There are currently three interactive Travlink kiosks in downtown Minneapolis locations: two are located at business centers (Hennepin County Government Center and Commuter Connection in the Pillsbury Building) and one is located at a transit store. The kiosks provide information on the following topics:

- Transit Information:

- How Do I Get There?

-- Downtown Minneapolis to Western Suburbs;

-- Western Suburbs to Downtown;

-- Downtown Minneapolis to/from Points of Interest; and

-. Downtown Minneapolis to/from the University of Minnesota/Minneapolis Campus;

- Schedules and Maps;

- Is My Bus Late?

- Bus Fares;

28 This traffic information is provided through Genesis, which is an operational test of personal communication devices (PCDs). The PCDs identified for Genesis include alphanumeric pagers, personal digital assistants (a small hand-held unit with 2-way radio frequency communications), and notebook computers. Currently, Genesis is in a six-month pilot phase which provides traffic information to commuters via 350 pagers and 50 Apple Newtons with pager cards. 
- Park-and-Ride Locations;

- I-394 Commuter Services;

- Special Events;

- Elderly and Disabled Services;

- Bus Service Changes;

- Customer Service;

- Traffic Information:

- Incidents and Delays; and

- Construction and Maintenance.

There are monitors at two major transit transfer centers that display real-time status information on arriving buses. Also, there are electronic signs displaying the same information at four park-and-ride locations. The information displayed on the monitors and electronic signs is formatted as shown in Figure 3.

\begin{tabular}{||l|l|l|l||}
\hline Route & Sched & Destination & Status Time: 11:13A \\
\hline \hline 61 & $11: 00 \mathrm{~A}$ & Downtown & $15+$ Min Late \\
\hline $9 \mathrm{~A}$ & $11: 19 \mathrm{~A}$ & So Mpls-4th Ave & No Status \\
\hline $75 \mathrm{~S}$ & $11: 30 \mathrm{~A}$ & Ridgedale-Mound & On Time \\
\hline
\end{tabular}

Figure 3. Sample Travlink Monitor/Electronic Sign Display

In the very near future, Travlink software will be available to anyone that has access to a personal computer or a videotext terminal at home or work. It is expected that 500 homes and offices will have access to Travlink. 
One other aspect of the Travlink project is the use of AVI on the same 80 buses that are equipped with GPS AVL. This technology, being supplied by $3 \mathrm{M}$, "will provide a comparative method for tracking buses that operate in the High Occupancy Vehicle (HOV) lane of I-394. Signpost detectors are mounted at regular intervals along the freeway and infrared emitters are installed on-board the buses. The buses are detected as they pass the signposts. Data are sent to a computer located at Mn/DOT's TMC. The computer will convert the data to vehicle speed and travel time information. Buses will thus be functioning as probe vehicles in the HOV lane. ${ }^{29}$

\subsection{SYSTEMS IN EUROPE}

In 1988, the European Commission began a program called Dedicated Road Infrastructure for Vehicle Safety in Europe (DRIVE). "The car industry with its partners have developed modules of modern information and communications technology for the road infrastructure and vehicles [DRIVE]. Since 1992, the modules developed have been tested in field tests and pilot projects (DRIVE II) on European trunk roads and in European cities." ${ }^{30}$ "In the current phase [of DRIVE projects], 64 projects, involving over 500 industrial, governmental and research partners, are running pilots at test sites in over 30 cities and on 13 major transport corridors. "31

The 64 DRIVE II projects are separated into seven operational categories:

- Demand Management;

- Travel and Traffic Information;

- Integrated Urban Traffic Management;

- Integrated Inter-Urban Traffic Management;

- Driver Assistance and Co-operative Driving;

- Freight and Fleet Management; and

- Public Transport Management.

The ERTIS projects that are described in the following subsections are part of the last category: Area 7 - Public Transport Management. The objectives of this area are to identify and develop solutions which improve the attractiveness and efficiency of public transport through:

Reference 37, p. 2.

30 Reference 82, pp. 17-18.

31 Reference 27. 


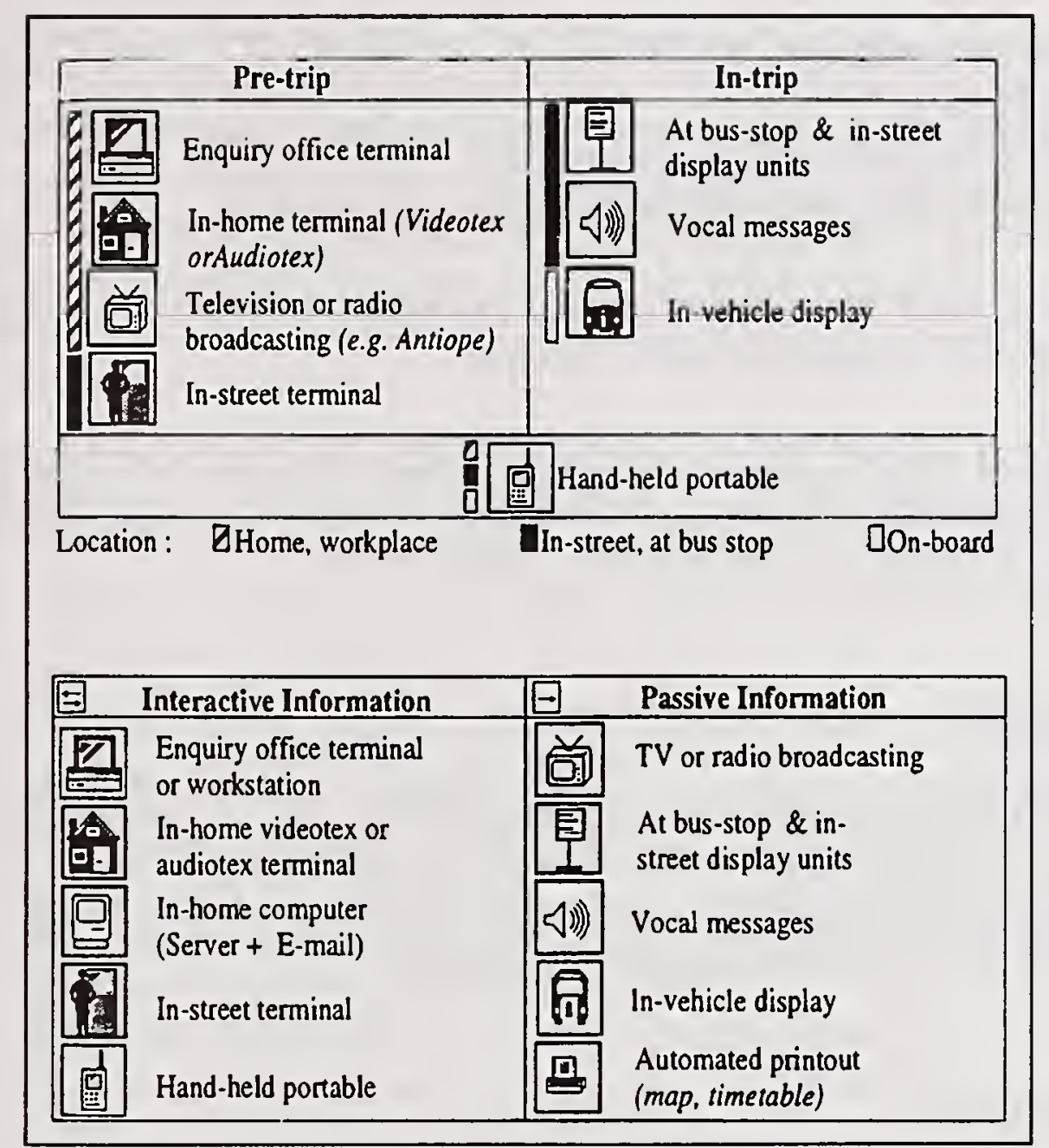

Figure 4. Popins Media (Reference 12, p. 2889)

- Effectively implemented advanced transport telematics (ATT) supporting sustainable transportation; and

- The maintenance of cost effective, flexible mobility for all travelers.

"The main focus of the work [in Area 7] has been:

- The development of common functional specifications for systems and contributions to the development of standards through a forum which has included operators, city authorities, planners and industrial partners.

- Identification, development and promotion of solutions which improve the attractiveness and efficiency of public transport particularly in relation to:

- Traveler information systems; 
- Vehicle priority systems;

- Integrated ticketing;

- Vehicle scheduling and control systems; and

- Database development for systems integration and planning.

- An assessment of some of the barriers facing successful implementation and further development of ATT systems for public transport. ${ }^{\text {"32 }}$

DRIVE and DRIVE II projects directly related to ERTISs have been demonstrated and, in some cases, implemented in five cities. "In [these] five cities, real-time information services give information to passengers at the bus stop or in the bus." ${ }^{33}$

\subsubsection{CARTRIDGE}

CARTRIDGE is one of the four task forces within DRIVE. Its purpose is "the implementation of public transport trip planning function within driver guidance systems. " ${ }^{34}$ To date, CARTRIDGE has produced guidelines on common access to route planning and public transit trip planning for travel and traffic information suppliers.

\subsubsection{EuroBus/Popins}

The EuroBus project involves the development of a data model for public transport. This model, called Transmodel, is a generic model which describes the structure of data necessary for a public transport system. This model has been proposed as a standard to the European Committee for Standardization. Popins has used this data model to develop computer-aided tools for passenger information services. Figure 4 shows the various media being used in Popins.

"The Popins work has focused on the use of a common transport database and GIS in the development of user information terminals for both inquiry office staff and the general public. The work has taken into account recent advances in the areas of man-machine interface, ergonomics, cooperative answering and knowledge-based systems to develop advanced passenger information terminals which are easy to use by both expert and occasional users. Following the design of and research on preliminary mock-ups, prototype terminals have been introduced in Marseilles, Madrid, Thessaloniki and Birmingham." 35

Reference 30, p. 2825 .

Reference 26. 
The Marseilles prototype, called AlterEgo, was developed to be used by inquiry offices of bus and rail operators. Marseilles' public transportation system includes two subway, one light rail and 60 bus lines. There are a total of 2,200 bus stops and subway stations. ${ }^{36}$ AlterEgo, a Windows-based system, currently provides transit schedules (not real-time), trip planning and multimodal options for a particular trip based on several algorithms that compute optimum path with transfers. In the future, AlterEgo will become an ERTIS when AVL information is added, along with transit delays and images of points of interest. Figure 5 shows a sample screen from AlterEgo.

Madrid has 13 prototype terminals in various locations around the city. The Madrid system, called SIT, currently covers ten subway lines with 155 stations, and 165 bus lines with more than 6,000 stops. Plans are to install 100 terminals in public places and to implement an inquiry office that uses the same terminal.

Thessaloniki has a system which is also not based on real-time data. The terminal, called THEPIS, is current being tested by an inquiry office. In the future, it is expected to be deployed in public. The system, which is still under development, includes:

- Expected arrival and departure times according to the schedule for the next three buses;

- Theoretical timetables for all bus lines at any bus stop;

- The whole transport and road network of the Greater Thessaloniki Area;

- Trip planning, including optimization with or without transfers; and

- Customized user information, such as points of interest.

Birmingham, which is also taking part in another DRIVE II project (QUARTET), is developing a system that uses various media, including hand-held devices, in-street terminals, at-stop displays, and inquiry offices, to distribute real-time transit information. This project, called BLUEPRINT, is testing a comprehensive set of integrated passenger information systems in a deregulated public transport environment.

Preliminary user survey results are available for Madrid and Marseilles, where terminals have been deployed. Results from Madrid are discussed in Section 5.9.

\subsubsection{HARPIST}

HARPIST is another of the four task forces set up to integrate the efforts of all the Area 7 public transport projects. Specifically, HARPIST focuses on "the establishment of common functional specifications for datamodels and terminology in passenger information systems. " ${ }^{37}$ To date, HARPIST has produced documentation on a Pan-European data model. 


\subsubsection{Information in Public Transport (INPUT)}

The Information in Public Transport (INPUT) Task Force establishes guidelines and recommendations for public transport passenger information systems. "The mission of INPUT is to contribute to the efficiency of telematics systems by proposing a harmonisation of the visual elements, the concepts of presentation and interactivity. The objective is to enable the user to access a family of consistent information tools, which for example offer the same logic in use, the same pictograms or icons, etc. Six European projects oriented towards transport user information provide a base for INPUT: EuroBus, PHOEBUS, QUARTET, SCOPE, PROMISE, and LLAMD. "138 To date, INPUT has produced guidelines on public transportation information to passengers and on guidelines for implementation of public transport information systems.

\subsubsection{London, Lyon, Amsterdam, Munich and Dublin (LLAMD)}

Currently, this project involves efforts in the following areas:

- Transport policy and evaluation;

- Central system design;

- In-vehicle information systems;

- Route guidance, and modeling and assessment;

- Public transport and park-and-ride information;

- Traffic monitoring;

- Public transport priority; and

- Accident recording.

ERTIS is an element of projects in three of the five cities: London, Lyon and Munich. Part of London's LLAMD effort involves COUNTDOWN, a system that displays real-time arrival information at bus stops. In March 1993, COUNTDOWN became fully operational on London Transport's Route 18. COUNTDOWN consists of "passenger information provided to bus stop signs utilizing an AVL system that also supplies the bus operating company with information to facilitate operational control of buses serving the route. ${ }^{139}$ 


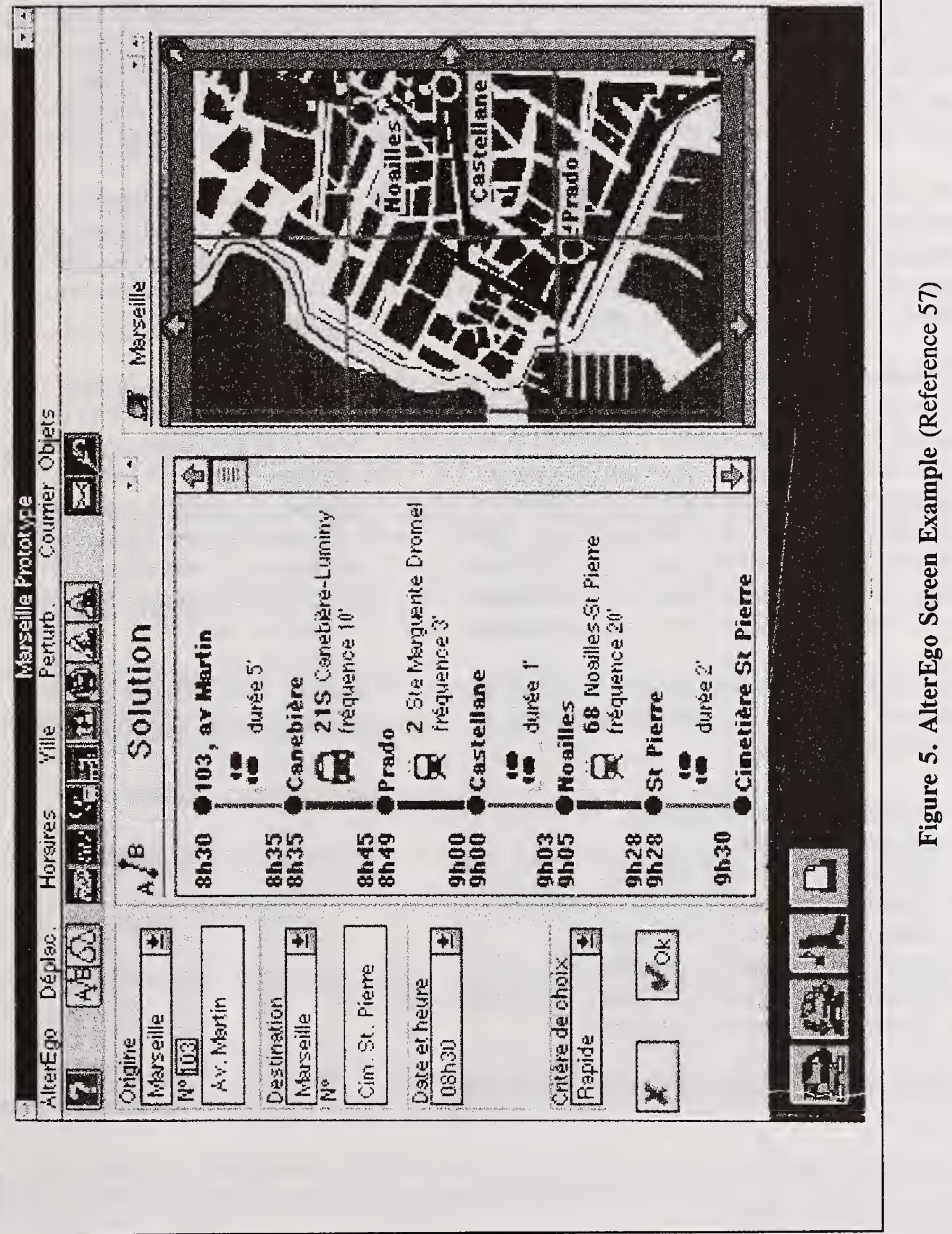


"Route 18 is operated by CentreWest, a west London bus operator, and runs between central and west London using double-deck one person operated buses. At the beginning of each bus journey, the driver registers the bus trip using a keypad in the driving cab; this information is sent to a central computer over the London Transport Buses radio system. As the bus travels along the route, microwave transmissions by roadside beacons are recognized by an on-bus receiver. Approximately every 30 seconds a group call over the radio system returns to the central computer the location data for every registered bus based on beacon message identification and the number of wheel revolutions since passing the last beacon. Thus the location of each bus serving Route 18 is known very frequently to a high degree of precision.

"By reference to a database structure and a predictive algorithm that uses the journey times of previous buses on each network link, estimates are made of the time to arrival at bus stops equipped with displays within a 20 minute time horizon. These forecasts are transmitted to the stops over dedicated landlines and are shown on a 24 character per line, 3-line dot matrix display screen of light emitting diodes (LED).

"Forecasts are updated after every polling cycle but the signs also count down in real time between forecasts. Originally on Route 18 up to three bus arrivals were shown with the second line scrolling between second and third arrivals. Now up to nine buses on different routes can be shown and signs can incorporate 3 or 4 line displays. A bottom line text message gives the possibility to present further information about bus services including regular, specific or timely messages (e.g., Route 36 buses also use this stop; No more Route 18 buses tonight; Traffic congestion in Wembley is affecting Route 18 buses today). Fifty stops (of 124 in total on Route 18) are equipped with COUNTDOWN displays; these stops cover some 7.5 million $(70 \%)$ annual passenger boardings along the route. ${ }^{40}$

COUNTDOWN has been extremely well-received by passengers, and is reliable as well as accurate. Extensive surveys and monitoring have been done throughout COUNTDOWN's operation, including:

- System technical reliability;

- Bus service regularity;

- Bus arrival prediction accuracy;

- Visibility and comprehension of the signs;

- Passenger behavior at bus stops;

- Passenger perceptions and attitudes;

- Passenger valuation of COUNTDOWN information; and

- Patronage and revenue generation. ${ }^{41}$

Results of these surveys are presented in Section 5.6.

40 Reference 73, p. 3050.

41 Reference 73, pp. 3049, 3053, 3054. 
Lyon's passenger information system project is called SYMPHONIE. SYMPHONIE is a modular system that does not require a central computer center or extensive communications network. The system can be implemented for one bus line with many stops (as it is now), and then it can be easily expanded to all bus stops on all lines. This modularity is accomplished by "downloading the [bus] timetables into the vehicles via an infrared link at the depot during refueling. The same infrared link is used at the bus stop to upload parts of the timetable to the bus-stop-module. This data, delivered to the bus-stop-module, makes it possible to give different forms of information to the travelers on the display. The bus-stop is fully selfcontained and uses LCD displays. The power supply is provided by solar panels.

"Although it does not provide a true automatic vehicle monitoring (AVM) system, SYMPHONIE allows operators to achieve schedule control and to store information on running times for future timetable construction.

"The levels of information provided are:

- Next bus theoretical timetable

- Time till next bus in minutes (maximum 10)

- Alphanumerical information such as: bus to arrive / line disrupted / see printed timetable / end of service

"The SYMPHONIE information system will:

- Provide users with next bus timetable

- Provide users with theoretical waiting time

- Inform users about perturbations on the line

- Give bus driver information if he is too early or delayed with respect to scheduled times

- Give next stop name in the bus

- Store information on real running times. These times can be used for the definition of new timetables" $^{\text {42 }}$

SYMPHONIE is operational on line 27 of the Lyon bus system, which has 47 bus stops and is served by 15 vehicles.

Munich Cooperative Management for Urban and Regional Transport (COMFORT) is a subproject within LLAMD. It involves the implementation of many traffic and transit 
advanced technologies in order "to achieve traffic flow which is more environmentally friendly, more reliable and more economical. ${ }^{143}$ Two of the seven technology areas covered by Munich COMFORT are public transport and park-and-ride information.

The public transport area is using technology to facilitate the integration of all Munich's public transit modes: subway, light rail and bus. Each of these modes are operated from different centers. Munich COMFORT has developed a data network to optimize this integration, and has developed a passenger information system based on electronic timetable information called Elektronische Fahrplan Auskunft (EFA).

EFA is used by 40 cities and towns in Germany, Austria and Switzerland that are served by 16 transit systems. Previously only available in passenger service centers or by videotext, EFA is now available via a Windows-based on-line system. EFA is set up as follows. After selecting the transit agency you are interested in, you can plan an entire trip by specifying the:

- Date of the trip;

- Origin (e.g., your home address);

- Destination (e.g., the name of a museum); and

- Departure or arrival time.

The trip options are displayed in terms of departure/arrival times and locations, length of trip segments in time, number of transfers, fare and transit lines involved. For each trip option, details are provided along with specific directions (e.g., take the U5 subway line in the direction of Freiburg).

Real-time information is going to be available shortly (e.g., the U5 subway to Freiburg is five minutes late). The real-time information is generated from the new Public Transport Data Center (PTDC), which links together the subway, light rail and bus control centers. PTDC collects data from each center concerning schedules, and shortly, concerning deviations from the schedules. The real-time data will be factored into development of the trip options in EFA, thus becoming dynamic EFA (DEFA), as follows: ${ }^{44}$

- Timetables will be added, changed or deleted;

- Disrupted vehicle journeys will be considered;

- Delay information will be integrated; and

- Preplanned emergency timetables will be activated, if necessary.

Reference 61, p. 1.

Reference 10, p. 2906. 
EFA, soon to be DEFA, will provide: ${ }^{45}$

- Up-to-date information for pre-trip planning at home; and

- Real-time information at inquiring offices and public touch-screen terminals.

In terms of the park-and-ride area, "in June 1994, the new terminal station of the U6 metro line was opened in Munich-Fröttmaning. Since then the Fröttmaning P\&R centre has been in operation, providing parking spaces for 1,200 cars and 80 coaches for passengers transferring to the Munich public transport network. A special feature is that the P\&R centre can only be accessed from the Fröttmaning motorway exit. As part of Munich COMFORT, freely programmable information signs [VMS] have been installed along the motorway in the direction of Munich. These signs indicate the number of free parking spaces and the current metro departure times. The signs can also provide other information. During the trial phase, several levels of information were tested and surveys were made of road users. The reaction to this P\&R information system was definitely positive. " ${ }^{46}$

Results on initial usage of the Fröttmaning P\&R and the VMS are discussed in Section 5.7.

\subsubsection{PHOEBUS}

The PHOEBUS project focuses on three key areas: public transport data base (PTDB), passenger information system (PIS) and demand responsive system (DRS). The PIS, most closely related to ERTIS, provides real-time information at bus stops. "It features:

- The Vehicle Scheduling and Control System (VSCS) which computes the real waiting times till arrival of the next one or two buses,

- The Radio Data System (RDS) receives from the VSCS the real waiting times and the operating messages, then transmits them to the RDS encoder,

- The RDS encoder adds an inaudible signal (sub-carrier) modulated by the data, to the audio signal of an FM radio station,

- The User Information Post (UIP) receives these data, decodes them into messages, formats the screen and displays them. It is composed of 3 subsets:

- The Top Casing containing:

-- A solar panel at the top of the post to capture the maximum amount of light,

-- A set of batteries to store the energy collected by the solar panel. 
- The post support, either a standard or an existing one.

- The display unit comprising:

-- An electronic board allowing connection of various peripherals, including external portable personal computer,

-- A graphic liquid crystal display (LCD),

-- An RDS receiver for decoding the sub-carrier,

-- A receiver antenna.

- Available options are:

-- A charger and battery for connection to the street lighting system,

-- A second LCD,

-- A presence detector and/or a brightness sensor,

-- Infrared or cable transmission of data instead of RDS.

The UIP displays three types of screens:

- The waiting time screen displays a predefined message with the bus line number and the destination (and via if applicable) plus a variable data corresponding to the real waiting time in minutes,

- The message screen displays:

- Messages which are predefined in the UIP,

- Messages composed by the operator which are real time received in ASCII format.

- The date screen displays the date and time. "47

PHOEBUS pilot operation began in spring 1994, with five UIPs installed in Brussels. It is expected that after full installation is completed, 45 UIPs will be implemented throughout the Brussels region. Preliminary results from the pilot operation are discussed in Section 5.8.

\subsubsection{PROMISE}

PROMISE is a DRIVE II project that is testing ATIS using PCDs in Gothenburg (a PROMPT site) and Birmingham (a QUARTET site). The information handled by PROMISE comes from different service providers all using different data formats. Therefore, data from each provider

Reference 40, p. 2883. 
must be translated into a common PROMISE format before it is distributed. In the future, it is expected that the service providers' databases will conform to the PROMISE format, eliminating the need for this translation process.

PROMISE identified three classes of communications that could be used with PCDs:

- Class A - one-way broadcast service;

- Class B - two-way service with limited throughput capacity; and

- Class C - interactive two-way service with high throughput and local processing capability.

In Gothenburg, PROMISE traveler information is sent to the Volvo Dynaguide in-vehicle information system, which includes a backlit color LCD display. Also, An HP100LX palmtop computer using a PCMCIA-based receiver is being used in Gothenburg to receive PROMISE information via Class A. Trip planning information is available in Gothenburg using Class B communications on a PSION 3a palmtop computer connected to a cellular telephone.

Transit information regarding timetables and deviation, and parking, weather and traffic information are available in Gothenburg. In initial trials in Gothenburg, the public transit information is being accessed more than the other services.

In Birmingham, a public transit database developed for the QUARTET project provides PROMISE with real-time timetable and deviation information. Information regarding initial PROMISE demonstrations in Birmingham are not available at this time.

\subsubsection{Priority and Informatics in Public Transport (PROMPT)/STOPWATCH}

Although the PROMPT project focuses on demonstrating real-time adaptive signal control for public transit vehicles, it contains an element of ERTIS which is based upon the implementation of AVL systems in each of the PROMPT cities: London, Southampton, Turin and Gothenburg. Of these four cities, all but London are developing real-time ERTISs.

In Southampton, AVL is being used for the STOPWATCH system which provides real-time passenger information at bus stops (see Figure 6). Southampton, which is also involved in a combined effort to integrate traffic and transit management in the Southampton-ColognePiraeus (SCOPE) project and the Road Management System for Europe (ROMANSE) project (a sub-project of SCOPE), installed electronic signs at 44 bus stops that display the route number, destination and expected time of arrival for up to the next five buses. Both LED and LCD displays are being used. 114 vehicles have been equipped with on-board computers, similar to the COUNTDOWN project in London described in Section 3.3.5. Some of the signs provide audio for those passengers with visual impairments.

Also, as part of the ROMANSE project in Southampton, the TRIPlanner system is being installed at key locations throughout the Southampton area. TRIPlanner terminals are touchscreen kiosks that provide itineraries for trips on public transit or by automobile. A user 


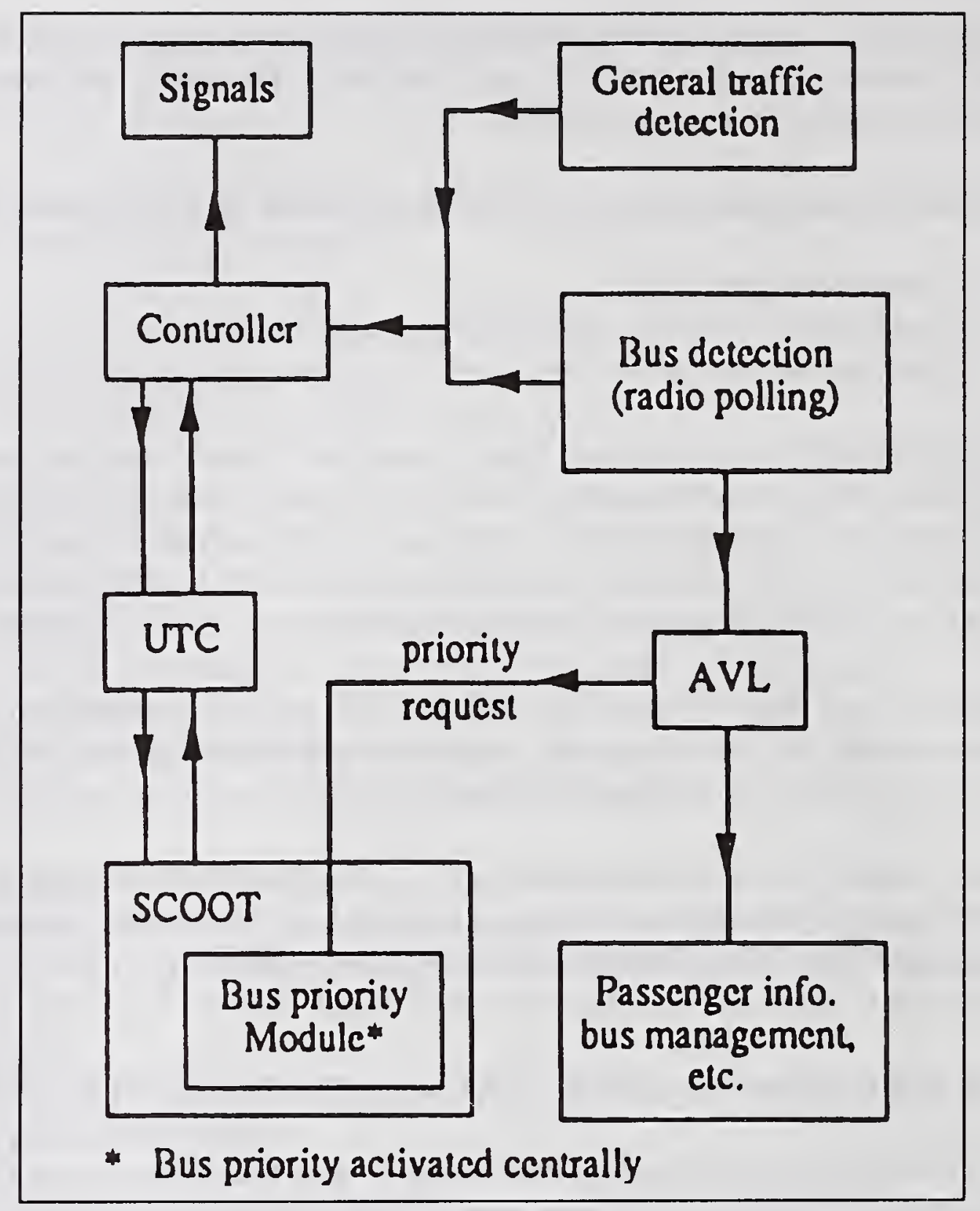

Figure 6. Southampton System Architecture

(Reference 9, p. 2844)

enters their origin, destination, date and time of travel, and TRIPlanner provides the details of the itinerary including written instructions (that can be printed) and maps. Information on transportation services beyond the Southampton area are also available through TRIPlanner. At some kiosks, real-time traffic and transit information will be available. In the future, all kiosks will have real-time data transmitted directly from the ROMANSE Traffic and Travel Information Center. 
Turin, which is also part of the Quadrilateral Advanced Research on Telematics for Environment and Transport (QUARTET), has developed the "5T Concept" (Telematic Technologies for Transport and Traffic in Turin), which will "integrate a number of [ATT] applications and services to provide a coordinated traffic and transport management and control system." ${ }^{48}$ The public transit component of $5 \mathrm{~T}$ involves an AVM system used to control the entire fleet of approximately 1,500 vehicles. "A user information system has also been developed and integrated with the AVM to provide information to users at stops and aboard vehicles. ${ }^{49}$ The Information Media Control subsystem of $5 \mathrm{~T}$ distributes trip planning and real-time traffic and transit information through user information terminals and other media, and connects directly with the Parking Control subsystem, which "monitors the use of car parks in the Turin area, calculates occupancy forecasts, and provides an advance booking service. " 50 T is expected to be fully operational in June 1995.

In Gothenburg, the focus is on adaptive signal control for public transport vehicles. The Gothenburg Traffic Information Center (GOTIC) project, however, is developing a PIS based on passenger requirements. To date, GOTIC has examined passenger needs for transit information and has identified the specific information needed. Table 4, which was developed based on passenger interviews, shows the need for three distinct types of information:

- Static (S on Table 4), such as timetables and maps;

- Automatic Dynamic (A on Table 4), such as real-time displays showing arrival time(s) of next bus(es); and

- Dedicated Dynamic (D on Table 4), such as VMS for incident messages.

To date, only research has been done in PIS development in Gothenburg.

\subsubsection{Quadrilateral Advanced Research on Telematics for Environment and Transport (QUARTET)}

QUARTET is a project in four European cities that is demonstrating the implementation of integrated ATT. The cities are Athens, Birmingham, Stuttgart and Turin. Birmingham is concentrating on public transit; specifically public transit management and information systems. The Birmingham project, called BLUEPRINT, began with a functional specification

Reference 85, p. 50.

Reference 85, p. 53.

Reference 85, p. 53.
} 

TABLE 4. PASSENGER INFORMATION PROBLEMS AND
INFORMATION SYSTEMS NEEDED

\begin{tabular}{|c|c|c|c|c|c|c|c|c|}
\hline Problem & Starting point & & Walking & & At stop & & In bus/tram & \\
\hline Travel time & $\begin{array}{l}\text { How long time } \\
\text { for the trip? } \\
\text { When should I } \\
\text { start the trip? }\end{array}$ & $\begin{array}{l}\mathrm{S} \\
\mathrm{S} \\
\mathrm{A}\end{array}$ & & & $\begin{array}{l}\text { How long time } \\
\text { for the trip? }\end{array}$ & $S$ & $\begin{array}{l}\text { How long time } \\
\text { for the trip? }\end{array}$ & S \\
\hline Position of stop & $\begin{array}{l}\text { Where is the } \\
\text { stop? } \\
\text { How long time to } \\
\text { the stop? }\end{array}$ & $\begin{array}{l}\mathrm{S} \\
\mathrm{S}\end{array}$ & $\begin{array}{l}\text { Where is the } \\
\text { nearest stop? } \\
\text { How long time } \\
\text { to the stop? }\end{array}$ & $\begin{array}{l}\mathrm{S} \\
\mathrm{S}\end{array}$ & $\begin{array}{l}\text { What stop in my } \\
\text { direction? }\end{array}$ & $S$ & $\begin{array}{l}\text { Where am I? } \\
\text { What is the name } \\
\text { of this or the next } \\
\text { stop? }\end{array}$ & $\begin{array}{l}\mathrm{A} \\
\mathrm{A}\end{array}$ \\
\hline $\begin{array}{l}\text { What line/ } \\
\text { route? }\end{array}$ & $\begin{array}{l}\text { What line/route to } \\
\text { choose? }\end{array}$ & S & & & $\begin{array}{l}\text { What line/route to } \\
\text { choose? }\end{array}$ & $\begin{array}{l}S \\
A \\
D\end{array}$ & $\begin{array}{l}\text { If disturbance: } \\
\text { Can I change to } \\
\text { other line? }\end{array}$ & $\begin{array}{l}\text { S } \\
\text { A } \\
\text { D }\end{array}$ \\
\hline $\begin{array}{l}\text { When will } \\
\text { vehicle arrive at } \\
\text { stop? }\end{array}$ & $\begin{array}{l}\text { How frequent is } \\
\text { the traffic? }\end{array}$ & $\mathrm{S}$ & $\begin{array}{l}\text { When does my } \\
\text { bus/tram } \\
\text { arrive? }\end{array}$ & $\begin{array}{l}S \\
A\end{array}$ & $\begin{array}{l}\text { When does my } \\
\text { bus/tram arrive? }\end{array}$ & $\begin{array}{l}\mathrm{S} \\
\mathrm{A} \\
\mathrm{D}\end{array}$ & & \\
\hline $\begin{array}{l}\text { When change or } \\
\text { leave vehicle? }\end{array}$ & $\begin{array}{l}\text { Where do I } \\
\text { change? }\end{array}$ & $S$ & & & $\begin{array}{l}\text { Where do I } \\
\text { change? } \\
\text { Name of stop }\end{array}$ & $\begin{array}{l}\mathrm{S} \\
\mathrm{S} \\
\end{array}$ & $\begin{array}{l}\text { When at change } \\
\text { stop or at end } \\
\text { stop? }\end{array}$ & $\begin{array}{l}\text { S } \\
\text { A }\end{array}$ \\
\hline $\begin{array}{l}\text { Walking from } \\
\text { stop }\end{array}$ & & & & & $\begin{array}{l}\text { How find my } \\
\text { destination? }\end{array}$ & $\mathrm{S}$ & & \\
\hline $\begin{array}{l}\text { What bus/tram } \\
\text { line? }\end{array}$ & & & & & $\begin{array}{l}\text { Is the bus/tram } \\
\text { arriving OK? }\end{array}$ & $\begin{array}{l}\mathrm{S} \\
\mathrm{A}\end{array}$ & & \\
\hline $\begin{array}{l}\text { Regulations and } \\
\text { fares }\end{array}$ & $\begin{array}{l}\text { Regulations } \\
\text { How much is the } \\
\text { trip? }\end{array}$ & $\begin{array}{l}\mathrm{S} \\
\mathrm{S}\end{array}$ & & & $\begin{array}{l}\text { Regulations } \\
\text { How much is the } \\
\text { trip? }\end{array}$ & $\begin{array}{l}\mathrm{S} \\
\mathrm{S}\end{array}$ & $\begin{array}{l}\text { How many } \\
\text { tickets/strips? }\end{array}$ & $S$ \\
\hline $\begin{array}{l}\text { Why } \\
\text { disturbance? }\end{array}$ & & & & & $\begin{array}{l}\text { Why no } \\
\text { bus/tram? }\end{array}$ & $\mathrm{D}$ & $\begin{array}{l}\text { Why stop of } \\
\text { bus/tram? }\end{array}$ & $\mathrm{D}$ \\
\hline
\end{tabular}


TABLE 5. FUNCTIONAL SPECIFICATION OF PIS

\begin{tabular}{|c|c|c|}
\hline FUNCTION & DESCRIPTION & OUTPUT TO \\
\hline 1. Inform on time & $\begin{array}{l}\text { Information about the actual time } \\
\text { day calculated by a central clock. }\end{array}$ & $\begin{array}{l}\text { All information terminals and } \\
\text { displays. }\end{array}$ \\
\hline $\begin{array}{l}\text { 2. Show street map and transport } \\
\text { routes }\end{array}$ & $\begin{array}{l}\text { An on-screen display showing } \\
\text { streets/important features/bus stops, } \\
\text { together with bus, train and (in some } \\
\text { cases) walk routes. }\end{array}$ & $\begin{array}{l}\text { Enquiry office terminals. In-street } \\
\text { terminals. In-home terminals (if } \\
\text { possible). }\end{array}$ \\
\hline 3. Give timetables & $\begin{array}{l}\text { Screen displays of timetables for any } \\
\text { defined route or bus stop available } \\
\text { to passengers and enquiry office } \\
\text { clerks. }\end{array}$ & All interactive terminals. \\
\hline 4. Inform on fares & $\begin{array}{l}\text { Information on fares for journeys on } \\
\text { the network. }\end{array}$ & All interactive terminals. \\
\hline $\begin{array}{l}\text { 5. Give optimum route and } \\
\text { timetable information }\end{array}$ & $\begin{array}{l}\text { Customized information provided in } \\
\text { response to individual enquiries } \\
\text { showing the optimum public } \\
\text { transport route and travel time } \\
\text { between any two points in the } \\
\text { Centro area. }\end{array}$ & All interactive terminals. \\
\hline 6. Give estimated waiting times & $\begin{array}{l}\text { Information available to passengers } \\
\text { at bus stops showing the predicted } \\
\text { waiting times for the next few buses. }\end{array}$ & At stop displays. \\
\hline 7. Give bus/train departure times & $\begin{array}{l}\text { Information provided to travellers } \\
\text { showing the forecast departure time } \\
\text { for the next few buses or trains at } \\
\text { specified stops. }\end{array}$ & In-home terminals. VMS signs. \\
\hline 8. Inform on service disruptions & $\begin{array}{l}\text { Information provided to information } \\
\text { system users about severe } \\
\text { disruptions to services which may } \\
\text { affect their travel plans. }\end{array}$ & All terminals and displays. \\
\hline 9. Give practical information & $\begin{array}{l}\text { Information provided to travellers } \\
\text { giving details of how to use the } \\
\text { public transport network and how to } \\
\text { obtain further information. }\end{array}$ & All interactive terminals. \\
\hline 10. Give local information & $\begin{array}{l}\text { Information to travellers about } \\
\text { tourist attractions, local authority } \\
\text { facilities, entertainment etc. }\end{array}$ & All interactive terminals. \\
\hline 11. Give messages & $\begin{array}{l}\text { Information to travellers on special } \\
\text { events, service changes, etc. } \\
\text { Includes advertising. }\end{array}$ & $\begin{array}{l}\text { All interactive terminals. } \\
\text { At-stop displays. }\end{array}$ \\
\hline
\end{tabular}


TABLE 5. FUNCTIONAL SPECIFICATION OF PIS (continued)

\begin{tabular}{||l|l|l||}
\hline FUNCTION & \multicolumn{1}{|c|}{ DESCRIPTION } & \multicolumn{1}{|c|}{ OUTPUT TO } \\
\hline 12. Inform on special needs & $\begin{array}{l}\text { Information to travellers on facilities } \\
\text { provided for people with mobility } \\
\text { difficulties. }\end{array}$ & All interactive terminals. \\
\hline 13. Provide reliability reports & $\begin{array}{l}\text { Information provided to Centro and } \\
\text { bus operators in the form of regular } \\
\text { report on service reliability }\end{array}$ & Printed reports. \\
\hline $\begin{array}{l}\text { 14. Provide priority to buses at } \\
\text { traffic signals }\end{array}$ & $\begin{array}{l}\text { Buses are given priority at traffic } \\
\text { signals according to pre-defined } \\
\text { criteria. }\end{array}$ & Urban Traffic Control Centre. \\
\hline 15. Provide statistics & $\begin{array}{l}\text { Information provided to Centro on } \\
\text { the status of in-street, in-home and } \\
\text { at-stop passenger information } \\
\text { devices. }\end{array}$ & Printed reports. \\
\hline
\end{tabular}

of a public transport PIS (PTPIS). This specification, shown in Table 5, led to the PTPIS implemented by Centro, the Passenger Transport Executive for the West Midlands region of the U.K. (see Figure 7).

"Four types of interactive terminals are available:

- In Centro enquiry offices an enhanced computer system (QUEST) has been provided for use by enquiry clerks. Route and bus stop timetables are available, but QUEST also includes Optimum Route Software (ORS), which calculates the optimum route between any two points in the Centro area.

- Similar facilities are also available on self-service in-street terminals. Screen-based displays are supplemented by optional print-outs giving timetables and details of optimum routes.

- In-home terminals based on the Minitel system have been available in France for some years. In the UK, the Keyline company is expected to market an in-home terminal in the near future. The terminal has the capacity to interface with various information services. A link has been developed to Centro's information system to make public transport information available to users in the West Midlands. As well as timetable and ORS information, the terminal gives real-time information on bus stop departure times.

- QUARTET is linked to the DRIVE project PROMISE, which is undertaking feasibility studies of hand-held portable information terminals (similar to portable telephones). A small scale field trial of a portable information system will be undertaken jointly by QUARTET and PROMISE in the summer of 1994. 


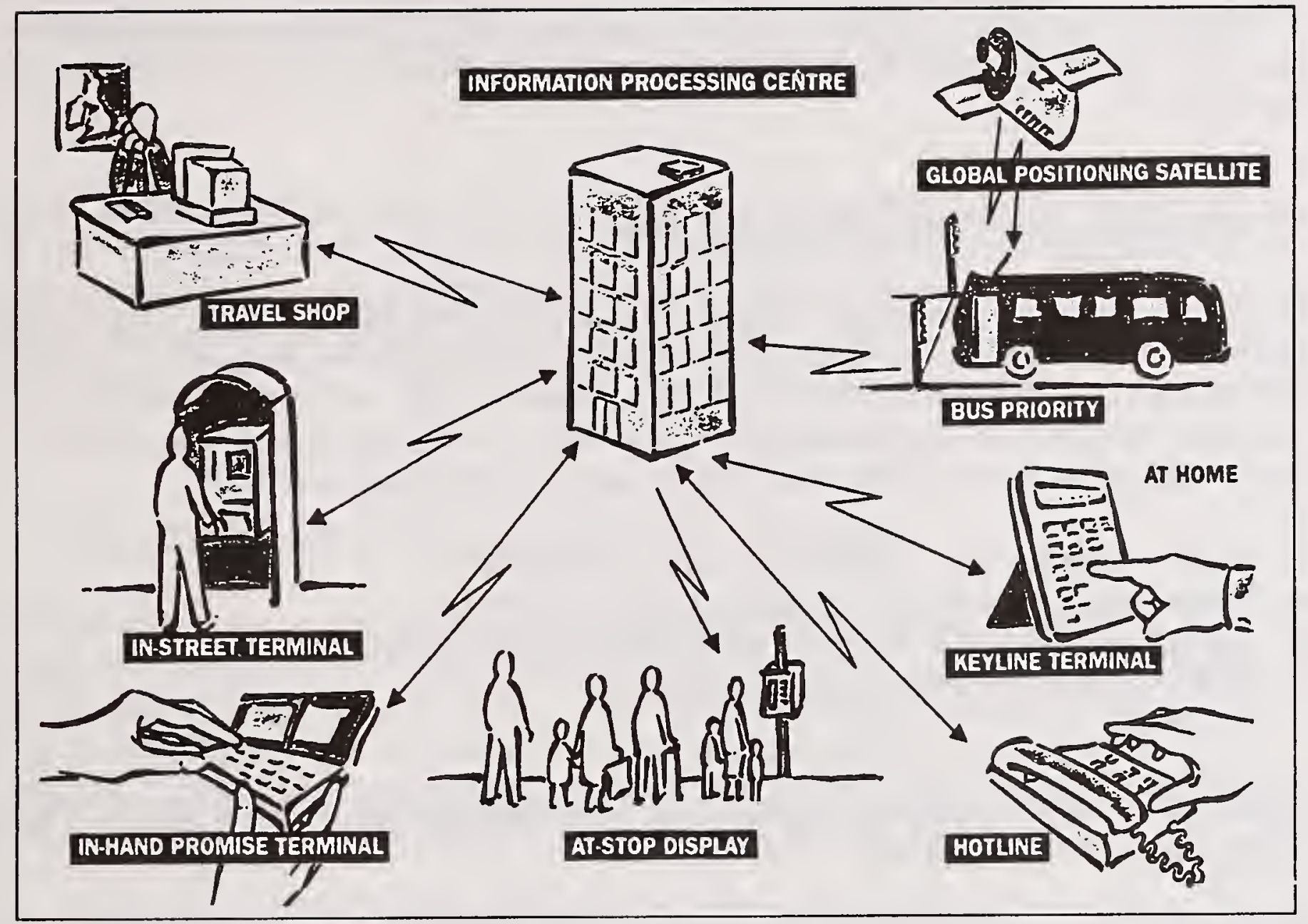

Figure 7. CENTRO Public Transport Passenger Information System (Reference 68, p. 2900)

"Real time information at bus stops is also provided within this system. An automatic vehicle location system using GPS has been fitted to 40 buses operated by 3 different companies providing competing services on a corridor in south Birmingham. Information about forecast bus arrival times is displayed at bus stops throughout the corridor which are equipped with displays; this system is known as [Tracking Using Satellite Tracking] TRUST.

"The vehicle location and journey time information available from this system is used to provide service reliability reports, and could in the future be linked to Urban Traffic Control centers for use in providing selective bus priority at traffic signals. ${ }^{152}$

"Athens has implemented a trial of real-time information at bus stops as a prelude to full implementation in the next few years. Stuttgart already has a well developed public transport information system which includes public access terminals providing ORS information as well as real time information on a number of Stadtbahn [light rail] stations. [Turin] has developed 
a sophisticated passenger information system which can provide comparisons between private and public transport journey times and costs as well as operating in response to real time traffic conditions. ${ }^{53}$

\subsubsection{Southampton-Cologne-Piraeus (SCOPE)}

SCOPE, as mentioned previously, involves ATT in three cities: Southampton, Cologne and Piraeus. The STOPWATCH system in Southampton was described in Section 3.3.7, 3.3.8. The Cologne part of SCOPE, called VICTORIA, involves VMS, which were installed at two new P\&R lots (Zoo and Bocklemünd) in order to attract more transit riders. On motorway A4, a VMS guides drivers to the Zoo P\&R lot and provides information on: ${ }^{54}$

- Public transport service with regular intervals of departure;

- Current parking situation at parking lots in the city center;

- Current traffic situation in various areas within the city on specific routes;

- Environmental situation (e.g., ozone level); and

- Incidents.

In the future, real-time transit information will be available through the VMS using a VSCS installed in the City of Cologne.

Preliminary results on the use and acceptance of the VMS are described in Section 5.10.

"The Piraeus sub-project of SCOPE, PORTS, has the objective of providing traffic and travel information to users of the port, in order to improve the network efficiency and encourage use of public transport. Specific ATT applications for public transport are public access terminals in the port area and information on the ferries about traffic conditions and onward journeys by public transport. Public access terminals are being installed at central locations near the port and will provide information on urban public transport, inter-urban coaches, train services, arrivals and departures at the Port of Piraeus and at the airport. Information concerning the port and airport is on-line information; information on urban public transport, inter-urban coaches and train services comes from static data bases. The user interface is a touch-screen terminal connected to the central computer via a leased line. ${ }^{55}$

Reference 43, pp. 2918-2919.

Reference 83. 


\section{INFORMATION AND TECHNOLOGIES EMPLOYED IN ERTIS}

The study identified specific transit information that is or will be distributed by the ERTISs, as well as the source of this information, and the technologies and media used to distribute the information. Section 4.1 discusses the collection of transit information that is or will be distributed through the ERTISs interviewed, and Section 4.2 covers the technologies used to distribute this information.

\subsection{TRANSIT INFORMATION DISTRIBUTED BY ERTISs}

Table 6 shows the types of information that are collected for distribution by an ERTIS for those agencies that directly responded to the list of interview questions. Currently, the source of most of the information listed in Table 6 is published timetables, reflecting the small number of AVL systems that are fully implemented and providing real-time schedule and location data. Table 7 shows the sources of the information provided through the ERTISs, and indicates the agencies that are planning to implement AVL systems in the future.

The best example of an ERTIS that provides information based upon data from an AVL system, in addition to other sources, is Travlink. The Travlink project is collecting and distributing extensive transit and traffic data through an ATIS. The data is collected from MCTO and the Traffic Management Center. Tables 8 and 9 show the specifications for transit and traffic data collection, respectively. ${ }^{56}$

\subsubsection{Ann Arbor Transportation Authority (AATA)}

Timetables that will be used in the Intelligent Transportation System are derived from UMA Trapeze run-cutting software. This database is updated at least three times per year.

\subsubsection{Dallas Area Rapid Transit (DART)}

The database is from a Teleride Sage system, used by the scheduling department. As markups to the schedules come through, headway sheets are transferred in ASCII format to the GIS department. The GIS department then loads the tables into files that can be accessed by the Customer Service Center.

Reference 84, pp. 3-6 to 3-7. 


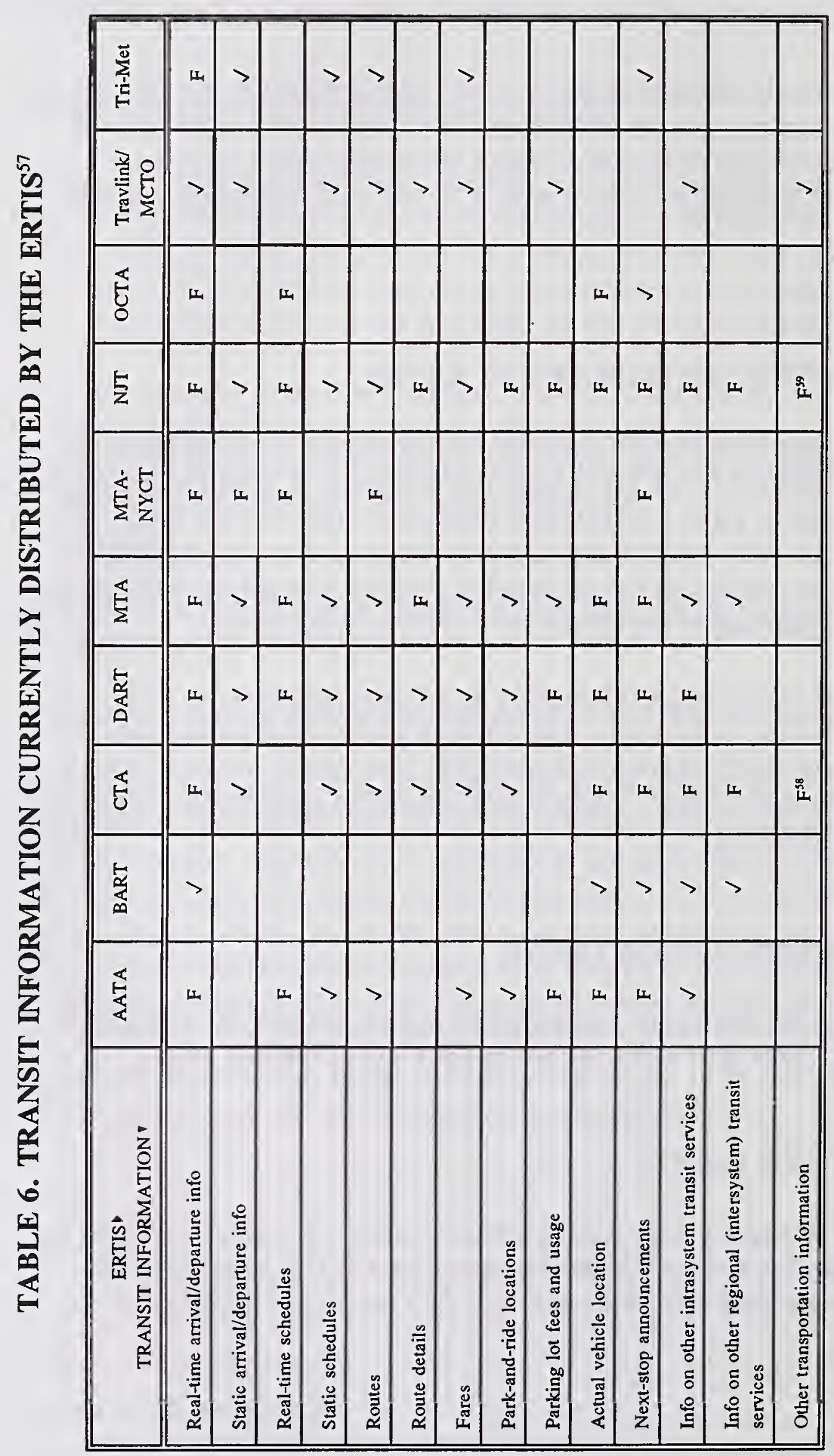

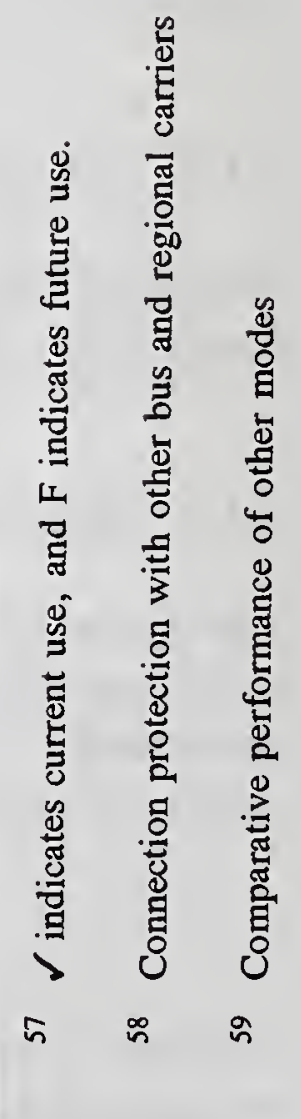



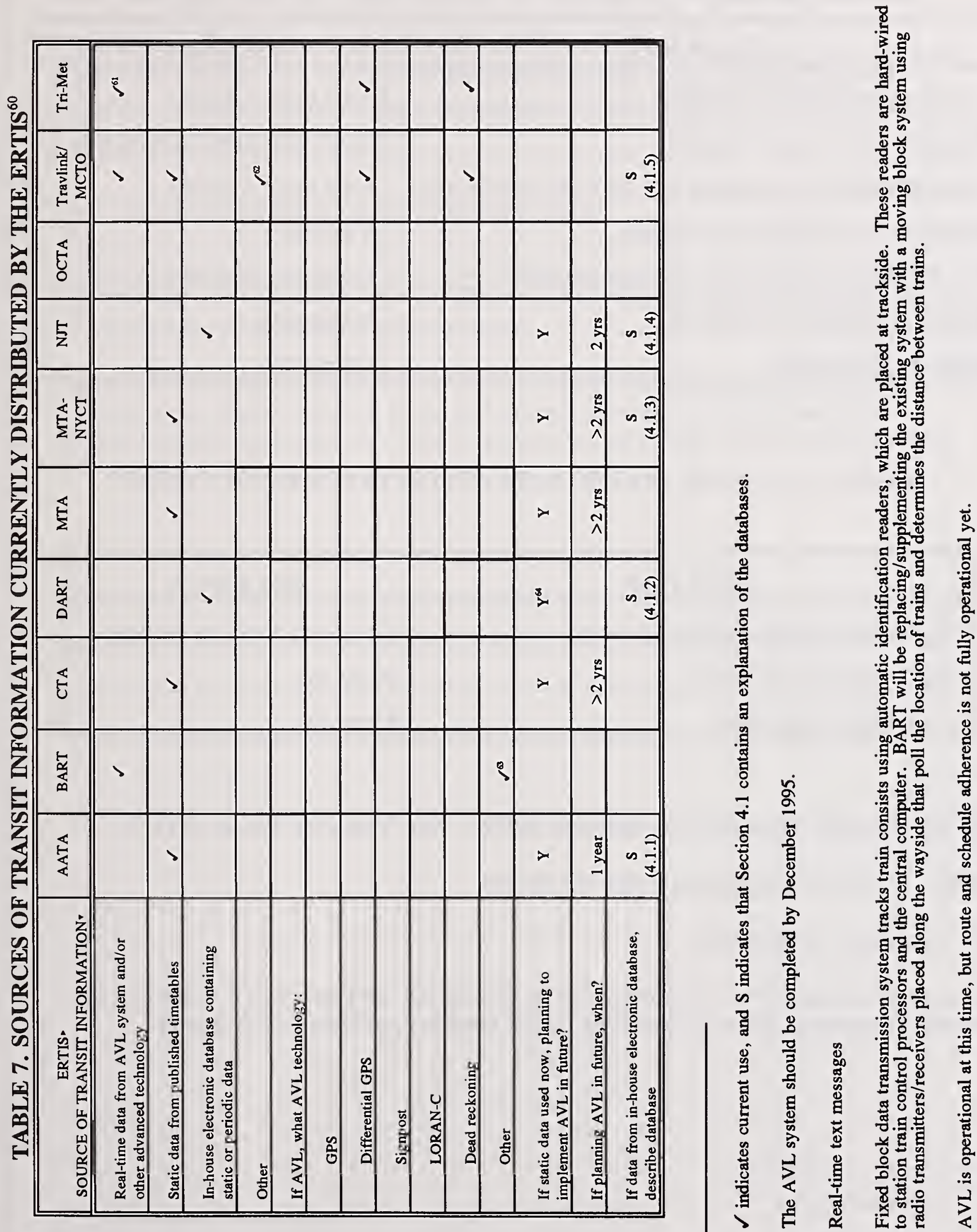
TABLE 8. TRAVLINK TRANSIT DATA COLLECTION SPECIFICATIONS ${ }^{65}$

\begin{tabular}{||l|l||}
\hline \multicolumn{1}{|c|}{ DATA TYPE } & \multicolumn{1}{c|}{ FREQUENCY } \\
\hline \hline Transit schedules/routes with fares & Once every 3 months \\
\hline Real-time transit exception reports & $20 \%-30 \%$ of 80 buses/minute \\
\hline Predefined transit trips (area to area for I-394 corridor only) & Once every 3 months \\
\hline Special transit informational messages & 8 per day \\
\hline Route maps (10 routes in the I-394 corridor only) & Once every 3 months \\
\hline Elderly and disabled / ridesharing & Infrequently \\
\hline Park-and-ride locations & Infrequently \\
\hline \hline
\end{tabular}

TABLE 9. TRAVLINK TRAFFIC DATA COLLECTION SPECIFICATIONS ${ }^{66}$

\begin{tabular}{|l|l|}
\hline \multicolumn{1}{|c|}{ DATA TYPE } & \multicolumn{1}{|c|}{ FREQUENCY } \\
\hline Traffic flow (highway link travel times) & Once every 5 min for all links \\
\hline Traffic incidents and delays & 10 per day \\
\hline Construction and detours & 90 per day \\
\hline
\end{tabular}

\subsubsection{Metropolitan Transportation Authority (MTA) - New York City Transit (NYCT)}

Currently, MTA-NYCT schedules are kept in a flat file.

\subsubsection{New Jersey Transit (NJT)}

There is an existing schedule/timetable database for bus and rail services, which is maintained by scheduling department. It is used to generate printed schedules and to feed CAD systems.

65 Reference 84 , p. 3-6

66 Reference 84 , p. $3-7$ 


\subsubsection{Travlink Project/Metropolitan Councl Transit Operations (MCTO)}

The UMA Trapeze schedule database is used for CAD/AVL, and the real-time status is passed to the ATIS database. The ATIS server distributes databases to ATIS devices (each has a computer). Both the CAD/AVL dispatcher and the ATIS administrator can enter special text messages into the system at any time.

\subsection{TRANSIT INFORMATION DISSEMINATION}

The study identified the means by which the ERTISs are or will be disseminating information, shown in Table 10. One of the only operational systems, Travlink, is using several of these means currently to distribute traveler information.

The traveler information provided by Travlink is available through four types of devices: electronic signs, display monitors, kiosks and videotex terminals. Both the kiosks and videotex terminals are interactive. Table 11 summarizes the traveler information available on each type of device. ${ }^{67}$ 

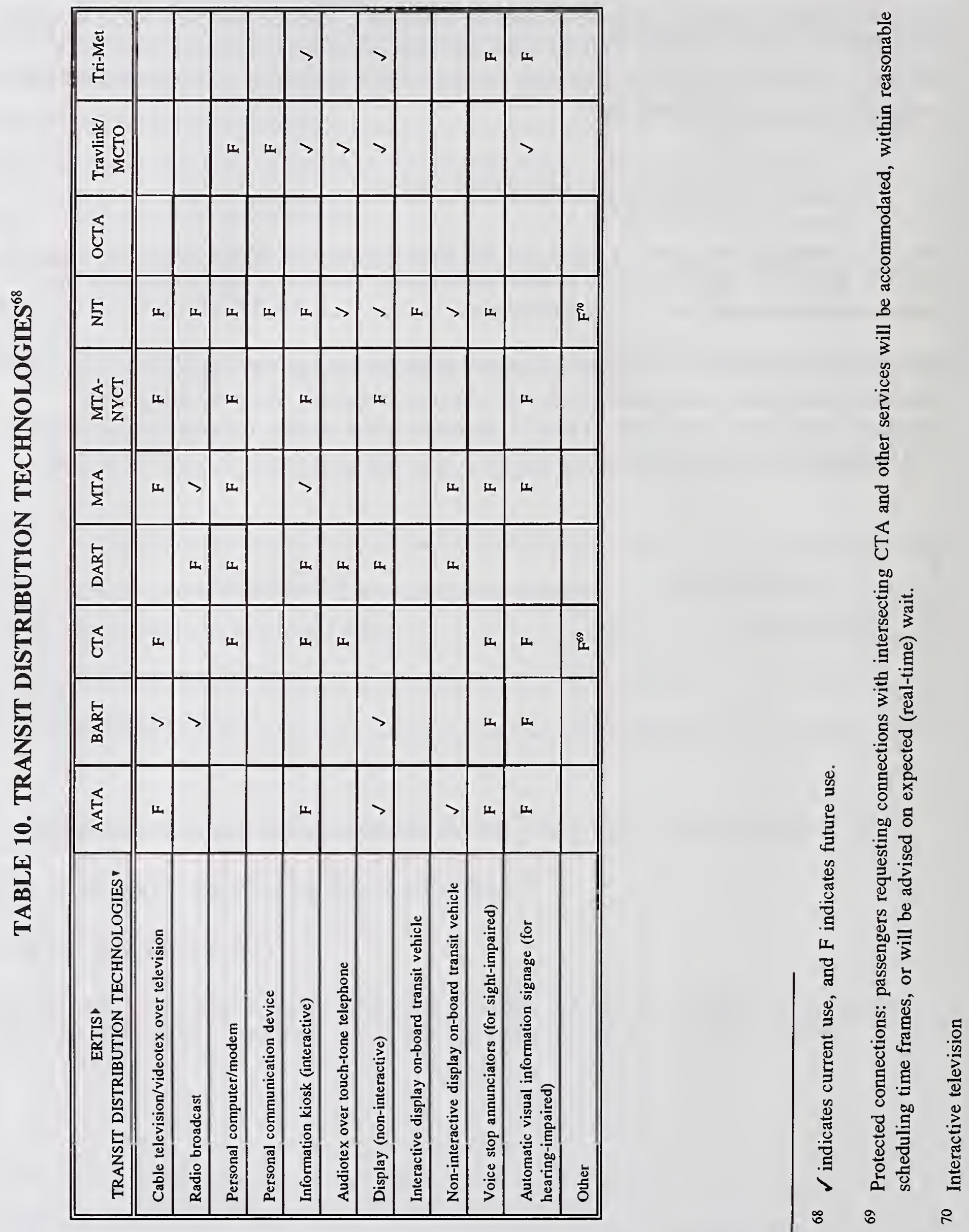
TABLE 11. TRAVLINK TRAVELER INFORMATION DISTRIBUTION

\begin{tabular}{|c|c|c|c|c|}
\hline \multirow{2}{*}{ TRAVELER INFORMATION } & \multicolumn{4}{|c|}{ DEVICE TYPE } \\
\hline & Sign & Monitor & Kiosk & Videotex \\
\hline \multicolumn{5}{|l|}{ Metinsit: } \\
\hline Route Schedules & & & $\checkmark$ & $\checkmark$ \\
\hline Route Maps & & & $\checkmark$ & $\checkmark$ \\
\hline Fares & & & $\checkmark$ & $\checkmark$ \\
\hline Bus Stop Schedules & $\checkmark$ & $\checkmark$ & & \\
\hline Real-Time Status & $\checkmark$ & $\checkmark$ & & \\
\hline Special Messages & $\checkmark$ & $\checkmark$ & $\checkmark$ & $\checkmark$ \\
\hline Park-and-Ride Parking & & & $\checkmark$ & $\checkmark$ \\
\hline Transit Trip Planning & & & $\checkmark$ & $\checkmark$ \\
\hline Ridesharing & & & $\checkmark$ & $\checkmark$ \\
\hline Elderly and Disabled & & & $\checkmark$ & $\checkmark$ \\
\hline \multicolumn{5}{|l|}{ 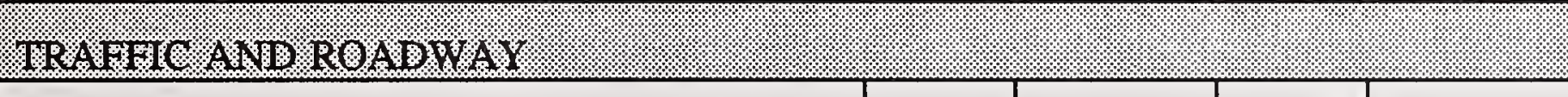 } \\
\hline Incidents & & & $\checkmark$ & $\checkmark$ \\
\hline Construction and Detours & & & $\checkmark$ & $\checkmark$ \\
\hline Highway Segment Information & & & $\checkmark$ & 1 \\
\hline \multicolumn{5}{|l|}{ MODE COMLARISONS. } \\
\hline Static Travel Time & & & $\checkmark$ & $\checkmark$ \\
\hline Static Cost & & & $\checkmark$ & $\checkmark$ \\
\hline
\end{tabular}





\section{INTEGRATION OF ERTIS AND ADVANCED TRAVELER INFORMATION SYSTEMS}

The purpose of this section is to discuss the relationship between ERTIS and ATIS, and to discuss the experience to date with ERTISs in North America and Europe. In the future, ERTISs will probably become part of multimodal ATIS, particularly in regions which offer extensive public transit systems and/or other HOV alternatives that provide more attractive solutions than driving alone. Eventually, the En-Route Transit Information User Service may be integrated with the En-Route Driver Information User Service to form the En-Route Traveler Information User Service.

\subsection{CHICAGO TRANSIT AUTHORITY (CTA)}

CTA expects that information on other regional transportation services and travel directions will be available through an ERTIS by automated and manual means beyond two years time frame. Information on regional services will be provided by automated means, and travel directions (aboard a transit vehicle) manually provided. At rail stations, automated kiosks are planned.

\subsection{DALLAS AREA RAPID TRANSIT (DART)}

DART expects real-time traffic information and information on restaurants, museums, theaters, and other entertainment to be available by both automated and manual means in one year.

\subsection{MASS TRANSIT ADMINISTRATION OF MARYLAND (MTA)}

In Baltimore, it is expected that travel directions and information on restaurants, museums, theaters, and other entertainment will be available by both automated and manual means beyond two years from the present time.

\subsection{NEW JERSEY TRANSIT (NJT)}

Between March 18 and 29, 1994, 1,002 travelers (867 commuters and 135 non-commuters) residing in the NY-NJ-CT area were surveyed by telephone for TRANSCOM to "measure the extent of the public's interest in and willingness to pay for travel information improvements as provided by an [ITS]. The survey asked about specific major enhancements to the existing travel information network that would be made possible through the use of advanced computer technology. The survey [also] asked questions about the public's current travel information 
needs, its satisfaction with the current travel information system, its reaction to possible improvements in the travel information system, and its willingness to pay for those improvements. "71

"The survey of travelers focused on nine areas:

- Types of travel information needed in the past year

- Sources of travel information used in the past year

- Ease of obtaining needed travel information

- Current impact of travel information

- Length of delay required to change travel behavior

- Reactions to possible travel information improvements

- Value of improved travel information

- Impact of enhanced travel information on modal use

- Public's willingness to pay for increased information"72

This extensive survey revealed nine key findings: ${ }^{73}$

- $88 \%$ of the respondents support building an enhanced travel information system. These $88 \%$ included:

- $94 \%$ of the suburban-to-central city commuters

- $91 \%$ of the commuters who live in central cities

- $88 \%$ of suburb-to-suburb commuters

- $91 \%$ of peak-period mass transit travelers

- $88 \%$ peak-period motorists

- $78 \%$ are prepared to pay something to obtain improved, real-time information. The median fee for those willing to pay a monthly fee is just over $\$ 11$ per month. Almost $2 / 3$ of the respondents would be willing to pay for the information on a fee-per-call basis: $44 \%$ would be willing to pay $\$ 1$ per telephone call, and $64 \%$ would be willing to pay $50 \mathrm{c}$ per call. This includes $22 \%$ who would pay per call but would not pay a monthly subscription fee. $31 \%$ of the respondents say that the improvements would have an affect on how often they travel on certain modes.

- $31 \%$ say the improvements would have an affect on how often they travel on certain forms of transportation. This includes $26 \%$ of peak-period motorists, $34 \%$ of peak-period mass transit customers and $35 \%$ of off-peak travelers.

\footnotetext{
71 Reference 54, p. i.

72 Reference 64, p. iii.

73 Reference 64, pp. ix-xii.
} 
- Mass transit ridership is likely to increase as a result of an improved traveler information system. $82 \%$ of the people who say they would travel more if enhanced travel information is available say they would use mass transit modes more often, and $13 \%$ say they would use the automobile more often.

- The most valued information improvements would be those that would provide real-time information on the locations and extent of delays and traffic congestion, travel times using various routes, and when the next mass transit vehicles would arrive. Respondents indicated that they would like this information available via computer at home and work, in their cars, on VMS, in transit facilities and at bus stops.

- $58 \%$ of peak-period motorists would value knowing the estimated travel times by other forms of transportation. 52\% would value real-time information about park-and-ride lot availability, and $51 \%$ of these motorists would like to know how close to schedule trains and buses are running.

- Travel information currently plays an important role in decisions people make on how, where, and when to travel. In the past year, $72 \%$ of the respondents needed some type of travel information. Peak-period motorists $(75 \%)$ and mass transit customers $(73 \%)$ are about equally likely to say they needed travel information in the past year. Among those who needed travel information, $70 \%$ changed their travel behavior as a result of receiving travel information. This increases to $86 \%$ among those who obtained the information they needed.

- $59 \%$ say they need information on unexpected delays, $42 \%$ need information on planned delays due to construction or major repairs, $28 \%$ need information on mass transit schedules, $21 \%$ need information on travel directions, $13 \%$ need information on transit fares, and $12 \%$ need information on bridge and tunnel tolls.

- $48 \%$ of the respondents that needed information on unexpected delays either could not obtain it or had difficulty obtaining it. This ranged from $38 \%$ of peak-period motorists to $66 \%$ of peak-period mass transit customers. $46 \%$ had problems obtaining information on planned delays resulting from construction or major repairs. This ranged from $42 \%$ for motorists to $54 \%$ for public transit customers.

Separate from this survey, NJT expects to provide information on other regional transportation services, real-time traffic information, travel directions, information on restaurants, museums, theaters, and other entertainment by automated and manual means in two years. Also, NJT expects that most kiosk implementations will be destination/attraction-driven (as opposed to transit route-driven) -- the transit service will be presented merely as a means for reaching the attractions advertised on the kiosk, along with whatever other information will make the kiosk optimally useful to potential travelers. (Terminal information kiosks, located at major transit hubs, however, will be transit route/destination-driven.) 


\subsection{TRAVLINK PROJECT/METROPOLITAN COUNCIL TRANSIT OPERATIONS (MCTO)}

Travlink has conducted several focus groups as part of the development of the project. Based on the results of the focus groups in Phase I, several market-based recommendations regarding the design of the system, features available to users of the system, and system promotion were used along with results of a 1993 survey performed by Strgar-Roscoe-Fausch, Inc. on Mn/DOT I-394 User Assessment to further refine the Travlink design. Major findings from the Phase I focus groups were: ${ }^{74}$

- Most participants were not "regularly agitated" about commuting on I-394;

- Commuting to the downtown Minneapolis or University area was not a very painful experience;

- Most participants were, in fact, relatively pleased with the design of I-394, except for lane reduction at Penn Ave.;

- People tended to strongly support alternate forms of transportation, but not at cost of personal convenience;

- Bus riders know "the system" and are pretty comfortable with it;

- Drive alones know little about the transit system and were not inclined to use it, except for emergencies;

- There is much curiosity about the impact of technology on the commute; many people were skeptical (but curious) about its application;

- The Travlink product was perceived as better suited to workplace and public sites. It was less perceived as a need for home use;

- The Trip Planner element clearly has the highest perceived value;

- The Travlink graphics will be critical - they want color and strong visuals;

- The immediacy of information was key, and there was much doubt about the ability of a Travlink to produce "current conditions;"

- Transit users wondered why they need Travlink - they were already comfortable with the transit system. Non-users imagined some value, but thought that Travlink was mostly an occasional need, not a recurring one; 
- Travlink bus schedules probably do not need real time. Flags for "major" (10 minutes or more) delays would be sufficient for most; and

- Carpoolers tended to be the most skeptical about Travlink.

The Phase II focus groups, which were held in June 1994, yielded very similar results to the Phase I focus groups. Specific improvements to Travlink that were suggested in Phase II were used in the final development of Travlink.

A detailed evaluation is being performed currently to determine how Travlink meets the national APTS and local objectives. Categories of evaluation measures that may be covered in the evaluation are as follows: ${ }^{75}$

- User acceptance;

- APTS functionality;

- APTS costs;

- Transit system efficiency;

- Transit system effectiveness;

- Other impacts; and

- Institutional and legal issues.

Preliminary cost figures for Travlink are shown in Table 12. These figures have changed as Travlink has been developed - the final figures are not yet available. NOTE: Approximately $1 / 4$ of the total is contributions from the private sector.

\subsection{COUNTDOWN}

Surveys conducted as part of the COUNTDOWN project covered the areas listed in Section 3.3.5. A summary of the results are as follows: ${ }^{.7}$

- Component reliability and system availability: Levels of failures is low and availability at over $99 \%$

- Information accuracy: Out of 1,379 COUNTDOWN sites, in July 1993:

- Accuracy within \pm 1 minute for $50 \%$ of the time

- Accuracy within \pm 2 minutes for $75 \%$ of the time

- Accuracy within \pm 5 minutes for $96 \%$ of the time

Reference 11, p. 4-1.

Reference 73, pp. 3050-3054.
} 
TABLE 12. PRELIMINARY TRAVLINK PROJECT COST

\begin{tabular}{||c|r||}
\hline \multicolumn{1}{||c|}{ COST CATEGORIES } & COST \\
\hline Capital: & $2,462,000$ \\
\hline CAD/AVL & $1,538,000$ \\
\hline ATIS & 232,000 \\
\hline Signpost System & 474,000 \\
\hline Videotex System & 300,000 \\
\hline Communications Equipment & 105,000 \\
\hline Operating: & 250,000 \\
\hline Professional Services: & 300,000 \\
\hline Systems Integration & 400,000 \\
\hline Project Management & 241,000 \\
\hline Evaluation/Market Research & $6,452,000$ \\
\hline Other In-Kind: & TOTAL \\
\hline \hline
\end{tabular}

- Cleardowns ${ }^{77}$ (In April 1994, improvements of up to 5\% of these were recorded):

-- $66 \%$ occurred within \pm 30 seconds of bus presence at bus stop

-- $81 \%$ occurred within \pm 1 minute of bus presence at bus stop

-- $92 \%$ occurred within \pm 2 minutes of bus presence at bus stop

- Ergonomics: Observation of passengers at bus stops, video surveys of passenger behavior at bus stops and interviews with passengers yielded:

- $70 \%$ look at display when first approaching the bus stop

- $90 \%$ observe the sign at least once during their waiting time

- $60 \%$ say they observe the sign at least once during their waiting time

- $40 \%$ view it almost constantly

- Elderly and non-regular passengers looked at the display least often 
- Visibility of the sign was good, with over $96 \%$ of survey respondents

- Passenger comprehension of information on the display was very good

- Passenger perceptions and attitudes: Before and after interviews were done at bus stops:

- Over $90 \%$ of respondents said that bus passengers deserve COUNTDOWN and the COUNTDOWN system should be introduced on all bus routes in London

- $82 \%$ said that the information displayed was acceptably accurate

- $45 \%$ said that the accuracy was improving

- $65 \%$ felt that they now waited a shorter time than before COUNTDOWN

- $83 \%$ said that the time passed more quickly if you know the bus is coming

- $\quad 89 \%$ said display made waiting time more acceptable

- The average perceived waiting time dropped from 11.9 minutes to 8.6 minutes between before and after

- $64 \%$ believed service reliability had improved since COUNTDOWN was introduced

- $68 \%$ said their general attitude toward bus travel had improved

- Passenger valuation of COUNTDOWN:

- Average passenger valuation was mid-20 pence range with a central value of 26 pence

- COUNTDOWN is worth $53 \%$ of the average fare

\subsection{MUNICH COMFORT}

Initial results ${ }^{78}$ on the VMS installed near the Fröttmaning P\&R are that out of 1,270 spaces for automobiles, an average of 750 cars are using it on each workday. The lot is often filled during special events. There has been an increase of $8 \%$ more vehicles per month that used the facility during the last quarter of 1994 . Before the P\&R existed, $26 \%$ who now use it used to drive into the city for the whole trip, $11 \%$ used public transportation and $63 \%$ used another P\&R. $60 \%$ of the Fröttmaning users trip purposes are shopping, leisure and occasional business. The average use of $P \& R$ for these trip purposes in Munich is $17 \%$ at rapid transit stations and $40 \%$ at other underground stations. This indicates a shift to public transportation early in the trip for these types of trips. 50\% of the Fröttmaning P\&R users said that the VMS 
was the only source of information on this particular P\&R. On weekdays, $17 \%$ of the drivers made their mode decision based solely on the information provided by the VMS.

\subsection{PHOEBUS}

Initial results from Brussels on the PHOEBUS project focused on the accuracy of the real waiting time displayed on each UIP. "During rush hours, the measured accuracy is about $100 \%$ for the range of wait time less than 5 minutes. When all the ranges are considered, even those of several tens of minutes, the accuracy remains better than $75 \%$. During off-peak hours, there is a paradoxical diminution of [these] results by $10 \%$. It is due to an incorrect adjustment of the theoretical journey time. In general, the display of the wait time is not available during $4.4 \%$ of the duty time. ${ }^{179}$

\subsection{POPINS}

Popins has been evaluating the terminals deployed in the four Popins cities. The evaluations have included measurements of user satisfaction, qualitative data on operations and quantitative data on terminal use. The SIT system in Madrid and the AlterEgo system in Marseille were not fully implemented when the first evaluation was done. A summary of results from Madrid, which conducted a survey of 35 SIT users prior to full implementation, is as follows: $:^{80}$

- $78 \%$ of respondents had no problem using SIT;

- $79 \%$ of respondents said that the proposed solution was appropriate;

- $50 \%$ of the users found the terminal very easy or easy to use;

- $47 \%$ of the users found the terminal average to use;

- $3 \%$ of the users found the terminal difficult or very difficult to use; and

- It took 3 times or less for $87 \%$ of the users to become familiar with the system.

\subsection{SCOPE}

Before and after surveys were conducted in Southampton on the STOPWATCH system. While the results of the "after" surveys are not yet available, the before survey indicated that for 1,538 passengers interviewed: ${ }^{81}$

Reference 40, p. 2884.

80

Reference 69, pp. 2902-3.

81

Reference 51, p. 2923. 
- $11 \%$ were aware that STOPWATCH would be installed;

- $16 \%$ claimed that STOPWATCH would increase their use of public transit;

- $73 \%$ claimed that STOPWATCH would have no effect on their use of public transit;

- $11 \%$ were uncertain about their use of public transit;

- $40 \%$ never use a car;

- $46 \%$ did not have regular access to a car;

- $70 \%$ had no driving license;

- Potential STOPWATCH usage by trip purpose:

- Positive responses for social trips;

- Above average responses for shopping trips;

- Neutral or negative response for working trips; and

- Changes in trip making linked with younger age groups.

For VICTORIA in Cologne, a survey of 345 people using the Vario route guidance VMS to the Zoo P\&R showed: ${ }^{82}$

- More than $90 \%$ of the P\&R users find the messages understandable;

- $80 \%$ consider the information sufficient;

- $60 \%$ use the P\&R regularly and most are for work trips;

- $22 \%$ use the P\&R infrequently or were first-time users; and

- $44 \%$ of less frequent users and $29 \%$ of frequent users find VMS a most important source of information. 



\section{RESULTS AND CONCLUSIONS}

Since ERTISs are not yet widely implemented in North America, the state-of-the-art reflects a majority of manual systems. However, with the growing implementation of AVL systems and sophisticated techniques to collect and distribute data, ERTISs based on real-time information are just starting to be developed. Even though the nature and ridership on transit in North America is different from that in Europe, many good examples of ERTIS development, demonstrations, and implementation can be used to further the state-of-the-art in North America.

ERTISs in North America are primarily manual systems, consisting of customer's use of printed timetables and their knowledge of making transfers or connections. ERTISs based on automated systems are in the minority. However, many automated pre-trip planning systems are widely available.

The limited number of automated ERTISs reflects the narrow scope of implementation of and experience with AVL systems in North America, which are an integral part of automated ERTISs. Although the number of transit agencies implementing AVL systems is growing rapidly, the use of data from AVL systems has been limited. Most transit agencies have not previously had the volume and types of data available from an AVL system, so they have yet to utilize this wealth of data.

Beside the limited number of automated ERTISs, there is little information on the need for ERTIS, its potential effect on transit ridership, and the costs and benefits associated with ERTISs. In Europe and Asia, many APTS systems, including ERTISs, have been initially evaluated according to these factors, and could be used in North America as these systems are being developed.

Currently, there are several projects that are integrating traffic and transit information in order to promote a shift from single-occupant vehicles (SOV) to HOV. Travlink and the California Smart Traveler are operational now, but not all of their elements are real-time. ${ }^{83}$ Systems such as driver guidance to $P \& R$ lots, including information on public transit service, which have been implemented in Europe, should be used as examples of how to further promote the modal shift to transit or HOVs. European studies have identified that service "reliability and punctuality are perhaps the most important requirements influencing the perception of a public transport system." ${ }^{84}$ ERTISs are probably one of the most important factors that can directly affect this perception.

Real-time transit data is available for 80 out of 800 MCTO buses in Travlink. Real-time transit data is not available through Smart Traveler. 
To date, automated information on real-time transfers and connections has not been available through existing ERTISs.

Based on these results, the following conclusions can be drawn:

- While ERTISs are just beginning to be developed in North America, full implementation requires installation of and experience with APTS, specifically AVL systems, as well as a thorough understanding of customer needs. This issue is identified in the USDP, but since none of the operational tests identified in the USDP have been fully implemented and are operating on a regular basis, this will remain an issue in the short term.

- ERTISs have the potential to reduce the perceived barriers for customers or potential customers to use public transit and to shift SOV drivers to public transit or HOVs. In Europe, it has been proven that when real-time arrival and disruption information is provided at transit stops, even if the transit service quality has not improved, customers perceive an improvement in service quality. Also, when HOV alternatives are presented to SOV drivers, a significant number of them will shift to an HOV option.

In the USDP, FTA is identified as the sponsor of research on the impact that traveler information has on mode choice. To date, this research has not been conducted.

- Since ERTISs based on automation directly reflect the reliability and quality of the transit service, ERTISs may not be a priority in terms of advanced technology applications. Politically, ERTISs can be perceived by transit systems to bring attention to the problems of service.

- While fully automated ERTISs are attractive from the technology perspective, they are not necessary to satisfy customers. Basic and reliable information should be the primary focus of ERTISs. This is not mentioned explicitly in the USDP, but is implied as an issue that identified database accuracy as a key data issue.

- Quantifiable costs and benefits of ERTISs are hard to determine. This is evidenced by the lack of cost/benefit information in the USDP. To date, little cost data reflecting the full costs of design, development, installation, testing, operations and maintenance are available. Further, the benefits will depend on customer reaction to and use of ERTISs, as well as mode shifts resulting from the use of the information. 


\section{RECOMMENDATIONS}

The review and assessment of ERTISs in North America, along with the review of existing ERTISs in Europe, indicates that the following should be considered:

- The collection of data regarding the need for ERTISs in North America and their associated costs and benefits. Even though public transit is a very localized market, an assessment of the need for ERTISs could focus on both transit and non-transit riders in several metropolitan regions around the U.S.;

- The sponsorship of a joint workshop with both transit and highway participation to explore the integration of En-Route Driver Information and En-Route Transit Information to develop "En-Route Traveler Information;" and

- The development of functional guidelines that address user needs for ERTISs, including recommended ERTIS features and presentation layers (e.g., graphical, solutions, interactivity, etc.).

The need for ERTISs has not been widely studied in North America, nor is there a great deal of information available on costs and benefits. Serious consideration should be given to the real need for such systems, and how APTS technologies such as AVL can supply the information to satisfy those needs. While transit ridership in Europe tends to be higher than in the U.S., several European "case studies" could be used to develop a framework to assess user needs. Further, costs and benefits, both qualitative and quantitative, should be identified based on existing systems in North America and Europe. A key factor that should be considered in the cost/benefit identification is the potential for and actual use of public/private partnerships, and the opportunities for joint funding between FHWA and FTA.

The study identified several European examples of the communication of transit information to drivers in addition to information on real-time traffic. Traditionally in the U.S., as evidenced by the National ITS Program Plan, highways and transit have remained separate. The integration of traffic and transit data, available to a driver on one device (e.g., an in-vehicle device), provides the driver with more alternatives than just driving around the congestion, thus it has the potential for the driver to entertain shifting modes. While it is equally as important to keep the transit rider fully informed of the real-time operational situation, the transit rider has already made a choice of transit; the driver has the opportunity to shift to transit or HOVs given that he/she is presented with the reliable and accurate information. This integration of driver and transit-related information should be explored jointly by the transit and highway community, initially by holding a workshop.

Since ERTISs are not widely deployed in North America, user requirements have not been developed. Further, it may be useful to produce guidelines on the presentation of en-route transit information, once the user needs are specified. A European example of this type of 
guidelines development is the effort of the INPUT Task Force, which was described in Section 3.3.4. Table 13 shows how the INPUT efforts have developed in terms of guidelines toward common presentation of information to the user.

While we are not recommending an effort on the same scale as the INPUT Task Force, general guidelines in these areas could be developed to assist transit agencies that are contemplating the design of an ERTIS.

\section{TABLE 13. INPUT ORIENTATIONS ${ }^{85}$}

\begin{tabular}{|c|c|c|c|c|}
\hline Layer & Items & $\begin{array}{l}\text { At-Stop } \\
\text { Display }\end{array}$ & $\begin{array}{l}\text { In-Street } \\
\text { Terminal }\end{array}$ & $\begin{array}{c}\text { Enquiry Office } \\
\text { Terminal }\end{array}$ \\
\hline \multirow{6}{*}{ Physical } & Screen: technology, structure & 姆 & 昰 & 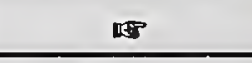 \\
\hline & Characters & 吗 & 昰 & 4 \\
\hline & Buttons & & $10+$ & $\log$ \\
\hline & Icons & & 108 & $\checkmark$ \\
\hline & Colors & $\cos$ & 108 & 18 \\
\hline & Environment & 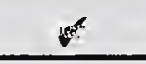 & 100 & age \\
\hline \multirow{8}{*}{ Representation } & Terminology & 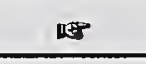 & $\checkmark$ & $\checkmark$ \\
\hline & Menu & $\cos$ & एक्ष & 呼 \\
\hline & Metaphor & 此 & Lets & 吗 \\
\hline & Solution presentation & $\cos$ & $s^{2}$ & $\cos$ \\
\hline & 1- Waiting time & $\checkmark$ & & \\
\hline & 2 - Trip planning solution & & $\checkmark$ & 呼 \\
\hline & 3 - Timetables solution & & 10 & 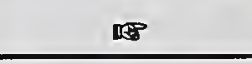 \\
\hline & Map presentation & & $f$ & $\operatorname{tat}$ \\
\hline \multirow{4}{*}{ Interactivity } & Map manipulation & & $\cos$ & $\cot$ \\
\hline & Navigation functions & & 108 & $\cos$ \\
\hline & Choice of language & & $\checkmark$ & $\mathrm{X}$ \\
\hline & Interactive communication tool & & $\leftrightarrow$ & $X$ \\
\hline
\end{tabular}




\section{APPENDIX A. LIST OF INTERVIEW QUESTIONS}





\section{EN-ROUTE TRANSIT INFORMATION SYSTEMS: LIST OF INTERVIEW QUESTIONS}

Name of Transit Agency:

Address:

City/Town: State:

Zip:

Contact Person:

Title:

Phone Number:

Fax Number:

1. In order to facilitate your responses to these questions, the definition of en-route transit information system is presented here:

An en-route transit information system provides information to travelers using public transportation after they begin their trip(s). This real-time and accurate information includes the status of transit and other high-occupancy vehicles (HOVs) (e.g., Bus 504 will arrive in 3 minutes) that can be used by travelers to facilitate their trip(s). En-route transit information systems can provide information on-board vehicles, in key locations such as transit centers, intermodal facilities, employment centers, shopping areas and entertainment centers, and at transit stops. Information provided by such a system can include real-time arrival and departure information, real-time connection/transfer information, information about other regional transportation services, fare, schedule and route information, etc.

The Federal Transit Administration is interested in reviewing current efforts to implement en-route transit information systems, and in providing preliminary guidance to transit agencies that are interested in implementing such systems.

2. At what stage are the components of your en-route transit information system? (Please specify which component is at which stage)

Planning/definition Component(s):

․ Development Component(s):

口 Installation/Testing Component(s):

口 Full Operation/Implementation Component(s):

․ Expansion Component(s): 


\section{EN-ROUTE TRANSIT INFORMATION SYSTEMS: LIST OF INTERVIEW QUESTIONS}

For those system components that are being planned/defined and are under development, when are they expected to be installed? In the next (check only one):

$\square 6$ months $\square \quad 1$ year $\square 2$ years $\square$ Beyond 2 years

3. What transit information is currently distributed through the en-route transit information system?

(check all that apply)

Real-time arrival/departure information

口 Static arrival/departure information

․ Real-time schedules

․ Static schedules

$\square$ Routes

$\square$ Route details

Fares

․ Park-and-ride locations

Parking lot fees and usage

․ Actual vehicle location

$\square$ Next-stop announcements

口 Information on other intrasystem transit services (e.g., elderly/disabled services, connections/transfers, carpools/vanpools, special event services)

口 Information on other regional (intersystem) transit services

Other transportation information Please specify:

4. What additional transit information will be distributed through the en-route transit information system in the future?

(check all that apply)

Real-time arrival/departure information

口 Static arrival/departure information

Real-time schedules

․ Static schedules

$\square$ Routes

Route details

Fares

ㅁ Park-and-ride locations

口 Parking lot fees and usage

․ Actual vehicle location

Next-stop announcements 


\section{EN-ROUTE TRANSIT INFORMATION SYSTEMS: LIST OF INTERVIEW QUESTIONS}

- Information on other intrasystem transit services (e.g., elderly/disabled services, connections/transfers, carpools/vanpools, special event services)

- Information on other regional (intersystem) transit services

$\checkmark$ Other transportation information Please specify:

For each of the types of information checked above, please specify when it will be available through the en-route transit information system:

6 months for information types:

ㅁ 1 year for information types:

․ 2 years for information types:

ㅁ Beyond 2 years for information types:

5. Is the information on your transit system schedules provided through the en-route transit information system based upon:

(check only one)

- Real-time data from an AVL system and/or other advanced technology

- Static data from published timetables

- In-house electronic database containing static or periodic data

口 Other (e.g., information from on-street supervisors)

Please specify:

a. If the information is from real-time data from an AVL system and/or other advanced technology, please specify type of AVL system and/or other advanced technology:

- Automatic vehicle location (AVL) technology Please specify: 


\section{EN-ROUTE TRANSIT INFORMATION SYSTEMS: LIST OF INTERVIEW QUESTIONS}

$\square$ GPS

D Differential GPS

- Signpost

$\square$ LORAN-C

Dead reckoning

- Combination of technologies (e.g., GPS and dead reckoning) Please specify combination:

ㅁ Other technology: Please specify:

b. If the information is from static data from published timetables, are you planning to implement an AVL system in the future?

$\square$ YES $\square$ NO

If NO: $\quad$ Is it too costly?

Is it not justified by the service?

口 Is there not enough information to judge at this time?

If YES, when will the AVL system be fully operational? In the next (check only one):

$\square 6$ months $\square \quad 1$ year $\square 2$ years $\square$ Beyond 2 years

c. If the information is from an in-house electronic database, please briefly describe this database and please specify how this database is maintained:

6. How is transit information currently distributed by the en-route transit information system?

(check all that apply)

- Cable television/videotex over television

口 Radio broadcast

- Personal computer/modem

口 Personal communication device (e.g., alphanumeric pager, personal digital assistant)

- Information kiosk (interactive) at business/shopping complex 


\section{EN-ROUTE TRANSIT INFORMATION SYSTEMS: LIST OF INTERVIEW QUESTIONS}

․ Information kiosk (interactive) at transit stop/center

ㅁ Audiotex over touch-tone telephone

․ Display (non-interactive) at business/shopping complex

口 Display (non-interactive) at transit stop/center

口 Interactive display on-board transit vehicle

Non-interactive display on-board transit vehicle

口 Voice stop annunciators (for sight-impaired)

Automatic visual information signage (for hearing impaired)

Other: Please specify:

7. How will transit information be distributed in the future by the en-route transit information system?

(check all that apply)

ㄷ Cable television/videotex over television

口 Radio broadcast

․ Personal computer/modem

Personal communication device (e.g., alphanumeric pager, personal digital assistant)

․ Information kiosk (interactive) at business/shopping complex

․ Information kiosk (interactive) at transit stop/center

․ Audiotex over touch-tone telephone

Display (non-interactive) at business/shopping complex

Display (non-interactive) at transit stop/center

$\square$ Interactive display on-board transit vehicle

口 Non-interactive display on-board transit vehicle

$\square$ Voice stop annunciators (for sight-impaired)

․ Automatic visual information signage (for hearing impaired)

$\checkmark$ Other: Please specify: $\rightarrow$

For each of the components/media checked above, please specify when it will be implemented in the future:

․ 6 months for components: 


\section{EN-ROUTE TRANSIT INFORMATION SYSTEMS: LIST OF INTERVIEW QUESTIONS}

․ 1 year for components:

ㄴ 2 years for components:

Beyond 2 years for components:

8. Is other transportation information currently available through the en-route transit information system?

$\square$ YES $\square$ NO

If YES, what type of information is available:

(check all that apply)

․ Information on other regional transportation services

․ Real-time traffic information

Travel directions

Information on restaurants, museums, theaters, etc.

$\square$ Weather

If YES, how is this information collected?

- Automated means (For example, providing dynamic/real-time information)

口 Manual means (For example, providing static information)

If NO, has this information been considered for inclusion in the en-route transit information system?

$\square$ YES $\square \quad$ NO

Comments: 


\section{EN-ROUTE TRANSIT INFORMATION SYSTEMS: LIST OF INTERVIEW QUESTIONS}

9. Will other transportation information be available through the en-route transit information system in the future?

$\square$ YES $\square$ NO

If YES, what type of information will be available:

口 Information on other regional transportation services

․ Real-time traffic information

․ Travel directions

口 Information on restaurants, museums, theaters, etc.

․ Weather

If YES, how will this information be collected?

ㅁ Automated means (For example, providing dynamic/real-time information)

口 Manual means (For example, providing static information)

If YES, when will this information be available? In the next (check only one):

$\square 6$ months $\square \quad 1$ year $\square 2$ years $\square$ Beyond 2 years

If NO, has this information been considered for inclusion in the en-route transit information system?

$\square$ YES $\square$ NO

Comments:

10. Were any studies conducted prior to designing and/or implementing the en-route transit information system that estimated potential usage, and identified consumer needs/requirements of such a system and/or consumer reactions to such a system?

$\square$ YES $\square$ NO 


\section{EN-ROUTE TRANSIT INFORMATION SYSTEMS: LIST OF INTERVIEW QUESTIONS}

11. Is there any information available about the current use of the en-route transit information system?

$\square$ YES $\square$ NO

If YES, what type of information is available:

(check all that apply)

$\square$ Use of system

$\square$ Consumer reactions/attitudes to the system

․ Technical performance of the system

․ System costs

․ Suggestions for improvement/enhancement of system

․ Automated data collection mechanisms built into system

12. Are you or have you considered partnering with other regional transportation providers and/or agencies to coordinate development and implementation of en-route transit information systems?

$\square$ YES $\square \quad$ NO

If YES, please list the providers/agencies:

13. Are there any technical and/or institutional issues or obstacles that surfaced during the development, installation and operation of the en-route transit information system? 


\section{EN-ROUTE TRANSIT INFORMATION SYSTEMS: LIST OF INTERVIEW QUESTIONS}

14. If there were any technical/institutional issues, how were they resolved? 


\section{EN-ROUTE TRANSIT INFORMATION SYSTEMS: LIST OF INTERVIEW QUESTIONS}

15. Are there any "lessons learned" that would benefit other organizations developing and implementing en-route transit information systems? 
APPENDIX B. LIST OF CONTACTS 



\section{LIST OF CONTACTS}

\begin{tabular}{|c|c|c|}
\hline NAME/TITLE & ORGANIZATION & PHONE/FAX \\
\hline $\begin{array}{l}\text { Ronald Baker } \\
\text { General Manager, } \\
\text { Communications } \\
\text { Implementation Task Force, } \\
\text { Communications/Power } \\
\text { Control }\end{array}$ & $\begin{array}{l}\text { Chicago Transit Authority } \\
\text { Merchandise Mart Plaza } \\
\text { Chicago, IL } 60654\end{array}$ & $\begin{array}{l}312-222-6122 \\
312-664-2748\end{array}$ \\
\hline $\begin{array}{l}\text { Andrew Bata } \\
\text { Senior Director of Service } \\
\text { Planning }\end{array}$ & $\begin{array}{l}\text { MTA-NYCT } \\
130 \text { Livingston Street } \\
\text { Brooklyn, NY } 11201 \\
\end{array}$ & $\begin{array}{l}718-694-3652 \\
718-488-6468\end{array}$ \\
\hline Serge Belanger & $\begin{array}{l}\text { MUCTC } \\
800 \text { rue de la Gauchetiere West } \\
\text { Montreal, Quebec } \\
\text { H5A 1J6 CANADA }\end{array}$ & $514-280-6262$ \\
\hline $\begin{array}{l}\text { Brenda Claybrook } \\
\text { Manager, GIS Applications }\end{array}$ & $\begin{array}{l}\text { DART } \\
\text { P.O. Box } 660163 \\
\text { MS } 7243 \\
\text { Dallas, TX } 75266 \\
\end{array}$ & $\begin{array}{l}214-749-3020 \\
214-749-3656\end{array}$ \\
\hline $\begin{array}{l}\text { Dean Delgado } \\
\text { Senior Transportation } \\
\text { Analyst }\end{array}$ & $\begin{array}{l}\text { OCTA } \\
550 \text { South Main Street } \\
\text { P.O. Box } 14184 \\
\text { Orange, CA 92613-1584 } \\
\end{array}$ & $\begin{array}{l}714-560-5744 \\
714-560-5794\end{array}$ \\
\hline Carol Douglas & $\begin{array}{l}\text { Seattle Metro } \\
821 \text { Second Avenue } \\
\text { Exchange Building } \\
\text { Seattle, WA 98104-1598 } \\
\end{array}$ & $\begin{array}{l}206-684-1571 \\
206-684-2034\end{array}$ \\
\hline Bernard Farrol & $\begin{array}{l}\text { Toronto Transit Commission } \\
1900 \text { Yonge Street } \\
\text { Toronto, Ontario } \\
\text { M4S 1Z2 CANADA }\end{array}$ & $\begin{array}{l}416-393-4491 \\
416-535-1391\end{array}$ \\
\hline Helen Gault & $\begin{array}{l}\text { OC Transpo } \\
1500 \text { Saint Laurent Boulevard } \\
\text { Ottawa, Ontario } \\
\text { K1G 0Z8 CANADA }\end{array}$ & $613-741-6440$ \\
\hline
\end{tabular}




\begin{tabular}{|c|c|c|}
\hline NAME/TITLE & ORGANIZATION & PHONE/FAX \\
\hline Lou $\mathrm{Ha}$ & $\begin{array}{l}\text { RTD } \\
1600 \text { Blake Street } \\
\text { Denver, CO } 80202 \\
\end{array}$ & $\begin{array}{l}303-299-6265 \\
303-299-6060\end{array}$ \\
\hline $\begin{array}{l}\text { David Hill } \\
\text { Senior Systems Engineer }\end{array}$ & $\begin{array}{l}\text { MTA } \\
300 \text { W. Lexington St. } \\
\text { Baltimore, MD } 20017\end{array}$ & $\begin{array}{l}410-333-3437 \\
410-333-4810\end{array}$ \\
\hline $\begin{array}{l}\text { Bill Hiller, Manager of } \\
\text { Information Systems }\end{array}$ & $\begin{array}{l}\text { Ann Arbor Transportation } \\
\text { Authority } \\
2700 \text { S. Industrial Highway } \\
\text { Ann Arbor, MI } 48104 \\
\end{array}$ & $\begin{array}{l}313-677-3944 \\
313-973-6338\end{array}$ \\
\hline $\begin{array}{l}\text { James Kemp } \\
\text { Senior Planner, APTS } \\
\text { Technology }\end{array}$ & $\begin{array}{l}\text { NJT } \\
\text { One Penn Plaza East } \\
\text { Newark, NJ } 07105\end{array}$ & $\begin{array}{l}201-491-7861 \\
201-491-7767\end{array}$ \\
\hline Joel Markowitz & $\begin{array}{l}\text { MTC } \\
\text { Metro Center } \\
101 \text { 8th Street } \\
\text { Oakland, CA } 94607 \\
\end{array}$ & $510-464-7760$ \\
\hline Margaret Moilov & $\begin{array}{l}\text { CALTRANS, District } 7 \\
\text { Public Transportation Branch } \\
120 \text { South Spring St. } \\
\text { Los Angeles, CA } 90012\end{array}$ & $\begin{array}{l}213-897-0188 \\
213-897-3803\end{array}$ \\
\hline Moss Mombourquette & $\begin{array}{l}\text { Metro Transit } \\
200 \text { Isley Avenue } \\
\text { Dartmouth, Nova Scotia } \\
\text { B3B 1V1 CANADA } \\
\end{array}$ & $\begin{array}{l}902-421-2647 \\
902-421-8072\end{array}$ \\
\hline $\begin{array}{l}\text { Bob Previdi } \\
\text { Superintendent }\end{array}$ & $\begin{array}{l}\text { MTA-NYCT } \\
130 \text { Livingston Street } \\
\text { Brooklyn, NY } 11201 \\
\end{array}$ & $\begin{array}{l}718-694-3692 / 1036 \\
718-488-6468\end{array}$ \\
\hline Laura Radin & Port Authority of NY and NJ & $\begin{array}{l}212-435-4785 \\
212-435-4809 \\
\end{array}$ \\
\hline Robert Ratcliff & $\begin{array}{l}\text { CALTRANS } \\
\text { Office of Advanced } \\
\text { Transportation and Management } \\
\text { and Information System } \\
1130 \text { K Street, Suite } 205 \\
\text { P.O. Box } 942874 \text {, Mailstop \#83 } \\
\text { Sacramento, CA } 94274\end{array}$ & $916-323-2644$ \\
\hline
\end{tabular}




\begin{tabular}{|c|c|c|}
\hline NAME/TITLE & ORGANIZATION & PHONE/FAX \\
\hline $\begin{array}{l}\text { Marilyn Remer } \\
\text { Director, Travlink Project }\end{array}$ & $\begin{array}{l}\text { Mn/DOT } \\
\text { Transportation Research and } \\
\text { Investment Management Division } \\
\text { Ford Building, 2nd Floor } \\
117 \text { University Avenue } \\
\text { St. Paul, MN 55155 }\end{array}$ & $\begin{array}{l}612-282-2469 \\
612-296-6599\end{array}$ \\
\hline Harriett Robbins-Smith & $\begin{array}{l}\text { MARTA } \\
2424 \text { Piedmont Rd., N.E. } \\
\text { Atlanta, GA } 30324\end{array}$ & $\begin{array}{l}404-848-4224 \\
404-848-5321\end{array}$ \\
\hline Ron Rutkowski & $\begin{array}{l}\text { Milwaukee County Department } \\
\text { of Public Works } \\
907 \text { North 10th Street } \\
\text { Milwaukee, WI } 53233\end{array}$ & $414-278-4888$ \\
\hline $\begin{array}{l}\text { Lloyd Smith } \\
\text { Director, Traffic } \\
\text { Management }\end{array}$ & $\begin{array}{l}\text { Houston Metro } \\
1201 \text { Louisiana } \\
\text { P.O. Box } 61429 \\
\text { Houston, TX } 77208-1429 \\
\end{array}$ & $\begin{array}{l}713-739-3870 \\
713-652-8998\end{array}$ \\
\hline $\begin{array}{l}\text { Isaac Takyi } \\
\text { Director, Facilities \& } \\
\text { Equipment Planning }\end{array}$ & $\begin{array}{l}\text { MTA-NYCT } \\
130 \text { Livingston Street } \\
\text { Brooklyn, NY } 11201\end{array}$ & $\begin{array}{l}718-694-3652 \\
718-488-6468\end{array}$ \\
\hline Katherine Turnbull & $\begin{array}{l}\text { Texas Transportation Institute } \\
\text { Texas A\&M University } \\
\text { College Station, TX } 77843\end{array}$ & $409-845-6005$ \\
\hline $\begin{array}{l}\text { Ken Turner } \\
\text { Manager, Project } \\
\text { Development }\end{array}$ & $\begin{array}{l}\text { Tri-Met } \\
\text { 4012 S.E. 17th Avenue } \\
\text { Portland, OR } 97202\end{array}$ & $\begin{array}{l}203-238-4918 \\
503-238-4997\end{array}$ \\
\hline Craig Van Alstyne & $\begin{array}{l}\text { BC Transit } \\
13401 \text { 108th Avenue } \\
\text { Surrey, British Columbia } \\
\text { V3T 5T4 CANADA } \\
\end{array}$ & $604-540-3436$ \\
\hline $\begin{array}{l}\text { Carol Walb } \\
\text { Manager, Special Projects, } \\
\text { Customer Service Dept. }\end{array}$ & $\begin{array}{l}\text { BART } \\
800 \text { Madison Street } \\
\text { Oakland, CA } 94604\end{array}$ & $\begin{array}{l}510-464-7129 \\
510-464-6247\end{array}$ \\
\hline
\end{tabular}





\section{APPENDIX C. USER SERVICE DEVELOPMENT PLAN FOR EN-ROUTE TRANSIT INFORMATION}





\subsection{EN-ROUTE TRANSIT INFORMATION}

\subsubsection{Introduction}

The En-Route Transit Information user service provides information to transit riders after their trips have begun. The service will provide real-time, accurate, transit and high-occupancy vehicle information so that travelers can select the most convenient and time effective choice of mass transit in order to reach their destinations.

En-Route Transit Information is distinguished from Pre-Trip Travel Information (User Service No. 2.1) in that the Pre-Trip concentrates on travel and transit information prior to making a trip or mode choice. Once a trip is initiated, travel information still needs to be provided to the traveler. En-Route Transit Information discusses the service provided during the transit commute.

En-Route Driver Information (User Service No. 1.1) discusses the service provided to the driver during the commute, including information provided to transit vehicle operators (e.g., bus drivers). En-Route Driver Information also provides drivers with information on transit schedules, parking availability, etc. to support mode change decisions mid-trip based on current traffic conditions. Electronic Payment Services (User Service No. 4.1) will allow transit users to pay for services quickly and conveniently, eliminating the need for exact change or awkward collection systems.

\subsubsection{Needs}

Encouragement to use mass transit as a means of commuting will help alleviate traffic congestion while providing for better management of existing facilities. This transportation mode is under-utilized in most urban and suburban areas. In fact, the 1990 census data indicates that use of transit throughout the country has been continually declining. Like any other good idea, transit will not help solve the traffic congestion problem unless it is put into greater use. To increase ridership and attract riders from other modes of transportation, public transit must provide good service and deliver its product on-time.

It has been found that the perceived wait time for transit passengers is considerably longer than the actual wait time. This is particularly problematic in low density suburban areas, where service is generally infrequent. More widespread use of mass transit, and thus more effective and efficient transit operations, can be achieved through en-route transit information systems that provide better information to travelers and better integration of transit with other modes of transportation.

Transit status information provided at the appropriate time and place will assist the traveler in completing the trip with minimal disruption and with considerably less uncertainty. Thus, there is an urgent need to take steps to provide travel information while En-Route to 
encourage the public to make greater use of this travel option. Capabilities exist today to provide the information in a number of languages in addition to English. Also, there are many transit users with visual and hearing impairments that need special audio and visual assistance to receive information. The application of proven advanced technologies to enhance information on public transportation can help reverse the declining trend in the use of transit as a travel mode.

Recent advancements in the fields of navigation, communications and information systems provide supporting technology using innovative methods to make transit more efficient and more attractive to potential riders, and thus more effective. It has been estimated that the diversion of just one of five solo drivers nationwide would save $\$ 30$ billion per year in congestion costs.

\subsubsection{Service Description}

The En-Route Transit Information user service provides travelers with real-time, accurate transit network information during their travel. This information assists travelers in making effective transfer decisions and modifications as needed to a trip underway. Information also provides traveler "comfort," reduced anxiety, and convenience. The information provided is inclusive of all transit services and modes in a given area, including car and van pools and shared ride taxis and would, eventually, be available from a single source. The data would be collected from transit systems, traffic management systems, and rideshare programs; and integrated, stored, and maintained on-line for interactive access from a wide variety of locations.

\subsubsection{Operational Concepts}

A traveler, having already made his mode choice and initiated a travel plan, will be provided with information along the route. Interactive service would be provided through kiosks at travel information centers and other transfer points. Interactive displays on board the bus would allow queries to be made concerning various options while En-Route to a destination. Similar interactive displays would also be available at a wayside stop or transfer point. Available options for completing the trip would be given to the traveler based upon real-time information. At bus stops, a visual display would give estimated arrival times of buses based on their actual location and an audio message would announce the arriving bus and route number. The traveler would board the bus and begin the trip. While on board, the traveler would determine if a transfer could be made at a rail station En-Route. If the on board display advises that the rail service is running late, the traveler could arrange to stay on the bus for the completion of the trip. When transferring to another bus is necessary, information about connections would be available on board the first bus.

These dissemination processes could be extended to include the integration and coordination with regional paratransit services. Public and private providers would be included in the 
information given throughout the jurisdiction of the service area. Each of the transit systems within the service jurisdiction would continually provide the integrated information service bureau with scheduled and actual service being provided. The information would include the next available vehicle based upon actual operating conditions. Information would be integrated with actual road and traffic data, resulting in on-the-fly route detours, where possible without missing riders.

During peak hours, there may be large crowds of people in several different queues at terminals or major stops where the same bay or stop is shared with more than one route. In these situations, the order of bus arrivals may be more important to the customer on the platform than the actual arrival time.

Since interactive displays at kiosks require on-line, interactive service similar to that offered by automatic teller machines (ATM's), arrangements can be made with the local ATM networks to tie into their communications networks to provide an integrated financialtransportation service. For example, tickets and farecards could be obtained as well as cash withdrawals in future applications of this user service.

\subsubsection{Technologies}

Multiple technologies can be employed for presenting the information to the traveler. Output devices include:

- Low-powered radio, which would be directed to a small geographic area and picked up by a receiver on the vehicle for transmission to the traveler. This concept is similar to that currently used for Highway Advisory Radio communication.

- Variable message signs, already used on highway systems, would provide travel information to the traveler en-route and at bus stops, and monitors would allow display to several travelers at once.

- Portable Personal Communications Devices (PCDs) would be carried by the traveler. Transportation information is but one of many applications that are anticipated for these devices.

- Interactive video displays in the form of smart kiosks at roadside or in transit centers. These would provide an on-line, interactive service.

- Audiotex over touch-tone phones.

- Videotex over television. 
- Cable TV would provide information concerning the status of transit operations and would eventually do this as soon as the status changes.

- Voice Stop Annunciators announce bus stops and the bus' ultimate destination as well as preplanned reroute announcements, as required by the Americans With Disabilities Act (ADA). These are especially important to the sight impaired.

- Automatic Visual Information Signage, which is activated by annunciators, permits deployment of next-stop information for the hearing impaired. The potential for displaying advertisements in a different color can also be supported. To function without driver intervention, both the visual and voice annunciators must make use of automatic vehicle location technology.

An infrastructure must be developed to supply the information to the output devices. Technologies within the En-Route Transit Information infrastructure include computers, telecommunication equipment, digital maps, voice synthesis, transponder-based vehicle roadside systems, tag-based automated stop identification systems, and dynamic multimodal database applications. Furthermore, on-board access to information regarding the location of a bus would be possible if a vehicle tracking system were being used locally.

Several technologies will need to be integrated to achieve the complete user service anticipated. For example, telecommunication equipment, touch-tone telephones, voice synthesis would be expected to be integrated to provide the needed user service information for smart kiosks.

\subsubsection{Potential Costs and Benefits}

[NOTE: Financial cost and benefit data are requested for this section of the En-Route Transit Advisory Program Plan. Targeted costs for individual equipment or systemwide cost could be used for this discussion. Distribution of costs between the public and the private sectors and the consumer could also be included.] Cost sharing is expected by non-direct users or service providers, since shifting travelers to public transit actually impacts all travelers positively in the transportation network.

\subsubsection{Assessment of Roles}

\subsubsection{Public Benefit}

This service has high potential for public benefit in three ways: (1) the individual traveler will benefit from being able to better use transit through the provision of real-time status information on transit-use opportunities and schedules, (2) readily available and accurate information will have the effect of "demystifying" a potentially complex experience for first time and infrequent transit users and, (3) increased convenience in using the system as a 
result of having reliable real-time information on vehicle location and coordinated timed transfers. Both of these benefits are expected to result in increased market share for transit. The public as a whole will benefit from the greater use of transit that would result from this service.

\subsubsection{Potential For Private Investment}

Without U.S. Department of Transportation (U.S. DOT) funding stimulus, the private market potential for vendor products that respond to this service appears to be medium. The U.S. DOT may, for example, help to support the private sector in the development and testing of low cost products such as personal portable traveler information systems for transit applications. To be affordable, transit information may need to be distributed in conjunction with other information. For example, existing computer network services could be provided with transit data that could be communicated to the public directly, or a public service channel on cable TV could possibly arrange its programming to include transit data.

\subsubsection{Public and Private Sector Roles In Deployment}

Although this service will require both public and private sector involvement, the public sector role will be dominant. Most transit providers are public organizations. Gathering of traffic and transit information will be a public role. Establishing an information system that is capable of analyzing and assimilating the data, coordinating the network for distribution of the information, and responding to the heavy peak inquiry demands for the information could be private. It is possible that media traffic reporting companies in major metropolitan areas would desire to be a part of this effort as a logical extension of their business.

Public sector involvement in the development and deployment of this user service will occur at all levels of government, including Federal, State, Metropolitan Planning Organizations, local government, and the public transit operator. All levels are important, but the ultimate decision to deploy publicly funded systems will be made at the local level.

\subsubsection{U.S. DOT Role In Developing Service}

The U.S. DOT role for the En-Route Transit Advisory user service is to foster development, operational testing, and evaluation of technologies and systems for both transit operators and users. This role will include assistance given for the development of guidelines and standards. The U.S. DOT will also need to eliminate institutional barriers that may arise. This is especially pertinent where jurisdictions build the partnerships needed to allow the integration and cooperation required at the local level. The information will need to be shared using common formats and will allow services to be funded in new innovative ways.

3.2.7.4.1 Research and Development: The U.S. DOT role in research and development is moderate. The limited research which the private sector and the non-DOT public sector will 
perform is expected to be very site or product specific and lacking in a national perspective. Adequate functional specifications need to be promoted by a national body.

3.2.7.4.2 Operational Tests: The role in operational testing for the U.S. DOT is high. Early operational testing of innovative technology applications in transit will need to be strongly supported by the U.S. DOT. There are many new technologies available from research in the defense industry with potential for commercial development in the transit industry. U.S. DOT involvement will ensure a national perspective for the full systems integration of each possible technology for appropriate transit applications. Careful evaluations are a critical element of this effort. Sites should be chosen to provide sufficient operational testing to accommodate a wide variety of final deployment projects.

3.2.7.4.3 Institutional and Legal: The U.S. DOT role is medium for ensuring institutional and legal issues are properly addressed. Coordination with national organizations and advisory committees to encourage compatibility will be a role for the U.S. DOT.

3.2.7.4.4 Deployment: The U.S. DOT role in deployment is high since the Department funds $80 \%$ of transit agencies' purchase costs of equipment. Information for the En-Route Transit Advisory will be gathered by the public sector, including local and state transportation agencies.

\subsubsection{Milestones and Activities}

Figure 3.0-1 in the introduction to this chapter identifies selected major milestones associated with developing this user service to a state of deployability.

This section elaborates on these milestones by identifying issues and providing a listing of more detailed, supporting activities. An issue is defined as a major potential challenge that has to be met to achieve deployability.

\subsubsection{Issues}

The key issues are data oriented. Up to the minute, real-time transit information (on vehicle locations, etc.) must be obtained. This will require major hardware and software systems to be in place, such as Automatic Vehicle Location (AVL) and computerized scheduling. Accurate databases must be maintained and kept current, incorporating schedule changes and congestion data, for example. Technologies are needed for transmitting the data to appropriate user devices, and effective means of outputting the data are needed. Improvements in radio or cellular system capacity will be needed to handle a quantum increase in communications. Finally, software must be developed for such functions as predicting travel times, recommending alternate transit routes, and determining transfer points and times. 
Security of display devices at unsecured places, such as bus stops, must be addressed.

The overall benefit of the service is also an issue--to what extent will provision of this service encourage more people to use mass transit in lieu of the automobile?

\subsubsection{Activities}

1. Define En-Route Transit Information system concepts

- The Federal Transit Administration (FTA) will be responsible for defining the system concepts, including those involving fixed location devices (e.g., kiosks) at traffic information centers and those involving portable devices on people or in vehicles. The appropriate technologies for making the data available will be considered. Candidates include kiosks, audiotex and videotex, and PCDs.

2. Sponsor En-Route Transit Information R\&D

FTA will sponsor the following R\&D projects:

- Research on the impact that traveler information has on mode choice

- Research on the technological support needed for traveler information centers

- Research on information display types

- Research on formats to be used in displaying En-Route transit information

- Initial studies will be single modal (e.g, "next bus" information). Later studies will focus on integrating multimodal information (e.g., bus/rail transfer information).

3. Conduct operational tests

- Travel Information Centers. Kiosks and other fixed location devices will be tested using traveler information centers and home and office information using audiotex and videotex. Initial tests will focus on single modal travel (e.g., buses only). Tests will be cooperative partnerships between FTA and local transit agencies. Examples follow.

- A Denver Smart Vehicle project will evaluate an automated, fully integrated, mass transit communications system using GPS and automatic vehicle location technologies for travelers. Major boarding and transfer points will be equipped with passenger displays.

- The Minnesota GuideStar "Genesis" project will test a portable digital PCD that is designed to receive traffic and transit information to allow a traveler to make appropriate mode and transfer choices during the travel. 
- The Minnesota "Travlink" project will evaluate real-time transit schedule and traffic information provided through a combination of kiosks and audiotex at various locations, including transit stations.

- The San Francisco Bay Area "TravInfo" project is testing a regionwide, multimodal traveler information system to encourage the use of public transportation and ridesharing.

- A New York City operational test will evaluate the effectiveness of various methods of providing comprehensive transit information at bus stops and on-board buses.

- A Los Angeles Smart Traveler project will provide public transportation users with appropriate and timely data to improve their travel decision making. Kiosks and other fixed location devices will be tested.

Other Traveler Information Sources. The following are included in the 1994 ITS Operational Tests chosen by U.S. DOT.

- TransCal (California, Nevada) will test a comprehensive inter-regional Traveler Information System integrating transit, road, traffic, weather, and value-added services information sources from along the I-80/US 50 corridor between San Francisco and the Lake Tahoe-Reno metropolitan areas.

- Seattle Wide Area Communication System--Bellevue Smart Traveler (Washington) will test three types of traveler information delivery devices: the Seiko Receptor Message Watch, an in-vehicle FM subcarrier radio to be developed by Delco Electronics, and a palm top computer provided by IBM. Each device will also support personal information and messaging services. The project will maximize the use of existing information systems, including Seattle METRO's vehicle location and scheduling systems. The Smart Traveler portion of the plan expands the 1993 FTA operational test, which supplies transit and real-time traffic information.

- Project Northstar (New York State). Traveler Assurance Services (TAS), an existing privately-developed traveler information service, will offer additional services over an FM subcarrier combined with cellular telephone and a portable digital assistant speech synthesis for personalized en-route traveler advisories and information. Included is an element of transit information, transit incident alerts and the use of a personal security device, which could be adapted for use by public transportation passengers. The emergency notification and personal security system includes a response to customer initiated panic alerts. 
- Advanced Rural Transportation Information and Coordination (ARTIC) (Minnesota) will coordinate the communications systems of several public agencies (transit, highway, and state patrol) by establishing a centralized communication site. Trilogy will provide traveler information through the Radio Broadcast Data System--Traffic Message Channel, an FM subcarrier, and $220 \mathrm{MHz}$ system. Selected transit, volunteer and emergency response vehicles will be AVL equipped using portable mobile data terminals. The operational test also has a demand response element.

- Atlanta Driver Advisory System (Atlanta, Georgia) tests a traveler information system that uses an FM subcarrier for metro-wide travel advisory. Vehicles will be outfitted with in-vehicle data processing, displays and storage, and a Mayday system. Information will include traffic condition and public transit information/options (routes and schedules).

4. Develop standards and guidelines for travel information centers

- FTA will support the development of kiosk performance standards

- Society of Automotive Engineers (SAE) will develop Information Interchange Standards for PCDs.

5. Initial deployment of travel information centers

- Deployment will be the responsibility of local transit agencies.

6. Conduct operational tests with portable Personal Communications Devices (PCDs)

- Additional tests will refine testing previously conducted and will focus on traveler information using portable devices

- The full operational concept will be explored in FTA-sponsored operational tests. These tests will incorporate the use of AVL system technologies and will include multi-modal information (e.g., bus/rail transfers).

7. Initial deployment with PCDs

Transit agencies will be responsible for collecting and disseminating the information. To be eligible for Federal grants, agencies will be required to adhere to standards and guidelines that have been developed 
- This service will develop as consumers decide to purchase PCDs. Individual riders will be responsible for purchasing their own PCDs.

8. Initial deployment of Automatic Voice Stop Annunciators and Automatic Visual Information signage systems, which are compliant with $\mathrm{ADA}$ requirements.

- FTA has funded a demonstration project to test available automated technology in Houston, Texas, where buses serving a concentration of visually impaired riders will be equipped with devices which feature both audio and visual display of next stop and destination information on the interior and voice annunciation of destination sign information on the exterior when bus doors open at stops. Demonstration projects in over 10 other cities are scheduled to get underway during 1994.

- Several transit systems have or are in the process of procuring voice annunciation hardware which is triggered manually by the bus driver. These include Santa Clara County, Califomia with 300 units, Stockton, California, Honolulu, Hawaii and Oklahoma City, Oklahoma.

- New Jersey Transit is procuring an on-board passenger information system for its buses and trains which will give announcements of service changes and carry advertising. The system will ultimately be expanded into a full digital and voice annunciator system. 


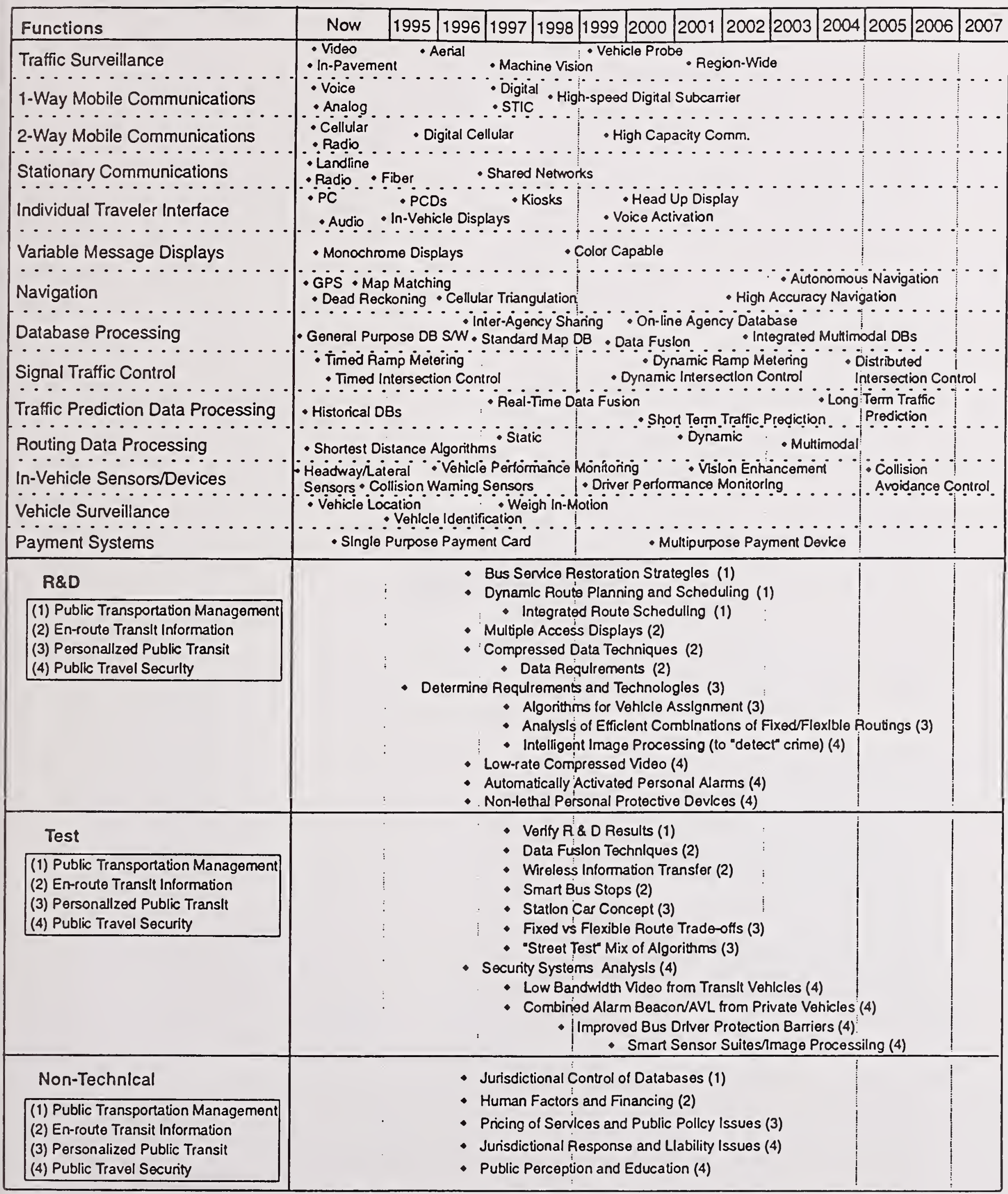




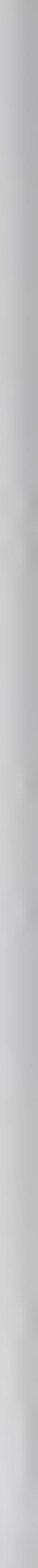


REFERENCES 



\section{REFERENCES}

1. Abernethy, Bruce, "An ITS for Houston METRO," Traffic Technology International '95, UK \& International Press, Surrey, United Kingdom, pp. 92-98, ${ }^{\odot} 1995$.

2. Abernethy, Bruce, "Integrated System Architecture and Real-Time Data Interchange Between Public Transit and Intelligent Transportation System Services," Proceedings of the First World Congress on Applications of Transport Telematics and Intelligent Vehicle-Highway Systems, Palais de Congrès de Paris, France, November 30 December 3, 1994, Volume 6, pp. 3001-3008, ${ }^{1} 1995$.

3. Ahern, Don, "Eye in the sky to keep buses in line, on time," Saint Paul Pioneer Press, November 21, 1994.

4. Ben-Akiva, Moshe, Isam Kaysi, Amalia Polydoropoulou, Haris Koustopoulos and Paul Whitworth, "Design of an Integrated Data Collection Program to Support Modeling of User Response to ATIS Services," Proceedings of the IVHS America 1994 Annual Meeting, Atlanta, GA, April 17-20, 1994, pp. 969-979, ${ }^{\circ} 1994$.

5. Blackledge, David and Dr. Laurie Pickup, "Public Transport Passenger Information Systems - The Potential of Advanced Transport Telematics," Proceedings of the IVHS America 1993 Annual Meeting, Washington, DC, April 14-17, 1993, pp. 295-301, ๑1993.

6. Briolat, C., A. Chesnoy and D. Bense, "GPS Tracking for Enhanced Bus Operations in Paris," Traffic Technology International '95, UK \& International Press, Surrey, United Kingdom, pp. 82-84, ${ }^{\circ} 1995$.

7. Brown, Melanie, "Notes from Travlink focus groups," Phase II, June 15, 1994.

8. BRW, Inc., Battelle, JHK and Associates, and Barrientos and Associates, Genesis Concept Definition and Preliminary System Design, prepared for Minnesota DOT, FHWA, University of Minnesota Center for Transportation Studies, and Motorola C\&E (Land Mobile Sector), March 1993.

9. Burton, R.S., "The PROMPT Project - Achievements and Field Trials," Proceedings of the First World Congress on Applications of Transport Telematics and Intelligent Vehicle-Highway Systems, Palais de Congrès de Paris, France, November 30 December 3, 1994, Volume 6, pp. 2842-2847, ${ }^{\circledR} 1995$.

10. Caarls, J.J., Paul Huber, and Ger van der Peet, "Public Transport Information in LLAMD-Project Achievements and Methodology in Comparative Evaluation," Proceedings of the First World Congress on Applications of Transport Telematics and Intelligent Vehicle-Highway Systems, Palais de Congrès de Paris, France, November 30 - December 3, 1994, Volume 6, pp. 2904-2911, ${ }^{\circledR} 1995$. 
11. Cambridge Systematics, Inc., Travlink Operational Test Evaluation Plan, prepared for Minnesota DOT, Draft Final Report, October 1994.

12. Cambridge Systematics, Inc., Travlink Operational Test: Evaluation Frame of Reference, prepared for Minnesota DOT Guidestar Program, July 1994.

13. Canoz, Florence, Benedict de Saint-Laurent and the EuroBus-Popins Consortium, "Commonalities in Man-Machine Interface Design for Passenger Information Computer Aids, Proceedings of the First World Congress on Applications of Transport Telematics and Intelligent Vehicle-Highway Systems, Palais de Congrès de Paris, France, November 30 - December 3, 1994, Volume 6, pp. 2888-2895, ${ }^{\circledR} 1995$.

14. Catling, Ian, Richard Harris and Hartmut Keller, "The LLAMD Euro-Project: Integrated Field Trials Testing Components of Urban and Regional Traffic Management," Proceedings of the First World Congress on Applications of Transport Telematics and Intelligent Vehicle-Highway Systems, Palais de Congrès de Paris, France, November 30 - December 3, 1994, Volume 5, pp. 2265-2272, ${ }^{\circledR} 1995$.

15. Cecchi, M. and L. Riccardi, "Cost-Benefit Analysis of an Urban Transit Communication and Information System," Proceedings of the First World Congress on Applications of Transport Telematics and Intelligent Vehicle-Highway Systems, Palais de Congrès de Paris, France, November 30 - December 3, 1994, Volume 6, pp. 2944$2951,{ }^{\circ} 1995$.

16. Chesnoy, A., D. Bense, and C. Briolat, "Radiopositioning of Mobiles in a Densely Built Up Urban Area and Applications to RATP Bus Fleet Management and Passenger Information," Proceedings of the First World Congress on Applications of Transport Telematics and Intelligent Vehicle-Highway Systems, Palais de Congrès de Paris, France, November 30 - December 3, 1994, Volume 6, pp. 2952-2959, ${ }^{\circledR} 1995$.

17. Colle \& McVoy Market Research, "1994 Focus Group Results (Phase II), "July 1994.

18. Colle \& McVoy Market Research, Transcripts of Travlink Focus Group Interviews, June 1994.

19. Colle \& McVoy Market Research, "Travlink Focus Groups: Executive Report," Phase I, April 1993.

20. Csallner, Astrid, Steierwald Schönharting und Partner and Dr. -Ing. habil. Hans Gg. Schlichter, "Park and Ride in Munich," Traffic Technology International '95, UK \& International Press, Surrey, United Kingdom, pp. 52-55, ${ }^{\circledR} 1995$.

21. Csallner, Astrid, Steierwald Schönharting und Partner and Dr. -Ing. habil. Hans Gg. Schlichter, "Munich COR.fFORT," Traffic Technology International '95, UK \& International Press, Surrey, United Kingdom, pp. 48-50, ${ }^{\circledR} 1995$. 
22. DeLeuw, Cather and Company, VISION 2000: Intermediate Report, prepared for New Jersey Transit, Contract number 93-EL-495, December 8, 1994.

23. Diversified Technologies, Recommendations for Patron Information System Technologies, prepared for Metropolitan Transportation Authority (Los Angeles, CA), Contract \#LFA-315-93, April 1993.

24. Drew, Duchesne Paul, "Satellite service: High-tech tracking system will tell riders along I-394 if bus is on time," Star Tribune, Monday, November 21, 1994.

25. Esteves, J. and P. Turbet Delof, "Bus Verts du Calvadis: An Example of Intermodal Transport Complementarity, " Proceedings of the First World Congress on Applications of Transport Telematics and Intelligent Vehicle-Highway Systems, Palais de Congrès de Paris, France, November 30 - December 3, 1994, Volume 6, pp. 3109$3116,{ }^{\circledR} 1995$.

26. European Commission, "Public Transport Management: Area 7," brochure available at First World Congress on Applications of Transport Telematics and Intelligent VehicleHighway Systems, Palais de Congrès de Paris, France, November 30 - December 3, 1994.

27. European Commission, "Uniting Europe Through Transport Telematics," brochure available at First World Congress on Applications of Transport Telematics and Intelligent Vehicle-Highway Systems, Palais de Congrès de Paris, France, November 30 - December 3, 1994.

28. European Road Transport Telematics Implementation Co-ordination Organization (ERTICO) and Ministere de L'equipment, des Transports et du Tourisme, "INPUT: Information in Public Transport," Fact Sheet provided at the First World Congress on Applications of Transport Telematics and Intelligent Vehicle-Highway Systems, Palais de Congrès de Paris, France, November 30 - December 3, 1994.

29. FHWA, Department of Transportation's Intelligent Transportation Systems (ITS) Projects, January 1995, Publication No. FHWA-JPO-95-001.

30. Finn, B. and K. Holmes, "DRIVE 2 Programme - Area Group 7 Report Public Transport Management and Information," Proceedings of the First World Congress on Applications of Transport Telematics and Intelligent Vehicle-Highway Systems, Palais de Congrès de Paris, France, November 30 - December 3, 1994, Volume 6, pp. 2825$2835,{ }^{\circ} 1995$.

31. "First Results from P\&R Field Trial in Munich," Traffic Technology International, Spring 1995, UK \& International Press, Surrey, United Kingdom, p. 114, ${ }^{\circledR} 1995$. 
32. Franzén, Stig, Hans-Ake Pettersson, MariAnne Karlsson and Li Wikström, "A UserOriented Systems Approach to Public Transport Passenger Information Services," Proceedings of the First World Congress on Applications of Transport Telematics and Intelligent Vehicle-Highway Systems, Palais de Congrès de Paris, France, November 30 - December 3, 1994, Volume 6, pp. 3078-3085, ${ }^{\circledR} 1995$.

33. FTA Office of Technical Assistance and Safety, "California Advanced Public Transportation Systems," APTS Brief 4, February 1994.

34. FTA Office of Technical Assistance and Safety, "Denver Smart Vehicle System," APTS Brief 7, August 1994.

35. FTA Office of Technical Assistance and Safety, "Houston Smart Commuter, " APTS Brief 6, June 1994.

36. FTA Office of Technical Assistance and Safety, "Los Angeles Smart Traveler Kiosk," APTS Brief 9, December 1994.

37. FTA Office of Technical Assistance and Safety, "Minnesota Guidestar Travlink Operational Test," APTS Brief 3, January 1994, p. 2.

38. Glazebrook, Garry and Keith McCombie, "New Technologies for Personalising Public Transport," Traffic Technology International '95, UK \& International Press, Surrey, United Kingdom, pp. 62-66, ${ }^{\circledR} 1995$.

39. Glazebrook, G., A. Middleton and M. Ratcliffe, "Personal Public Transport for Perth," Proceedings of the First World Congress on Applications of Transport Telematics and Intelligent Vehicle-Highway Systems, Palais de Congrès de Paris, France, November 30 - December 3, 1994, Volume 6, pp. 3032-3039, ${ }^{\circledR} 1995$.

40. Gold, Alexandre, "Primer of Lessons from the PHOEBUS Project, "Proceedings of the First World Congress on Applications of Transport Telematics and Intelligent VehicleHighway Systems, Palais de Congrès de Paris, France, November 30 - December 3, 1994, Volume 6, pp. 2880-2887, ${ }^{\circ} 1995$.

41. Haselkorn, Mark, Jay Spyridakis, Brian Goble, and Susan Michalak, "Bellevue Smart Traveler: An Integrated Phone and Pager System for Downtown Dynamic Ride Sharing," Proceedings of the IVHS America 1994 Annual Meeting, Atlanta, GA, April 17-20, 1994, pp. 126-131, ${ }^{\circ} 1994$.

42. Higgins, Paul, "BLISS in Brisbane: Integrated Vehicle Identification and Traffic Management," Traffic Technology International '95, UK \& International Press, Surrey, United Kingdom, pp. 100-105, ${ }^{\circledR} 1995$. 
43. Holmes, K., D. Blackledge, G. Foti, W. Meier, L. Pickup, and V. Psaraki, "The Development of Integrated Public Transport Passenger Information Systems in the Quartet Project," Proceedings of the First World Congress on Applications of Transport Telematics and Intelligent Vehicle-Highway Systems, Palais de Congrès de Paris, France, November 30 - December 3, 1994, Volume 6, pp. 2912-2919, ${ }^{\circledR} 1995$.

44. ICL, "Integrated Public Traveller Information," Traffic Technology International '95, UK \& International Press, Surrey, United Kingdom, pp. 74-77, ${ }^{\circledR} 1995$.

45. ITS America, National ITS Program Plan: Synopsis, Edited by Gary W. Euler and H. Douglas Robertson, First Edition, March 1995.

46. J.R. Associates, Recommendations for Patron Information Systems and Strategic Marketing, prepared for Metropolitan Transportation Authority (Los Angeles, CA), Contract \#LFA-315-93, undated.

47. JRL Associates, Inc., Request for Proposals \#276: Intelligent Transportation System, prepared for the Ann Arbor Transportation Authority, undated.

48. Leonard, Barbara, Glenn Havinoviski, and Dean Delgado, "A Multi-Modal IVHS Strategic Plan," Proceedings of the IVHS America 1994 Annual Meeting, Atlanta, GA, April 17-20, 1994, pp. 79-88, ${ }^{\circ} 1994$.

49. LLAMD Information Notes Numbers 1 through 9, November 1994, available at the First World Congress on Applications of Transport Telematics and Intelligent VehicleHighway Systems, Palais de Congrès de Paris, France, November 30 - December 3, 1994.

50. Los Angeles County Metropolitan Transportation Authority, Request for Information and Qualifications (RFIQ) No. 94-30: Electronic Patron Information System, September 30, 1994.

51. Mansfield, R.S. and Dr. Bannister, "The Use of ATT Applications for Public Transport in SCOPE Cities, " Proceedings of the First World Congress on Applications of Transport Telematics and Intelligent Vehicle-Highway Systems, Palais de Congrès de Paris, France, November 30 - December 3, 1994, Volume 6, pp. 2920-2927, Q1995.

52. Markowitz, Joel and Jeff Georgevich, "San Francisco Bay Area IVHS Early Deployment Plan," Proceedings of the IVHS America 1994 Annual Meeting, Atlanta, GA, April 17-20, 1994, pp. 222-223, ${ }^{\circ} 1994$.

53. Markowitz, Joel and Lawrence Sweeney, Jr., "TravInfo: Bay Area Intermodal Traveler Information System," Proceedings of the IVHS America 1993 Annual Meeting, Washington, DC, April 14-17, 1993, pp. 315-327, ${ }^{\circ} 1993$. 
54. Mechtel, G.H. and R.H. Patel, "Architecture Requirements for Combining Advanced Traveler Information Systems and Advanced Public Transportation Systems," Proceedings of the IVHS America 1994 Annual Meeting, Atlanta, GA, April 17-20, 1994, pp. 146-150, ${ }^{\circledR} 1994$.

55. Mentz, Dr. Hans-J., Peter Oelbaum, and Paul Huber, "Online Electronic Timetable Information for Everybody Via ISDN and Other Media," Proceedings of the First World Congress on Applications of Transport Telematics and Intelligent VehicleHighway Systems, Palais de Congrès de Paris, France, November 30 - December 3, 1994, Volume 6, pp. 3056-3063, ${ }^{\circledR} 1995$.

56. Metropolitan Atlanta Rapid Transit Authority, Request for Proposals: MARTA's Intelligent Transportation System, RFP P780, September 1, 1994.

57. Metropolitan Transit Authority of Harris County, "Request for Technical Proposals for Commuter Information Delivery System for the North Freeway Corridor," METRO Request for Technical Proposal (RFTP) No. 94X233P, March 13, 1995.

58. Ministere de L'equipment, des Transports et du Tourisme, and Centre D'Etudes Techniques de L'equipment, "EuroBus Project Popins Terminals: interactive information system for public transport users," Fact Sheet provided at the First World Congress on Applications of Transport Telematics and Intelligent Vehicle-Highway Systems, Palais de Congrès de Paris, France, November 30 - December 3, 1994.

59. Ministere de L'equipment, des Transports et du Tourisme, and Centre D'Etudes Techniques de L'equipment, "EuroBus Project Transmodel: European datamodel for public transport, " Fact Sheet provided at the First World Congress on Applications of Transport Telematics and Intelligent Vehicle-Highway Systems, Palais de Congrès de Paris, France, November 30 - December 3, 1994.

60. Moreyne, Marshall, "Visual Communication Network - A Real-Time Electronic Passenger Information and Communication System," Proceedings of the First World Congress on Applications of Transport Telematics and Intelligent Vehicle-Highway Systems, Palais de Congrès de Paris, France, November 30 - December 3, 1994, Volume 6, pp. 3016-3023, ${ }^{\circ} 1995$.

61. Munich COMFORT Press Information, available at the First World Congress on Applications of Transport Telematics and Intelligent Vehicle-Highway Systems, Palais de Congrès de Paris, France, December 1, 1994, p. 1.

62. Orange County Transportation Authority, "Intelligent Vehicle Highway System Transit Probe Analysis and Design Request for Proposals (RFP) 95-911," Issued March 1, 1995. 
63. Pesce, Carolyn, "In Minnesota, 'smart' buses getting a whirl," USA Today, Monday, November 28, 1994.

64. Peter Harris Research Group," The Public's Interest In and Willingness to Pay for Enhanced Traveler Information as Provided by IVHS, " prepared for TRANSCOM, July 1994.

65. QUARTET brochure, available at the First World Congress on Applications of Transport Telematics and Intelligent Vehicle-Highway Systems, Palais de Congrès de Paris, France, November 30 - December 3, 1994.

66. Quebec Ministry of Transport, Directory of User Information Systems in Public Transit, October 1991.

67. "Riderlink Spreads Transit Data Throughout Puget Sound Area," Passenger Transport, February 20, 1995, page 12.

68. Rolston, David, "Toward a Travinfo Architecture," Proceedings of the IVHS America 1994 Annual Meeting, Atlanta, GA, April 17-20, 1994, pp. 454-461, ${ }^{\circledR} 1994$.

69. Saint-Laurent, Bénédict de, Michael Shields, and Fouad Khodja, "Advanced Interactive Terminals Developed Within the EuroBus-Popins Project: Methodology and Results of Evaluation," Proceedings of the First World Congress on Applications of Transport Telematics and Intelligent Vehicle-Highway Systems, Palais de Congrès de Paris, France, November 30 - December 3, 1994, Volume 6, pp. 2896-2903, ${ }^{\circledR} 1995$.

70. Saint-Laurent, Bénédict de and Bouzid Sennane, "Benefits and Costs of ATT in Public Transport - Possible Contribution to Modal Shift," Proceedings of the First World Congress on Applications of Transport Telematics and Intelligent Vehicle-Highway Systems, Palais de Congrès de Paris, France, November 30 - December 3, 1994, Volume 6, pp. 2928-2935, ${ }^{\circledR} 1995$.

71. Schroeder, J.L. and Jeff Green, "The Emergence of Smart Traveler Kiosks and the User Interface Requirements for Their Successful Deployment, " Proceedings of the IVHS America 1994 Annual Meeting, Atlanta, GA, April 17-20, 1994, pp. 831-837, ๑1994.

72. SCOPE brochure with STOPWATCH, TRIPlanner, SIS (Strategic Information System), and TRAFFIC WATCH pamphlets, available at the First World Congress on Applications of Transport Telematics and Intelligent Vehicle-Highway Systems, Palais de Congrès de Paris, France, November 30 - December 3, 1994. 
73. Smith, Richard, Stephen Atkins, and Robert Sheldon, "London Transport Buses: ATT in Action and the London Countdown Route 18 Project," Proceedings of the First World Congress on Applications of Transport Telematics and Intelligent VehicleHighway Systems, Palais de Congrès de Paris, France, November 30 - December 3, 1994, Volume 6, pp. 3048-3055, ${ }^{\circ} 1995$.

74. Sommerville, Fraser and Andrew Tate, "The Testing of a PROMISE in Traveller Information," Proceedings of the First World Congress on Applications of Transport Telematics and Intelligent Vehicle-Highway Systems, Palais de Congrès de Paris, France, November 30 - December 3, 1994, Volume 5, pp. 2249-2256, ${ }^{\circledR} 1995$.

75. Starr, Ray and James Wright, "Genesis - Project Design and Pilot Test," Proceedings of the IVHS America 1994 Annual Meeting, Atlanta, GA, April 17-20, 1994, pp. 471$477,{ }^{\circledR} 1994$.

76. Strgar-Roscoe-Fausch, Inc., "Analysis of Focus Group Findings (Phase I Market Research)," undated.

77. Travlink, "Minutes from June 4, 1993 Marketing Committee."

78. "The Finger on the Pulse of the Roadways," The New York Times, December 31, 1992.

79. Toliver, Paul A., "Information Technology and the Transit Manager," adapted from a presentation to the American Public Transit Association Annual Meeting in Boston, MA, September 1994.

80. Toliver, Paul A., "Seattle's Computerized Infosystem," Mass Transit, March/April 1995, Volume XXI, No. 2, pp. 28 and 30.

81. Turnbull, Katherine, "The Use of Information Generated from Transit AVL Systems," Proceedings of the IVHS America 1993 Annual Meeting, Washington, DC, April 1417, 1993, pp. 82-88, ${ }^{\circledR} 1993$.

82. Verband der Automobilindustrie e.V., "Advanced Transport Telematics for Europe," brochure available at the First World Congress on Applications of Transport Telematics and Intelligent Vehicle-Highway Systems, Palais de Congrès de Paris, prepared for an informal meeting of the transport ministers of the European Union and applicant countries on July 22-23, 1994 in Ludwigsburg, Germany, ${ }^{\circledR} 1994$, pp. 17-18.

83. VICTORIA (c/o Stadt Köln), "VARIO - Information System Programmable glass fibre optics display panel," VICTORIA 1992-1994 brochure available at the First World Congress on Applications of Transport Telematics and Intelligent Vehicle-Highway Systems, Palais de Congrès de Paris, France, November 30 - December 3, 1994. 
84. Westinghouse Electric Corporation, Strgar-Roscoe-Fausch, Inc., 3M and Rennix, U.S. West Communications Services, Inc., and Motorola, Travlink Project: Concept Definition and Preliminary System Design, prepared for Minnesota DOT, Federal Highway Administration, Federal Transit Administration, Regional Transit Board and Metropolitan Transit Commission, April 1994.

85. Wrathall, Chris and Gino Franco, "5T-Unique Solutions for Common Problems," Traffic Technology International, Spring 1995, UK \& International Press, Surrey, United Kingdom, pp. 50-56, ${ }^{\circ} 1995$.

86. Wright, James and Ferrol Robinson, "Travlink - Can Information Influence Choice?," Proceedings of the IVHS America 1993 Annual Meeting, Washington, DC, April 1417, 1993, pp. 89-93, ${ }^{\circ} 1993$.

87. Wright, James, Marthand Nookala and Ferrol Robinson, "Minnesota Guidestar Project Travlink," Proceedings of the IVHS America 1994 Annual Meeting, Atlanta, GA, April 17-20, 1994, pp. 166-171, ${ }^{\circledR} 1994$.

R-9/R-10 



\section{NOTICE}

This document is disseminated under the sponsorship of the U.S. Department of Transportation in the interest of information exchange. The United States Government assumes no liability for its contents or use thereof.

The United States Government does not endorse manufacturers or products. Trade names appear in the document only because they are essential to the content of the report.

This report is being distributed through the U.S. Department of Transportation's Technology Sharing Program.

\section{DOT-T-96-03}

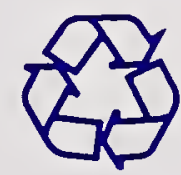




\section{DOT-T-96-03}

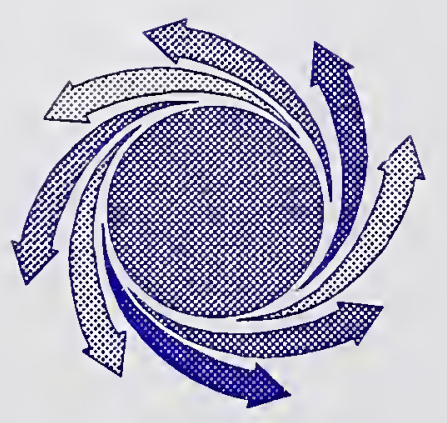

\section{Technology Sharing}

A Program of the U.S. Department of Transportation 